\title{
Étude et description de la sépulture de l'enfant de l'abri Labattut (vallon de Castelmerle, Sergeac, Dordogne, France)
}

Study and description of the child burial from the Labattut shelter (vallon de Castelmerle, Sergeac, Dordogne, France)

Dominique Henry-Gambier, Philippe Rocher et Dorothée Drucker

\section{OpenEdition}

Journals

Édition électronique

URL : http://journals.openedition.org/paleo/4668

DOI : $10.4000 /$ paleo.4668

ISSN : 2101-0420

Éditeur

SAMRA

Édition imprimée

Date de publication : 30 décembre 2019

Pagination : 170-203

ISSN : 1145-3370

Référence électronique

Dominique Henry-Gambier, Philippe Rocher et Dorothée Drucker, «Étude et description de la sépulture de l'enfant de l'abri Labattut (vallon de Castelmerle, Sergeac, Dordogne, France) », PALEO [En ligne], 30-1 | 2019, mis en ligne le 29 mai 2020, consulté le 07 juillet 2020. URL : http:// journals.openedition.org/paleo/4668; DOI : https://doi.org/10.4000/paleo.4668

\section{c) (†) $\odot$}

PALEO est mis à disposition selon les termes de la licence Creative Commons Attribution - Pas d'Utilisation Commerciale - Pas de Modification 4.0 International. 


\section{ÉTUDE ET DESCRIPTION DE LA SÉPULTURE \\ DE L'ENFANT \\ DE L'ABRI LABATTUT (VALLON DE

CASTELMERLE, SERGEAC, DORDOGNE, FRANCE)

\author{
Dominique Henry-Gambiera, \\ Philippe Rocherb, \\ Dorothée Druckerc
}

a. UMR 5199 PACEA, Université Bordeaux, Bât. B8, allée Geoffroy-St-Hilaire CS 50023, FR-33615 PESSAC cedex - dominique.gambier@u-bordeaux.fr b. Réserve naturelle géologique, 17, chemin de l'Église, FR-33650 Saucats Rocphl@free.fr

c. Senckenberg Centre for Human Evolution and Palaeoenvironment (S-HEP) at Tübingen University, Hölderlinstr. 12, D-72074 Tübingen -

dorothee.drucker@ifu.uni-tuebingen.de du décès.
PALE0 30 | t. 1

DÉCEMBRE 2019

PAGES 170 À 203
La redécouverte du squelette de l'enfant de l'abri Labattut (vallon de Castelmerle, Sergeac, Dordogne), dégagé en 1913 par M. Castanet et " perdu » depuis sept décennies, a permis l'étude d'un ensemble inédit, comprenant le squelette de l'enfant et plusieurs dizaines de coquilles de gastéropodes.

Du squelette, très dégradé à la suite des fouilles et d'une histoire chaotique postérieure à la découverte, une datation ${ }^{14} \mathrm{C}$ a pu être effectuée. Elle indique un âge dryas ancien, synchrone du Magdalénien moyen récent, rompant avec la littérature antérieure qui attribuait le squelette au Solutréen. L'étude des os, du mobilier et de l'architecture du dépôt conforte la présomption de sépulture, ajoutant de précieux indices à la connaissance des pratiques funéraires du Paléolithique supérieur, vu la rareté des tombes datées de cette époque, a fortiori de sujets immatures. En effet, l'analyse de l'âge dentaire et des os situe l'enfant dans la classe d'âge 0-1 an. En revanche, le sexe est inconnu, et aucune pathologie expliquant le décès n'a été diagnostiquée.

Le corps a probablement été inhumé dans une fosse, de l'ocre a été déposé. De nombreux coquillages, ornant un vêtement ou constituant un bijou ou encore tout autre objet, étaient associés. La majorité d'entre eux a, semble-il, une origine méditerranéenne et correspond à des choix de taille et d'espèces traditionnelles : Tritia neritea, Homalopoma sanguineum, Zonaria pyrum ou Schilderia achatidea. Vitta picta, espèce fossile des faluns bordelais, élargit le champ d'approvisionnement.

Tous les coquillages sont percés. Plus ou moins bien conservés, ils montrent des stigmates d'usage d'intensité variable selon les espèces, invalidant l'hypothèse d'un ensemble fabriqué à l'occasion

La comparaison avec les autres sépultures du Paléolithique supérieur européen montre que la mort de cet enfant, en dépit de son jeune âge, n'a pas donné lieu à un traitement funéraire particulier sauf en ce qui concerne la parure. Les caractéristiques de cette sépulture sont comparables à ce que l'on connaît pour d'autres défunts adultes ou immatures. Toutefois, le nombre de coquillages est l'un des plus élevés pour une sépulture du Paléolithique supérieur. Les cyprées - avec vingt-sept exemplaires, et cela en dépit des difficultés supposées d'acquisition (rareté, éloignement...) de ces gastéropodes emblématiques et sans doute prisés - constituent à elles seules un ensemble unique d'autant plus insolite que le défunt est un très jeune enfant.

Plusieurs hypothèses expliquant le dépôt de ces coquillages sont discutées (objets personnels, signe d'affection, témoignage de l'appartenance à un groupe particulier, privilégié ou non...). Aucune n'est véritablement démontrable, mais il demeure que l'inhumation de ce jeune enfant a donné lieu à une séquence de gestes témoignant de l'intérêt qui lui était porté ou de ce qu'il représentait.

MOTS-CLÉS Paléolithique supérieur, Magdalénien, France, datation $\mathrm{C}^{14}$, enfant, sépulture. 
Study and description of the child burial from the Labattut shelter (vallon de Castelmerle, Sergeac, Dordogne, France).

The rediscovery of the skeleton of the child from the Labattut Shelter (vallon de Castelmerle, Sergeac, Dordogne), released in 1913 by M. Castanet and "lost" for seven decades, allowed the study of a unique set, including the child and several dozen gasteropod shells. The skeleton is very degraded as a result of the excavations and a chaotic history after the discovery. $\mathrm{A}{ }^{14} \mathrm{C}$ date was made. It indicates an ancient Dryas age, synchronous to the recent Middle Magdalenian, breaking with earlier literature, which attributed the skeleton to the Solutrean.

The analysis of the bones, archaeological finds furniture and architecture of the deposit reinforces the presumption of burial, adding precious clues to the knowledge of the funerary practices of the Upper Palaeolithic, given the scarcity of graves dated from this period, especially immature subjects.

The dental age and bones puts the child in the $0-1$ year age class. However, the sex is unknown and no pathology explaining the death has observed.

The body was probably buried in a pit with ochre. Many shells, adorning a cloth or any other object or constituting a jewel, were associated.

The majority of them appear to be of mediterranean origin and correspond to traditional choices of size and species, Tritia neritea, Homalopoma sanguineum, Zonaria pyrum, Schilderia achatidea. Vitta picta, a fossil species of Bordeaux Miocene Faluns, broadens the supply territory.

All the shells are pierced. More or less well preserved, they show stigmata of use of varying intensity depending on the species, invalidating the hypothesis of a set made at the time of death.

Comparison with the other burials of the European Upper Palaeolithic shows that the death of this child in spite of his young age did not give rise to any special funerary treatment. The characteristics of this burial are comparable to those known for other adult or immature deceased persons.

However, the number of shells is one of the highest for a burial of the Upper Paleolithic. The "cyprees" with twenty-seven specimens of the probable difficulties (rarity, remoteness, etc.) of acquiring these iconic gastropods and no doubt prized are a unique set all the more unusual in that the deceased is a very young child.

Several hypotheses explaining the deposit of these shells are discussed (personal objects, signs of affection, testimony of belonging to a particular group, privileged or not, etc.). None is demonstrable, but the fact remains that the burial of this young child gave rise to a sequence of gestures that testify to his interest or what he represented.

KEY-WORDS Upper Palaeolithic, Magdalenian, France, radiocarbon dating, child, burial.

\section{INTRODUCTION}

Le squelette de l'enfant, Labattut 2 (Oakley et al. 1971), est découvert en avril 1913 dans un abri du vallon de Castelmerle par M. Castanet (1878-1962), agriculteur et fouilleur de F. Delage, L. Didon et D. Peyrony (Delluc et Delluc 2010). C'est au cours de fouilles commanditées par L. Didon (1866-1927), préhistorien amateur et collectionneur, que la découverte a lieu. L. Didon écrit à H. Hubert (7 mai 1913) : " Anthropologiquement je crains qu'il ne présente pas grand intérêt puisqu'il s'agit d'un tout petit enfant mais il est très intéressant pour le beau collier de coquillages qu'il porte autour du cou [...], il y en a, genre porcelaine, plus gros que des oufs de pigeon, de tout petits blancs et d'autres également petits roses. » Effectivement, les érudits de cette époque (y compris les anthropologues) n'ont pas vu l'intérêt de l'étude d'un petit enfant, mais ont bien remarqué les « œufs de pigeon » qui sont des cyprées.

Le squelette fera partie du matériel de la collection L. Didon vendu par l'intermédiaire d'H. Breuil au musée d'Archéologie nationale, alors musée des Antiquités nationales (MAN). Un prix ne pouvant être fixé, le squelette fut ajouté " en cadeau » au lot vendu 950-980 F (Breuil, 6 septembre 1913 ; Hubert, conservateur adjoint du MAN, 28 novembre 1913). Inventorié sous le numéro 56336, il sera confié en 1952 à H. Vallois, professeur d'anthropologie au Muséum et directeur du musée de l'Homme (Périn 2004). Restés inédits, squelette et matériel étaient portés disparus depuis cette date. Ils seront retrouvés en 2003 dans les locaux du département de préhistoire du Museum national d'histoire naturelle et identifiés par R. White et D. Henry-Gambier. Après une série d'échanges par courriel et de réunions entre le département de préhistoire du MNHN (dir. F. Sémah) et le musée d'Archéologie nationale (dir. P. Périn) dans le cadre du récolement des collections, le squelette et le matériel associé seront rapatriés en 2004 au MAN, où un premier inventaire sera effectué par l'un d'entre nous. En mars 2010, le squelette sera transféré au laboratoire d'Anthropologie de l'université de Bordeaux (ostéothèque) et confié pour étude à D. Henry-Gambier. Diverses difficultés ont ensuite retardé les recherches.

Les résultats de l'étude du squelette et des coquillages présentés dans cet article apportent de nouvelles informations sur les enfants et les pratiques funéraires du Paléolithique supérieur récent d'Europe.

La datation ${ }^{14} \mathrm{C}$ en SMA d'un échantillon d'os humain a permis de préciser l'ancienneté du squelette. De l'étude ostéologique découle l'estimation de l'âge au décès ainsi que des données sur certains aspects de la morphologie. L'analyse des ossements (nature, état de conservation, relations...), de l'ensemble étonnant de coquilles associé, ainsi que des données de terrain rapportées par M. Castanet dans ses lettres à L. Didon permettent de qualifier le dépôt et de restituer une partie des gestes déployés autour du corps. Tout indique que l'on est face à une sépulture remarquable.

Ces résultats ouvrent sur une série d'interrogations concernant les motivations du comportement des chasseurscueilleurs qui ont déposé le corps de cet enfant, la place des enfants et, au-delà, l'organisation sociale du groupe. De plus, l'origine géographique des coquillages identifiés apporte des 
éléments sur les territoires parcourus, dont les ressources sont au moins en partie cernées, et sur de possibles contacts et échanges intergroupes.

\section{1 | LE VALLON DE CASTELMERLE ET L'ABRI LABATTUT}

Le vallon de Castelmerle est situé à environ 500 m du village de Sergeac, en Dordogne, à $9 \mathrm{~km}$ de Montignac. Plusieurs abris - Blanchard, Castanet, Reverdit, la Souquette et Labattut - sont creusés dans un escarpement de calcaire coniacien sur les rives du vallon des Roches, affluent de la Vézère (fig.1).

Le vallon est connu depuis la fin du XIXe siècle et, très vite, plusieurs des abris feront l'objet de fouilles, publiées sommairement ou inédites. L'abri Labattut, repéré par M. Castanet en 1911, échappera à la frénésie des premières interventions.

Les fouilles, les révisions des stratigraphies, du matériel et des datations $\mathrm{C}^{14}$ récentes indiquent une fréquentation du vallon du Paléolithique moyen aux périodes historiques, mais l'intérêt du site tient surtout aux importantes installations aurignaciennes (abris Blanchard et Castanet), gravettiennes (abri Labattut) et magdaléniennes (abris Reverdit et La Souquette). D'abondantes collections ${ }^{1}$ d'outils, d'armes sur os ou en silex, d'objets d'art et de parure, ainsi que des décors pariétaux et des

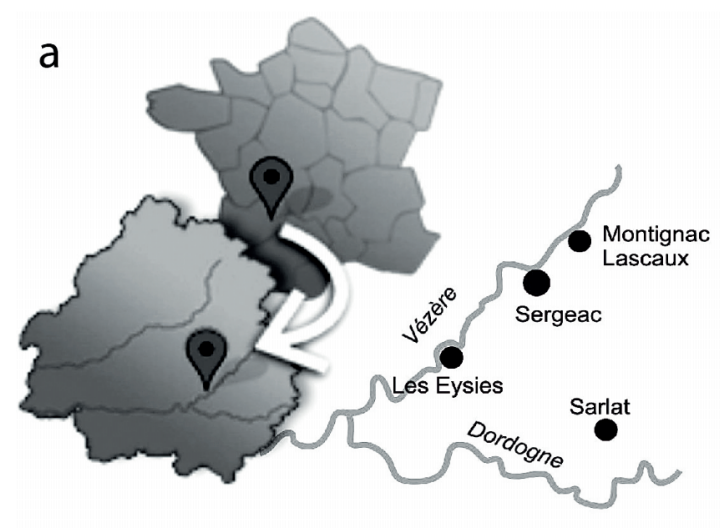

Vallon de Castelmerle (Sergeac)

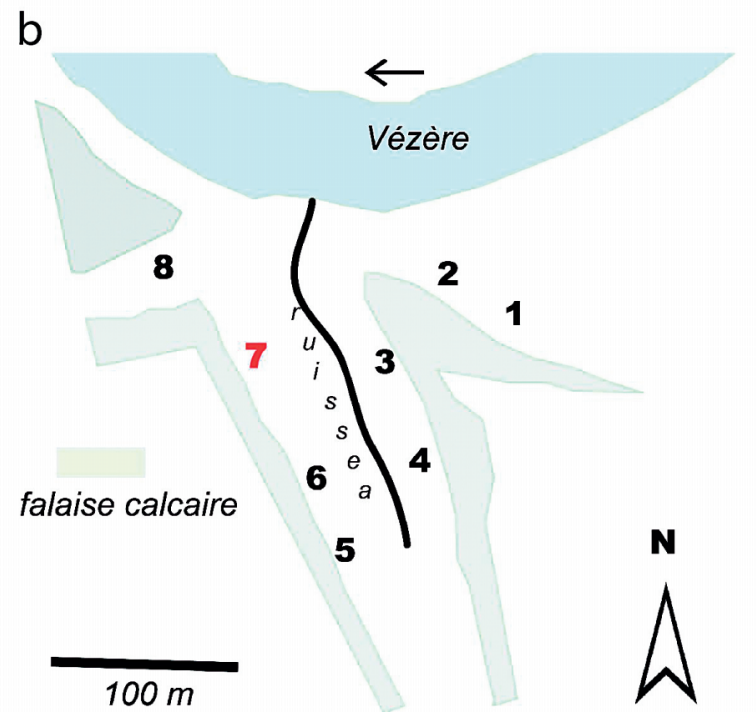

blocs ornés en témoignent (Reverdit 1878 ; Hardy 1880 ; Didon 1911; Breuil 1929; Delage 1935, Peyrony 1935 ; Delage 1938, 1947 ; de Sonneville-Bordes 1960 ; Delluc et Delluc 1981 ; Roussot 1982, 1984, 1985 ; Delluc 1985 ; Robin 1986 ; Delluc 1987 ; Bourdier 2008 ; White et al. 2012 ; Bourdier et al. 2014). Du Solutréen est aussi mentionné à Labattut et à La Souquette (Smith 1966). Enfin, à Reverdit, trois dates ${ }^{14} \mathrm{C}$ sur industrie osseuse plaideraient en faveur d'un passage de groupes contemporains du Badegoulien (Bourdier et al. 2014).

L'abri Labattut (ou Labatut), abri $\mathrm{n}^{\circ} 2$ selon la numérotation de L. Didon (1913), est, comme l'ensemble des abris (fig. 1) du vallon, la propriété de la famille Castanet-Daumas. Il est classé aux Monuments historiques depuis le 24 août 1931.

Il s'ouvre au nord-est, sur la rive gauche du ruisseau des Roches, comme l'abri Reverdit situé en amont sur la même rive, tandis qu'en aval se trouve l'abri de la Souquette. En face, sur la rive droite, s'étendent les abris Castanet et Blanchard, encore fouillés récemment. En grande partie effondré après les occupations gravettiennes, l'abri Labattut était très vaste. Il n'en existe pas à notre connaissance de relevé topographique publié, hormis celui très succinct de J.-M. Mormone (1983). D'après l'acte de vente du 23 mai 1911, établi entre L. Didon, J. Labattut et A. Thrivier (Delluc 1985), les parcelles (492 et 493) de terrain achetées $270 \mathrm{~F}$ par L. Didon à J. Labattut étaient de « 36 ares 10 centiares ». Elles s'étendaient de la paroi du

[1] Les collections du vallon sont dispersées dans plusieurs établissements (MAN, MNHN, IPH, MNP, musée de Périgueux, musée de site Sergeac, British Museum, Field Museum Chicago, Peabody Museum, Boston, American Museum of natural History, NY, Logan Museum).

\section{FIGURE 1}

a : localisation géographique du site ; $b$ : les abris du vallon de Castelmerle. 1 Abri Les Merveilles ; 2 - Abri Blanchard ; 3 - Abri Blanchard ; 4 - Abri Castanet ; 5 - Abri Reverdit ; 6 - Rochers de l'Acier ; 7 - Abri Labattut ; 8 - Abri de La Souquette

a: Geographical situation of the site; $b$ : The shelters of the vallon de Castelmerle 1 - Abri Les Merveilles ; 2 - Abri Blanchard ; 3-Abri Blanchard ; 4-Abri Castanet; 5 - Abri Reverdit ; 6 -Rochers de l'Acier ; 7 - Abri Labattut ; 8 - Abri de La Souquette. 
fond de l'abri jusqu'au ruisseau. La largeur, évaluée le long de la ligne des rochers distante de 40 à 50 m du ruisseau, était d'environ 80 m (Castanet, 11 mai 1911 dans Delluc 1985 - p. 822). L'emplacement des blocs d'effondrement sur la coupe sud, relevée par M. Castanet en 1914 (dans Delluc 1985 - p. 864), suggère une avancée de la voûte vers l'est d'au moins 10 à $12 \mathrm{~m}$.

\section{2 | LES FOUILLES DE M. CASTANET ET LA DÉCOUVERTE DU SQUELETTE}

L. Didon n'a pas publié les fouilles. Seules quelques lignes leur sont consacrées dans les BMSHAP (Didon 1921 p. 296). La quasi-totalité des publications sur l'abri Labattut s'intéresse aux blocs ornés (Breuil 1929 ; Delluc 1985 ; Delluc et Delluc 1991). Quelques-unes concernent l'industrie lithique et l'art mobilier (Breuil 1929 ; de Sonneville-Bordes 1960 ; Smith 1966 ; Delluc S. 1987). La correspondance entre L. Didon et différents interlocuteurs (archives MAN, MNP), et surtout les lettres de M. Castanet à L. Didon (archives L. Didon) retranscrites par G. Delluc (1985), constituent la seule source écrite d'informations sur les fouilles.

Les fouilles se déroulent de 1912 à 1914. L. Didon est peu sur le terrain. Les travaux sont réalisés par M. Castanet, parfois aidé par un ouvrier. Le matériel est envoyé à L. Didon par le train, dans des caisses expédiées de Montignac à Périgueux, ou transporté en voiture par L. Didon. Au cours de cette période, M. Castanet fouille aussi l'abri Reverdit, pour F. Delage, l'abri Castanet, pour D. Peyrony, et participe aux travaux agricoles.

Le chantier débute le 8 avril (Castanet, 10 avril 1912 dans Delluc 1985 - p. 825). La méthode de fouille est celle de l'époque. Trois tranchées irrégulières, deux perpendiculaires au fond de l'abri, une parallèle à la ligne de rochers, sont creusées pour atteindre et dégager les niveaux riches en matériel archéologique (Castanet, 10 avril 1912, et figures dans Delluc 1985 - p. 831, 837, 838, 849, 851, 863, 864). Pelle, pioche, crochet, barre à mine ainsi que des explosifs pour réduire les blocs d'effondrement de la voûte sont employés (Castanet, 11 juin 1912 ; 20 septembre 1912 dans Delluc 1985 - p. 825 et 829). Les déblais sont laissés sur place. Ils gêneront le suivi ultérieur des couches dont le pendage augmente fortement en direction du ruisseau à quelques mètres du fond de l'abri (Castanet, 13 octobre 1912 dans Delluc 1985 - p. 833). Les plans et les coupes, dessinés à main levée par M. Castanet, fournissent des estimations de profondeur (niveau 0 non précisé), d'épaisseur et de distances commentées dans les lettres mais ils ne comportent ni échelle ni orientation. Certains schémas combinent vues en plan et de profil (fig. 2). Pour qui était sur le chantier au moment de la fouille, ces schémas et ces lettres devaient être explicites, mais aujourd'hui leur décryptage est difficile. Les rares photographies publiées, dues à G. de Fayolle (Delluc et Delluc 2006 - p. 114), sont centrées sur les visiteurs et les acteurs de la fouille et non sur les niveaux archéologiques. Seuls les objets jugés exceptionnels, tels que les blocs ornés et des outils de grande «qualité », sont reportés sommairement sur les plans et sur les coupes. Cette approche se solde par une sélection du matériel collecté, une faible probabilité d'identifier des structures et une origine spatiale et altimétrique des objets très approximative. Plus de 3000 outils lithiques sont sans attribution de couche (Sonneville-Bordes 1960).

En revanche, le tamisage à l'eau des sédiments (Castanet, 13 août 1912 dans Delluc 1985 - p. 829), inhabituel à l'époque, permet la récolte de petits éléments. Toutefois, il ne fut probablement pas systématique étant donné le volume de sédiment remué, et le tri des microvestiges obtenus par tamisage a peut-être été sélectif.

La découverte de coquilles le 11 avril 1913 alerte M. Castanet. II décrit l'événement ainsi (Castanet, 11 avril 1913 dans Delluc 1985 - p. 846) : «Dans l'éboulis entre la terre végétale et la couche supérieure j'ai trouvé une masse de terre rouge sans silex, d'un diamètre de $0 \mathrm{~m}, 60$, où se trouvent de superbes coquillages percés, j'en ai ramassé 10 gros comme des oufs de pigeons; il y en a plusieurs autres apparents dans des mottes que je garde pour vous les montrer, je n'achève pas de démolir l'emplacement, il

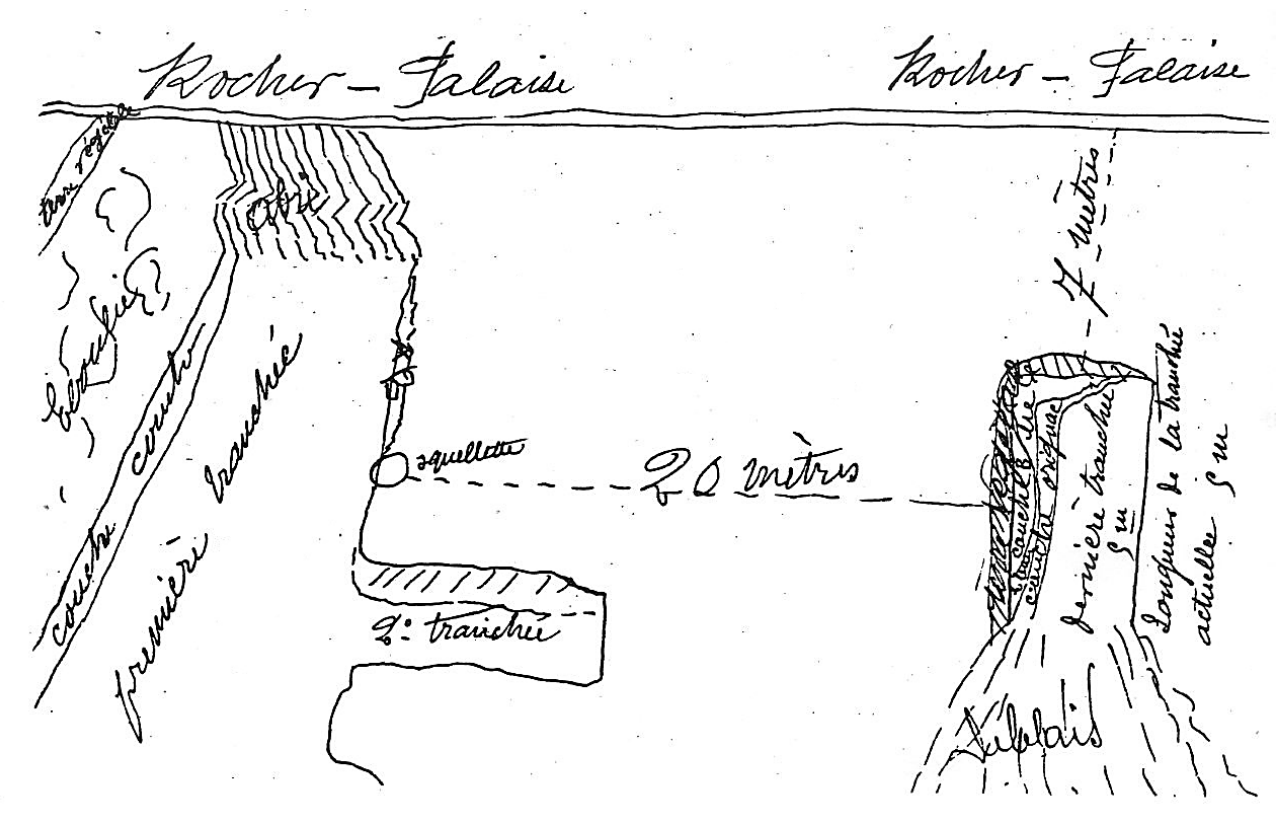

\section{FIGURE 2}

Plan et coupes d'après M. Castanet (Delluc 1985 - p. 851).

Plan and sections according to M. Castanet (Delluc 1985 - p. 851) 
reste encore des coquillages, je veux que vous en preniez connaissance, il y a des petits os aussi. Mais des tout petits coquillages, percés aussi : il y en a beaucoup, beaucoup [sic]. Cette masse de terre est intéressante. Au cas où ceci vous obligerait à venir un de ces jours, je vous préviens que je suis obligé à m'absenter lundi, mais, j'y travaillerai dimanche [...], une autre idée m'est venue au dernier moment, à savoir si, non loin de là, il n'y aurait pas, par hasard... un squelette. Peut-être non. Mais, au cas, je n'avance pas plus loin sans vous. »

L'emplacement est laissé en l'état et protégé de la pluie par du feuillage afin que L. Didon puisse l'examiner, ce qu'il fera à plusieurs reprises entre le 19 et le 24 avril. Le secteur est alors clairement identifié comme renfermant un squelette, situé à 5,80 m de la paroi, sous une couche de terre végétale épaisse de $30 \mathrm{~cm}$. Des os sont visibles dans les blocs de sédiment et les petites "mottes » que M. Castanet prélève. La terre autour est « criblée » (Castanet, 20 avril 1913 dans Delluc 1985 - p. 848). À partir du 24 avril, alors qu'une partie du squelette est encore en place, M. Castanet ouvre une nouvelle tranchée à $20 \mathrm{~m}$ au nord de celui-ci. Une couche blanchâtre, épaisse, reposant sur des blocs ( « couche B » sur le plan de M. Castanet dans Delluc 1985 - p. 851) livre la feuille de laurier incomplète à l'origine de l'attribution du squelette au Solutréen (Didon 1913).

Début mai, L. Didon annonce la découverte. Le 6 mai 1913, D. Peyrony visite le site (Peyrony 1913). Du 11 au 28 mai, plusieurs journaux étrangers et français, dont Le Temps du 11 (p. 1) et du 22 mai (p. 4) 1913, relaient la découverte. L'extraction du reste du squelette est organisée le 15 mai en présence de L. Didon, A. Déluguin et G. de Fayolle, membres de la Société d'histoire et d'archéologie du Périgord, M. Féaux, conservateur du musée du Périgord, et D. Peyrony. Le mauvais temps empêche le dégagement des os sur place. Des blocs sont prélevés et transportés à Périgueux (Anonyme 1913 ; Didon 1913 ; Peyrony 1913).

En juin, les fouilles se poursuivent, et l'emplacement du squelette est détruit (Castanet, 24 juin 1913 dans Delluc 1985 - p. 854).

Les fouilles sont définitivement interrompues à la mobilisation de M. Castanet, en août 1914, alors que le site est en partie vidé. Des lambeaux de niveaux en place pourraient subsister sous les déblais (Rigaud 1982 ; Mormone 1983).

\section{3 | DONNÉES STRATIGRAPHIQUES, SÉQUENCE CULTURELLE}

Deux couches, " une supérieure ou de surface et une inférieure ou du fond ", d'autant plus riches qu'elles étaient proches du fond de l'abri, ont été rapidement identifiées (Castanet, 16 juin, 21, 26, 27 juillet, 9 août 1912 dans Delluc 1985 - p. 826,827, 828). Une troisième couche dite "à gros os » est repérée au-dessus de la couche supérieure (Castanet, 2 décembre 1913 dans Delluc 1985 p. 858). Une quatrième couche, dite « couche B », blanchâtre, est observée entre la terre végétale et l'éboulis, à 20 m du squelette. Est aussi citée, mais non figurée, une couche noire et pauvre, au-dessus de la couche supérieure, semble-t-il. Cinq schémas (Castanet 20, 24 avril 1913 ; 10 janvier 1914 dans Delluc 1985, p 831, 837, 838, 849,
850, 851), dont trois coupes, illustrent la situation (fig. 2, 3, 4). Les relations entre « la couche à gros os », la couche B et la couche noire ne sont pas véritablement explicitées. H. Breuil (1929), F. Delage (1935), D. Peyrony (1949), G. Delluc (1985), B. Delluc et G. Delluc (1991) attribuent les couches inférieure et supérieure au Gravettien et admettent l'existence d'une couche de Solutréen moyen (couche B), sans pointe à cran selon H. Breuil (1929). Pour G. Delluc (1985), la « couche à gros os » serait aussi gravettienne.

Selon D. de Sonneville-Bordes (1960), les collections de l'abri Labattut conservées à l'IPH comprennent trois ensembles d'outils : 403 pièces de la couche supérieure, 354 pièces de la couche inférieure et 3096 pièces sans indication stratigraphique. Elle attribue les couches inférieure et supérieure au Gravettien à burins de Noailles. Le lot sans distinction stratigraphique est constitué «de lames à retouche continue et même de lames aurignaciennes, de quelques burins busqués, de gros burins transversaux sur encoche faits sur éclats épais, trapus sur calotte de nucléus, de pièces d'aspect massif, de pièces esquillées, d'une raclette. Ces outils, aberrants comparés aux outils uniquement laminaires de la couche supérieure, nous font penser que les anciennes fouilles n'ont peutêtre pas distingué quelque niveau ou lambeau de niveau aurignacien ou magdalénien, comme à l'abri Reverdit tout voisin (?), existant en quelque point de l'abri : la question se pose » (Sonneville-Bordes 1960 - p. 202). Elle doute de l'importance du Solutréen, et même de la réalité d'une occupation solutréenne, la majeure partie de la série « solutréenne » recueillie par L. Didon étant composée de pièces gravettiennes. Trois feuilles de laurier et une ébauche (collection Vésigné) constituent toutefois des indices de Solutréen (Sonneville-Bordes 1960 - p. 322). P. Smith (1966 - p. 170) confirme ces conclusions. Ailleurs dans le vallon, les fouilles du Field Museum (Chicago) dans l'abri la Souquette auraient aussi mis en évidence du Solutréen.

Une intervention de J.-M. Mormone en 1981 dans l'abri n'apporte pas d'indice décisif sur la séquence archéologique (Mormone 1983). À partir d'un inventaire sommaire du matériel lithique des déblais, l'existence d'un niveau magdalénien est évoquée, et J.-M. Mormone rappelle que M. Castanet parlait, en 1961, d'un niveau magdalénien au-dessus du Gravettien.

En résumé, la séquence de l'abri Labattut communément admise comprenait, de bas en haut, au moins deux (voire trois) niveaux de Gravettien à burins de Noailles séparés par des éboulis plus ou moins stériles. Après le Gravettien, un effondrement de la voûte aurait colmaté en grande partie l'abri et réduit son extension vers le ruisseau. Audessus de ces éboulis, du Solutréen et du Magdalénien achevaient peut-être la séquence.

\section{4 | DATATION ${ }^{14} \mathrm{C}$ DU SQUELETTE ET ATTRIBUTION CULTURELLE}

D'après les inventeurs, le squelette était dans la couche B, solutréenne, située sur l'éboulis supérieur sous l'humus. En l'absence d'éléments univoques sur l'ancienneté du squelette, une datation radiocarbone d'un échantillon d'os humain a été tentée. Elle a été réalisée à Groningen, aux Pays-Bas (Centrum voor IsotopenOnderzoek). Plusieurs 


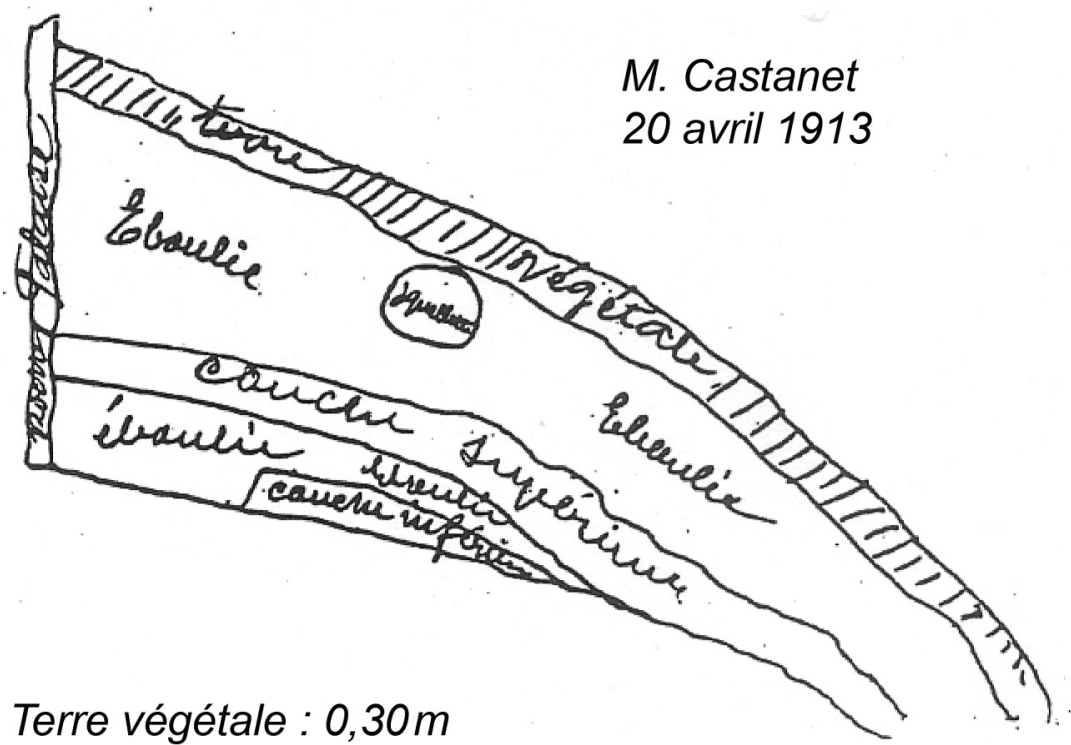

Eboulis entre la couche et la terre végétale :0,90 m

Terre rougeâtre du squelette : 0,45 à $0,50 \mathrm{~cm}$

(La terre rougeâtre du squelette arrive presque à toucher

la terre végétale).

Couche supérieure

Eboulis

Couche inférieure

\section{FIGURE 3}

Coupe d'après M. Castanet, 20 avril 1913 (Delluc 1985 - p. 849).

Stratigraphical section according to M. Castanet, 20th April 1913 (in Delluc 1985 - p. 849).

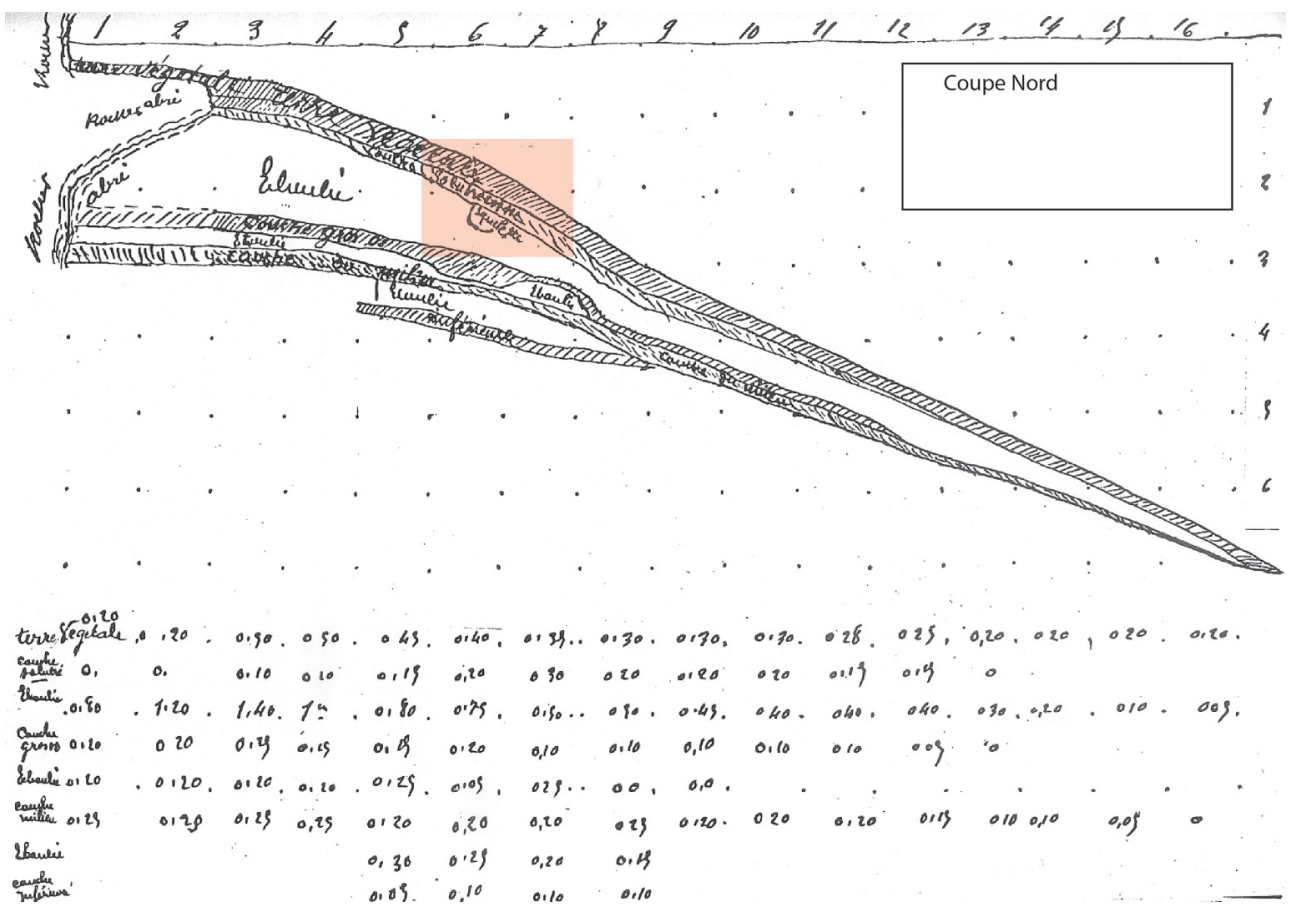

\section{FIGURE 4}

Coupe d'après M. Castanet (Delluc 1985 - p. 863).

Stratigraphical section according to M. Castanet (in Delluc 1985 p. 863). 
fragments de côtes et de vertèbres sans intérêt anthropologique et sans trace de conservateur, de colle ou d'autre produit chimique ont été réunis pour constituer un échantillon suffisant. L'âge conventionnel obtenu est $13740 \pm 60 \mathrm{BP}$ (GrA 47274). La quantité de collagène, le pourcentage de collagène, le rapport $\mathrm{C} / \mathrm{N}$, les pourcentages de carbone et d'azote (tabl.1) indiquent que le résultat est fiable, selon les critères fournis par van Klinken (1999). La calibration de la date a été faite avec le logiciel OxCal 4.2.4 basé sur la courbe IntCal13 (Reimer et al. 2013). À deux sigmas, cette date se place dans l'intervalle 16873-16338 cal BP, ce qui correspond au Dryas ancien et, dans le registre culturel, à la phase récente du Magdalénien moyen (Barshay-Szmidt et al. 2016). La fiabilité de la date étant certaine, il faut admettre soit l'existence d'un niveau magdalénien non observé à la fouille, comme le proposait D. de Sonneville-Bordes, soit un lien entre l'enfant et les occupants magdaléniens de l'un des autres abris du vallon. Les abris Reverdit et La Souquette, qui encadrent l'abri Labattut, semblaient des candidats possibles, mais seul le Magdalénien moyen ancien, voire seulement le Badegoulien et le Magdalénien inférieur (J.-M. Pétillon com. pers.), est identifié à Reverdit (Bourdier et al. 2014). Quant à la séquence magdalénienne de l'abri La Souquette, elle est très mal connue
(Sonneville-Bordes 1960 ; O'hara et al. 2015), et le Magdalénien moyen récent n'y est pas attesté (J.-M. Pétillon com pers.). Les indices de Magdalénien moyen récent sont donc, en l'état actuel des études, inexistants dans les deux abris. Une troisième hypothèse serait d'admettre l'idée d'un dépôt hors contexte d'habitat, au cours du passage d'un groupe.

Quoi qu'il en soit, la datation du squelette de l'enfant est un résultat important:

1) il s'agit de la première date radiocarbone obtenue pour l'abri Labattut;

2) il invalide l'hypothèse d'une contemporanéité du squelette avec le Solutréen ;

3) le squelette est le seul document du vallon rapportable à une période synchrone du Magdalénien moyen récent. Cela indique au moins un bref passage dans le vallon d'un groupe contemporain de cet épisode culturel. Il constitue aussi le seul document anthropologique de ce type en France pour cette période : les sépultures magdaléniennes connues jusqu'à présent (tabl. 2) sont toutes plus anciennes, contemporaines du Magdalénien moyen ancien, et aucune ne concerne un enfant isolé (Gambier et al. 2000 ; Henry-Gambier 2018).

\begin{tabular}{|l|l|}
\hline Poids de l'échantillon & $1147,5 \mathrm{mg}$ \\
\hline Référence laboratoire & GrA 47274 \\
\hline Âge conventionnel & $13740 \pm 60 \mathrm{BP}$ \\
\hline Âge calibré & $16338-16873$ cal BP \\
\hline Masse de collagène & $15,40 \mathrm{mg}$ \\
\hline$\%$ de collagène & 1,3 \\
\hline$\%$ C & 35,0 \\
\hline$\%$ N & 14,3 \\
\hline C/N Atomique & 3,0 \\
\hline
\end{tabular}

\section{TABLEAU 1}

Résultat de la datation $\mathrm{C}^{14}$ du squelette de l'enfant.

Result of ${ }^{14} \mathrm{C}$ dating of the child's skeleton.

\begin{tabular}{|c|c|c|c|c|c|}
\hline $15 / 01 / 2019$ & & & & & \\
\hline Site - Laboratoire & Pays & Intervalle & Intervalle & $\mathbf{P}$ & Références \\
\hline La Madeleine-GifA-95457 & France & 12377 & 11398 & 95,5 & Gambier et al. 2000 \\
\hline Roc de Cave-GifA-95 & France & 13320 & 12753 & 95,4 & Gambier et al. 2000 \\
\hline Oberkassel-OxA-4792 & Allemagne & 14501 & 13758 & 95,4 & Street et Joris 2015 \\
\hline Wilczyce-OxA-16729 & Pologne & 15611 & 15155 & 95,4 & Irish et al. 2008 \\
\hline Labattut-GrA 47274 & France & 16873 & 16338 & 95,4 & \\
\hline Chancelade-OxA-29885 & France & 18480 & 18031 & 95,4 & \begin{tabular}{|l|} 
Gambier et al. 2000 \\
Barshay-Szmidt et al. 2016 \\
\end{tabular} \\
\hline Lafaye-GrA 37881 & France & 18546 & 18138 & 95,4 & Gambier et al. 2000 \\
\hline Lafaye-GifA 95047 & France & 18864 & 18196 & 95,4 & Gambier et al. 2000 \\
\hline Laugerie-Basse-GifA 94204 & France & 19235 & 18645 & 95,4 & Gambier et al. 2000 \\
\hline El Miron - MAMS 14585 & Espagne & 19125 & 18864 & 95,4 & Straus et al. 2015 \\
\hline St-Germain-la-Rivière-GifA 95456 & France & 19555 & 18661 & 95,4 & Gambier et al. 2000 \\
\hline
\end{tabular}




\section{5 | ÉTUDE DE L'ENFANT ET DES COQUILLAGES}

\section{1 | État des lieux}

Les vestiges retrouvés au MNHN comprennent des blocs de sédiment plus ou moins induré de 1 à $25 \mathrm{~cm}$ de diamètre, avec des os fragmentaires visibles en coupe ou plaqués à la surface, des os isolés très incomplets et de nombreuses esquilles millimétriques. Quatre des blocs (les plus volumineux ?) avaient été numérotés et leur ordre spécifié. Malheureusement, les étiquettes ont été désolidarisées des blocs et regroupées.

Dans tous les cas, l'altération de l'os cortical est très forte. Il se délite et est pulvérulent. Les os ont manifestement subi une dessiccation trop rapide et intense après la fouille. Aux restes osseux s'ajoutent de nombreuses coquilles percées de gastéropodes². Quelques-unes sont encore en place, à la surface des blocs. Cinq espèces de gastéropodes: Homalopoma sanguineum, Tritia neritea, Vitta picta (petits gastéropodes), Zonaria pyrum, Schilderia achatidea (cyprées) ont été identifiées. Les petits gastéropodes ont été déterminés par P. Rocher, paléontologue (réserve géologique de Saucats, Gironde), les cyprées par L. Dolin, paléontologue (collaborateur MNHN, département Systématique et Évolution, Paris). Aux altérations et aux remaniements postérieurs au dépôt, notamment un processus de bréchification dû au ruissellement, qui ont affecté le sédiment se sont ajoutées les conséquences d'un prélèvement inadapté à la fragilité de l'assemblage et d'un parcours mouvementé depuis l'extraction. Les cassures sont très nombreuses. Dix des cyprées ont été ramassées au moment de la découverte. Les blocs et les petites mottes de sédiment ont été prélevés en plusieurs fois (voir supra). Nous ignorons à quel moment les autres coquilles et les os libres ont été extraits.

Aussi, l'ensemble actuel est-il partiel au regard de ce qu'il devait être au moment de la découverte, il y a plus de cent ans.

\section{2 | Méthode d'étude}

Devant l'extrême fragilité des os et des coquilles, et la dureté du sédiment, nous avons exclu tout dégagement de ceux encore enchâssés, le risque de les voir « disparaître » étant trop grand. Nous avons aussi écarté toute consolidation afin de préserver les possibilités d'analyses ultérieures. Notre intervention s'est limitée au nettoyage à l'eau des cyprées pour enlever le sédiment meuble au niveau de l'ouverture afin d'assurer une détermination fiable, et au niveau de la perforation pour en étudier la technique. Quelques-unes avaient déjà été nettoyées. La coquille $n^{\circ} 27$ a été vidée pour rechercher dans le sédiment d'éventuels restes d'organismes marins issus de leur milieu d'origine (foraminifères, fragments de coquilles). Le sédiment a été conservé.

[2] La technique de fouille et l'histoire postfouille ne garantissent pas, au moins pour les plus petites coquilles, un ramassage et une conservation exhaustifs. À ce propos, il faut insister sur les biais des échantillons de petit matériel issus des fouilles sans tamisage. Le cas du site de La Marche est exemplaire : avec un tamisage des déblais, on passe de 65 coquilles issues des fouilles de la première moitié du XXe siècle à 800 (Granger et AirvauX 2010)
Les observations ont été réalisées à l'œil nu et à la loupe binoculaire (grossissement $\times 6$ à $\times 50$ ).

Sur les os et sur les coquillages ont été recherchés et analysés:

- des stigmates d'une fracturation naturelle ou anthropique, survenue avant la fouille, pendant ou après, ou due à l'action des animaux;

- les altérations de surface (exfoliation, fissuration, cupules...) ;

- les dépôts de surface (sédiment, concrétion, ocre, manganèse, colle, consolidant, produit de moulage, encre...); - les signes d'une persistance des couleurs naturelles des coquilles et, pour les cyprées, la limite du manteau;

- les traces d'aménagement

- les stigmates d'usage « usure » ou « utilisation».

Des tentatives de remontage entre les blocs et entre les os ont été effectuées.

Une couverture photographique (numérique et argentique noir et blanc) a été réalisée.

\section{3 | Étude de l'enfant}

\subsection{1 | Le bloc cranio-facial}

Le bloc cranio-facial semble pratiquement complet, mais il est cassé en multiples fragments déformés par le poids du sédiment (depuis des esquilles de quelques millimètres carrés jusqu'à des fragments de plusieurs centimètres carrés), inclus dans des blocs ou déjà extraits. Seuls les plus significatifs sont présentés ici. Excepté la fragmentation liée au poids des sédiments, la totalité des cassures sont survenues sur os sec pendant ou après la fouille. Nous n'avons trouvé aucun contact entre les blocs et aucun remontage entre les fragments d'os isolés et ceux encore présents dans les blocs.

La détermination anatomique des éléments déformés et de petite taille s'est révélée dans la plupart des cas impossible. Toutes les surfaces des os sont très altérées, exfoliées et fissurées. Des vermiculations dues aux racines ainsi que des traces linéaires évoquant un nettoyage mécanique de l'os existent (ex. : $n^{\circ} 10$, fig. 7). En revanche, on ne note ni trace de carnivore ou de rongeur ni modification anthropique ancienne, pour autant que l'état des surfaces permette d'en juger. Le sédiment des blocs et les traces qui en subsistent sur les os sont brun-rouge. Os et sédiment ont en partie conservé des vestiges ténus d'ocre.

Parmi les éléments plus significatifs on note :

$n^{\circ} 1$ : bloc de sédiment brun très induré et compact $(145 \times$ $118 \times 70 \mathrm{~mm}$ ). Sur la face convexe, nous observons un placage d'os aplani et très fissuré qui occupe la presque totalité de la surface. Plusieurs fragments ont glissé. Par endroits, seule l'empreinte de l'os subsiste. Les dimensions et la forme sont difficiles à déterminer. Sur la face opposée apparaissent en coupe d'autres fragments d'os crâniens ; l'os spongieux est apparent et des traces de cire ou de résine d'origine inconnue sont perceptibles (fig. 5).

$n^{\circ} 2$ : fragments d'os de la voûte plaqués sur du sédiment induré peu épais (93 × $74 \times 21 \mathrm{~mm})$. Sur la face convexe, le placage est mince (1 à 2 mm d'épaisseur) et fissuré, avec des lacunes; des pièces se chevauchent. L'autre face, concave, est aussi recouverte d'un placage d'os très peu 
épais et cassé en place. Par endroits ne subsiste que l'empreinte de l'os. L'un des bords pourrait correspondre à une suture.

Les os des blocs 1 et 2 correspondent probablement à une partie de l'os frontal (moitié gauche?) et aux os pariétaux; le placage très fin visible sur la face concave du bloc $n^{\circ} 2$ évoque l'écaille temporale (gauche ? ; fig.6).

$\mathrm{n}^{\circ} 9$ : fragment d'os $(41 \times 28 \mathrm{~mm})$ peu épais (1 à $2 \mathrm{~mm}$ ) dont l'une des faces est masquée par du sédiment induré. Sur la face la plus exposée, un léger relief existe. Ce fragment pourrait correspondre à un fragment d'écaille temporale ou occipitale.

$\mathrm{n}^{\circ} 10$ : fragment d'os $(33 \times 25 \mathrm{~mm})$ avec une face libre convexe et très fissurée, et une face concave oblitérée par du sédiment. La courbure et une possible suture évoquent soit un fragment de pariétal avec la suture antérieure, soit un fragment de frontal (partie droite) avec la suture coronale (fig.7).

n 17 : l'os pétreux droit très endommagé, limité à la partie médiane avec le trou acoustique interne et l'eminentia arcuata. L'apex et la partie postérieure manquent. Aucun caractère particulier n'apparaît.

Au moins deux Homalopoma sanguineum sont inclus (fig. 8 et 9).
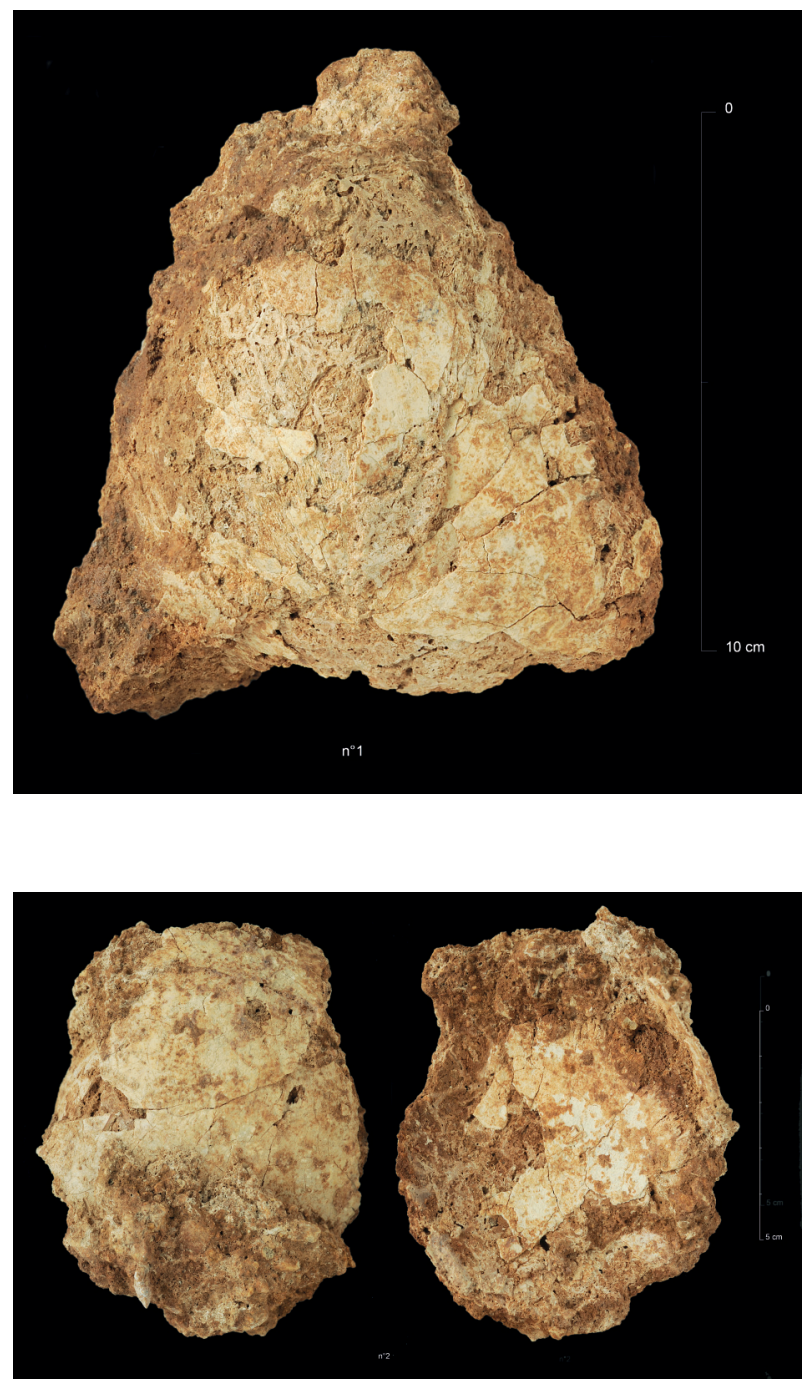

$n^{\circ} 18$ : bloc de sédiment très induré et très dense (210 $\times$ $138 \times 75$ mm). À une extrémité de l'une des faces existe un petit placage de voûte concave de $2 \times 4 \mathrm{~cm}$ qui apparaît par la face endocrânienne. Une partie de l'os a disparu, et seule sa trace subsiste.

Deux cyprées ( $n^{\text {os }} 19$ et 20) et l'empreinte d'une troisième se trouvent à hauteur de l'os. Visibles par la face supérieure, elles sont en contact par l'extrémité postérieure de la coquille (fig.10).

$n^{\circ} 15$ : bloc très induré et compact, brun rosé, assez volumineux $(111 \times 73 \times 34 \mathrm{~mm})$. Sur l'une des faces, l'os maxillaire gauche, incomplet, est écrasé (fig. 11).

Les germes des deux molaires déciduales gauches sont en place, visibles par les faces occlusale et linguale. Le germe de la canine, au contact de la première molaire déciduale supérieure, est en légère rotation (fig. 12). D'autres fragments avec de l'os spongieux, non identifiables, sont discernables en coupe.

Au moins trois coquilles de Tritia neritea et trois autres d'Homalopoma sanguineum sont à proximité de l'os maxillaire et des dents, au moins une de Tritia et une d'Homalopoma sont sur la face opposée du bloc.

Aux dents supérieures en place s'ajoutent quatre germes isolés (fig. 13, 14, 15) :

\section{FIGURE 5}

Squelette humain : élément de la voûte crânienne, bloc n 1 (๑ Nathalie Gambier).

Human skeleton: Element of the cranial vault, block no. 1 (○ Nathalie Gambier).

\section{FIGURE 6}

Squelette humain : élément de la voûte crânienne, bloc nº 2, (d) face exocranienne, (g) face endocranienne avec fragment écaille temporale (৫) Nathalie Gambier).

Human skeleton: Element of the cranial vault, block no. 2, (d) exocranial face, (g) endocranial face with fragment of squamous temporal bone ( 0 Nathalie Gambier). 

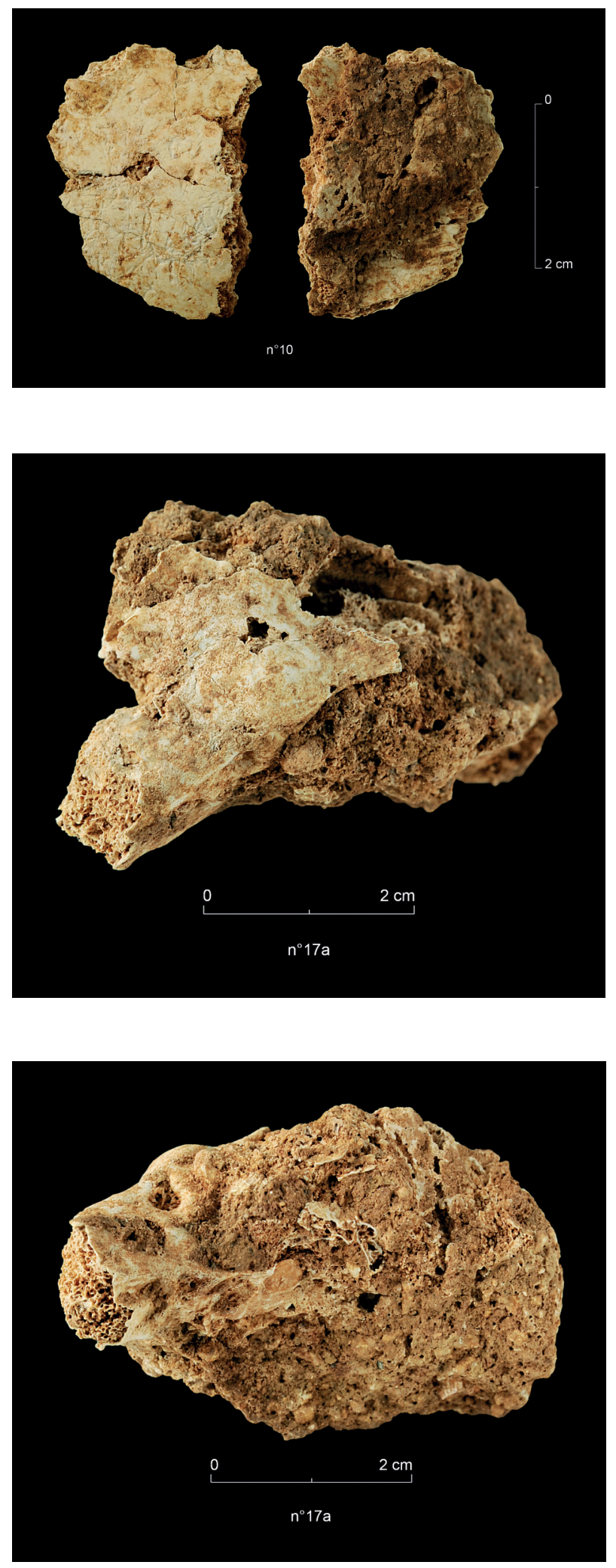

- n 192 : germe de seconde incisive supérieure gauche ; la couronne est intacte, et la racine est formée sur $1 \mathrm{~mm}$ au maximum :

- n²39 : germe de première incisive déciduale supérieure gauche ; la couronne est intacte, et la racine est formée sur $1 \mathrm{~mm}$ au maximum. Cette dent est compatible, pour ce qui est du développement, avec la dent nº 192.

\section{FIGURE 7}

Squelette humain : élément de la voûte crânienne, bloc nº 10, (d) face exocrânienne, (g) face endocrânienne (ํ Nathalie Gambier).

Human skeleton: Element of the cranial vault, block no. 10, (d) exocranial face, (g) endocranial face (@ Nathalie Gambier).

\section{FIGURE 8}

Squelette humain : os pétreux droit, bloc n 17a, face supérieure (@ Nathalie Gambier).

Human skeleton: Right petrous bone, block no. 17a, upper side (๑ Nathalie Gambier).

\section{FIGURE 9}

Human skeleton : os pétreux droit, bloc $n^{\circ} 17 a$, face médiale (๔ Nathalie Gambier).

Human skeleton: Right petrous bone, block no. 17a, medial side (๔ Nathalie Gambier).

- n² 240 a : germe de première molaire déciduale supérieure droite limité à la couronne. Il est symétrique à la dent en place sur l'os maxillaire. Ce germe se trouvait initialement au contact de la seconde molaire inférieure droite, face occlusale contre face occlusale.

- n²40 b : germe de seconde molaire déciduale supérieure droite limité à la couronne. Il est symétrique à la dent gauche en place sur l'os maxillaire. 

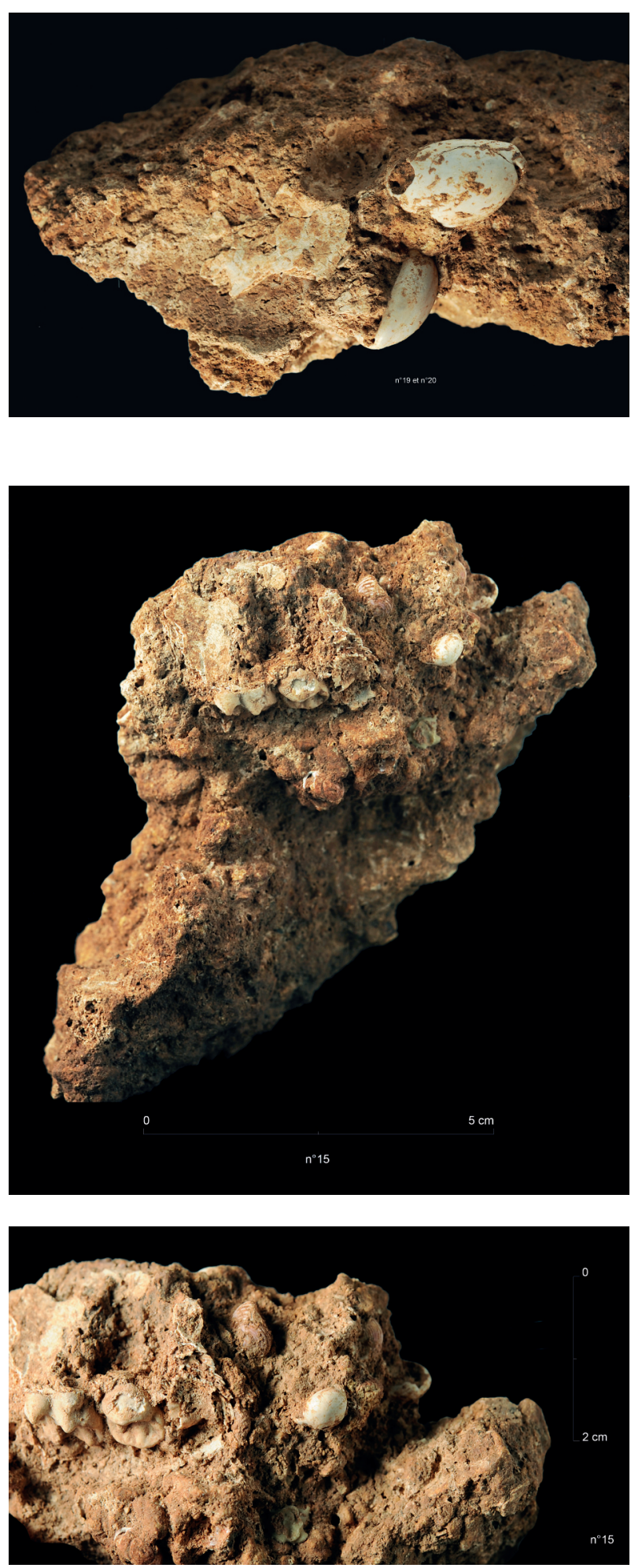

Les dents supérieures de cet enfant ont une morphologie classique pour Homo sapiens sapiens fossile ou actuel : elles montrent deux cuspides et une fovea profonde pour la première molaire déciduale supérieure ; quatre cuspides et une ébauche de tubercule de Carabelli pour la seconde; un tubercule lingual et des crêtes distale et mésiale peu marquées pour les deux incisives supérieures (Henry-Gambier 2001; Le Roy et Henry-Gambier 2017). Seule la couronne de l'incisive centrale supérieure gauche est mesurable. Ses dimensions (diamètres BL- ML) s'insèrent dans la variation des sujets connus pour le Paléolithique supérieur et celle d'enfants actuels (tabl.3).

\section{FIGURE 10}

ragment de voûte crânienne et cyprées (nos 19 et 20), bloc n 18 (๔ Nathalie Gambier).

Fragment of cranial vault and cyprées (nos. 19, 20), block no. 18 (๔ Nathalie Gambier).

\section{FIGURE 11}

Squelette humain : os maxillaire gauche avec dm1 et dm2, vue par la face linguale, bloc $n^{\circ} 15$ (๔ Nathalie Gambier).

Human skeleton: Left maxillary bone with $\mathrm{dm} 1$ and $\mathrm{dm} 2$ (lingual side), block no. 15 (৫) Nathalie Gambier).

\section{FIGURE 12}

Squelette humain : os maxillaire gauche avec dm1 et dm2, vue par la face occlusale, bloc $n^{\circ} 15$ détail (৫ Nathalie Gambier).

Human skeleton: Left maxillary bone with $\mathrm{dm} 1$ and $\mathrm{dm} 2$ (occlusal surface), block no. 15 (@ Nathalie Gambier).

\subsection{2 | La mandibule}

$n^{\circ} 16$ : elle est incluse dans un bloc de sédiment brun rosé induré et compact $(84 \times 87 \times 44 \mathrm{~mm})$. Elle comprend les deux corps mandibulaires en position anatomique, non soudés, ainsi que plusieurs germes de dents déciduales (fig. 16 et 17). La face latérale de chaque corps, de la symphyse à l'alvéole de la seconde molaire supérieure déciduale, est dégagée ; l'état de la surface est bon. Diverses lacunes postérieures au dépôt sont observables. Ainsi le bord alvéolaire droit est très endommagé. Le corps gauche est le mieux conservé. Les branches sont absentes. 

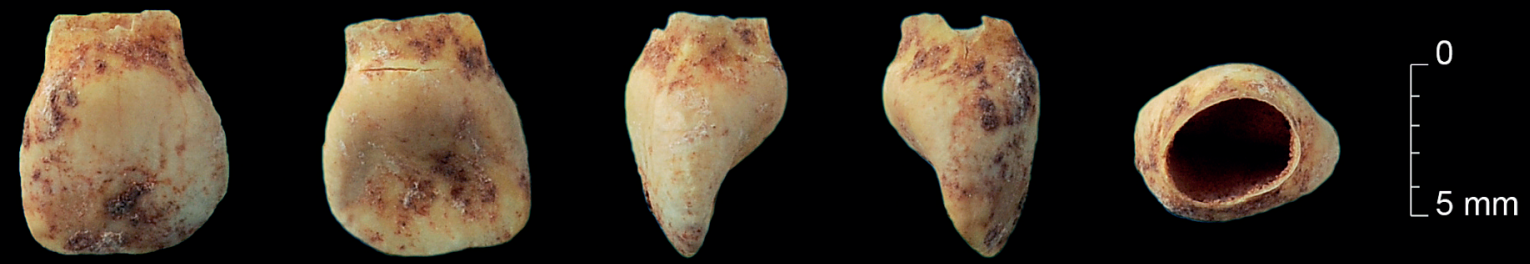

$\mathrm{n}^{\circ} 239$

\section{- FIGURE 13 -}

Première incisive déciduale supérieure gauche $n^{\circ} 239$, faces vestibulaire, linguale, distale et mésiale ( Nathalie Gambier).
First upper left deciduous incisor no. 239, vestibular, lingual, distal and mesial face (® Nathalie Gambier).
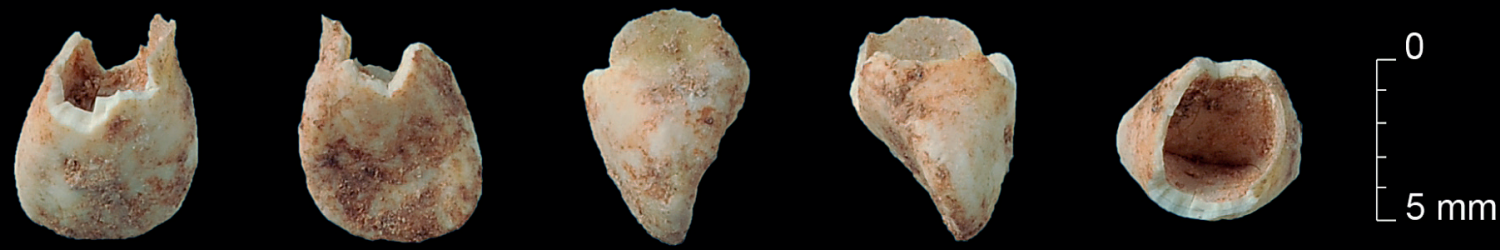

n'192

\section{- FIGURE 14 -}

Seconde incisive déciduale supérieure gauche $n^{\circ}$ 192, faces vestibulaire, linguale, distale et mésiale (@ Nathalie Gambier).
Second upper left incisor no. 192, vestibular, lingual, distal and mesial face (৫) Nathalie Gambier)

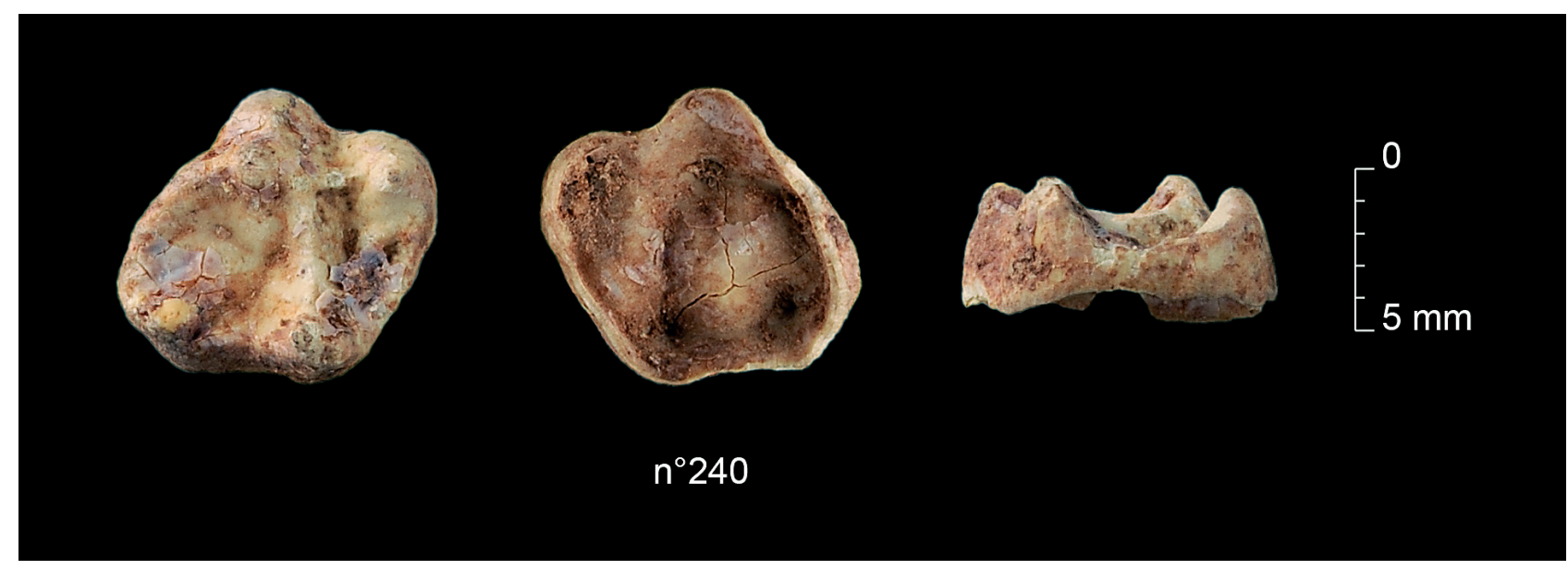

\section{- FIGURE 15 -}

Seconde molaire déciduale supérieure $n^{\circ} 240 \mathrm{~b}$, faces occlusale, supérieure et vestibulaire (๑ Nathalie Gambier).
Upper deciduous second molar no. 240b, occlusal, upper and vestibular face (๔) Nathalie Gambier). 


\begin{tabular}{|c|c|c|c|c|c|}
\hline Échantillon & Dent & Position & Côté & $\mathrm{D} \mathrm{BL}(\mathrm{mm})$ & $\mathrm{D} M D(\mathrm{~mm})$ \\
\hline Labattut $n^{\circ} 239$ & di1 & sup & G & 5,3 & 6,9 \\
\hline Lafaye $25(1-4)$ ans - G & di1 & sup & D & 5,0 & 6,3 \\
\hline Lafaye $25(1-4)$ ans - D & di1 & sup & $G$ & 4,8 & 6,4 \\
\hline Paléolithique sup. européen (1-5) ans - N= 20 & di1 & sup & D & $4,9-6,1$ & $6,7-8,0$ \\
\hline Paléolithique sup. européen (1-5) ans - N= 20 & di1 & sup & $G$ & $4,9-5,8$ & $6,8-8,0$ \\
\hline Enf. Récents Cognac- St- Martin (1-5) ans - N= 16 & di1 & sup & D & $4,6-5,8$ & $5,6-6,3$ \\
\hline Enf. Récents Cognac- St- Martin (1-5) ans - N= 16 & di1 & sup & $G$ & $4,7-5,6$ & $5,6-6,5$ \\
\hline
\end{tabular}

- TABLEAU 3 -

Dimensions de la couronne de la première incisive déciduale.

Sur les corps et dans la région de la symphyse, les caractéristiques morphologiques habituelles chez un très jeune enfant (niveau de développement du menton, fosse incisive nette, gonflement du corps à hauteur de la canine déciduale) sont visibles. On ne note pas de caractère particulier. Les deux incisives centrales et l'incisive latérale droite ont un bord incisif crénelé. La couronne de la canine droite est légèrement déplacée. On devine la première molaire déciduale droite. La morphologie de la surface occlusale des molaires n'est pas observable.

Plusieurs fragments d'os (clavicule, métacarpien et/ou phalanges ?) sont discernables en coupe ou en partie écrasés à la surface du bloc. Il est impossible de les déterminer avec certitude ; l'un d'eux, situé sous le corps droit, pourrait être une côte ou une des clavicules. À droite, un ensemble plus massif avec de l'os spongieux pourrait correspondre au processus mastoïdien. Les cassures se sont produites sur os sec au moment de la découverte ou après la fouille.

Les coquilles en place appartiennent à trois des espèces identifiées : trois Tritia neritea sensiblement alignées sont incluses à 1 ou $2 \mathrm{~cm}$ au-dessus de la mandibule; une quatrième est localisée à $2 \mathrm{~cm}$ de l'extrémité postérieure du corps gauche ; une coquille d'Homalopoma sanguineum et une de Vitta picta apparaissent respectivement à 0,5 et $2 \mathrm{~cm}$ au-dessus des incisives centrales.

\subsection{3 | Le squelette infracrânien}

Aux quelques fragments visibles dans le bloc $n^{\circ} 15$ s'ajoutent des éléments isolés. L'altération de l'os cortical est très forte. Les cassures sont toutes survenues sur os sec (voir figures) au moment des fouilles ou plus tard, au hasard des pérégrinations du squelette. Aucune trace de carnivore ou de rongeur ni aucune modification anthropique ancienne n'ont été observées. En revanche, on note une coloration rouge plus ou moins intense du sédiment attribuable à de l'ocre. Aucun collage entre les os des blocs et les fragments isolés n'a été trouvé.

\subsubsection{1 / Colonne vertébrale}

n 186-188: atlas représenté par les hémi-arcs neuraux non jointifs. Le gauche est plus complet (corde A/P gauche $=18 \mathrm{~mm}$; droite $=8,6 \mathrm{~mm}$; fig. 18). Le tubercule postérieur et le foramen transverse sont conservés. Les deux surfaces articulaires supérieures sont planes. Il n'y a pas de fusion de la synchondrose postérieure.

$n^{\circ}$ 272d : axis représenté par le corps de l'odontoïde complet et non concrétionné, mais dont la surface est très altérée (fig. 19). Les deux moitiés du corps sont soudées. Il présente une forme légèrement pyramidale (hauteur maximale $=7,4 \mathrm{~mm}$; largeur maximale $=11,4 \mathrm{~mm}$ ) analogue à ce que l'on observe chez les enfants actuels de la même classe d'âge (Scheuer et Black 2000).

n 185 : hémi-arc neural droit complet (longueur A/P = 18,8 mm) de vertèbre thoracique. Légèrement érodé avec de l'os spongieux apparent, il n'était pas fusionné avec la moitié droite (fig. 20).

n 187 : hémi-arc neural gauche de vertèbre thoracique cassé en deux et incomplet, il s'agit probablement du symétrique du numéro 185.

S'ajoutent à ces éléments divers fragments millimétriques provenant de l'érosion des arcs neuraux de vertèbres de rang indéterminable.

\subsubsection{2 / Ceinture pelvienne}

$n^{\circ} 176$ : fragment $(27 \times 15 \mathrm{~mm})$ d'ilium droit avec une partie de la surface sacro-pelvienne en partie masquée par du sédiment induré (fig. 21).

$n^{\circ} 272$ c : fragment $(15,7 \times 14,8$ mm) d'os plat peu épais (1 à $2 \mathrm{~mm}$ ) de couleur légèrement rose et avec du sédiment sur une face. De l'os spongieux est visible en coupe. Ce fragment non latéralisable pourrait appartenir à l'ilium. 

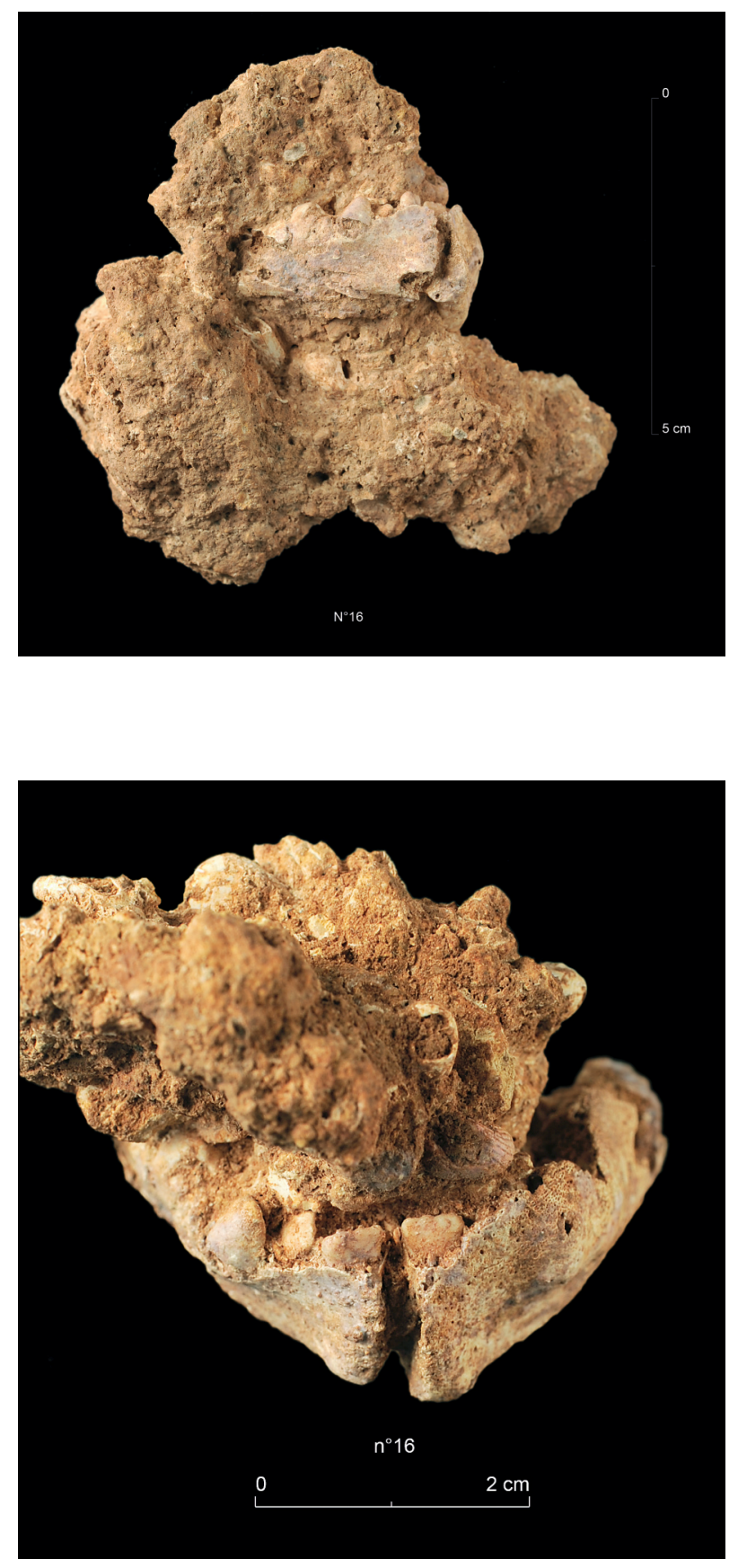

\subsubsection{3 / Côtes}

$n^{\circ} 44$ : bloc de sédiment très induré brun rosé $(60 \times 41 \times$ $29 \mathrm{~mm}$ ). Sur une face, trois fragments de côtes (longueur $=29 \mathrm{~mm}$ ) parallèles et en ordre anatomique apparaissent par leur face latérale (fig. 22). D'autres fragments d'os spongieux, dont une côte, sont aussi visibles. Sur la face opposée du bloc, une coquille d'Homalopoma a pu être identifiée.

n 177a : fragment de côte accolé par une extrémité à un petit bloc de sédiment ( $35 \mathrm{~mm} \times 5 \mathrm{~mm})$. On remarque la présence d'une coulée de résine verdâtre (trace de moulage?).

$\mathrm{n}^{\circ} 184$ : petit bloc $(32 \times 23 \times 18 \mathrm{~mm})$ de sédiment rosé avec deux segments de côte de $25 \mathrm{~mm}$ de long, l'une au-dessus de l'autre, en position anatomique (fig. 23).

\section{FIGURE 16}

Squelette humain : mandibule et dents (dc et di1), face latérale droite et symphyse, bloc $n^{\circ} 16$ (๔ Nathalie Gambier).

Human skeleton: Mandible and teeth (dc and di1), right and symphysis side, block no. 16 (๔ Nathalie Gambier).

\section{FIGURE 17}

Squelette humain : mandibule et dents (dc et di1), face antérieure, bloc n 16 (O) Nathalie Gambier).

Human skeleton: mandible and teeth (dc and di1), anterior face, block no. 16 (○ Nathalie Gambier).

Par souci de précision, signalons également la présence de plusieurs esquilles issues du délabrement des côtes.

\subsubsection{4 | Membre supérieur}

n 180 : humérus droit limité au segment distal de la diaphyse (longueur $=60 \mathrm{~mm}$ ). L'extrémité distale est très érodée latéralement (largeur maximale $=14 \mathrm{~mm}$; épaisseur maximale $=8,2 \mathrm{~mm}$ ), et toute la surface corticale est très altérée (fig. 24).

\subsubsection{5 / Membre inférieur}

$n^{\circ} 181$ : tibia droit (?) limité à une portion de diaphyse longue de $34,8 \mathrm{~mm}$. La surface corticale est très érodée (os spongieux apparent) et altérée, avec notamment des traces de racines (fig. 25). Le diamètre antéro-postérieur au foramen est de $10,3 \mathrm{~mm}$, et le diamètre transverse au même niveau est de $8 \mathrm{~mm}$. 

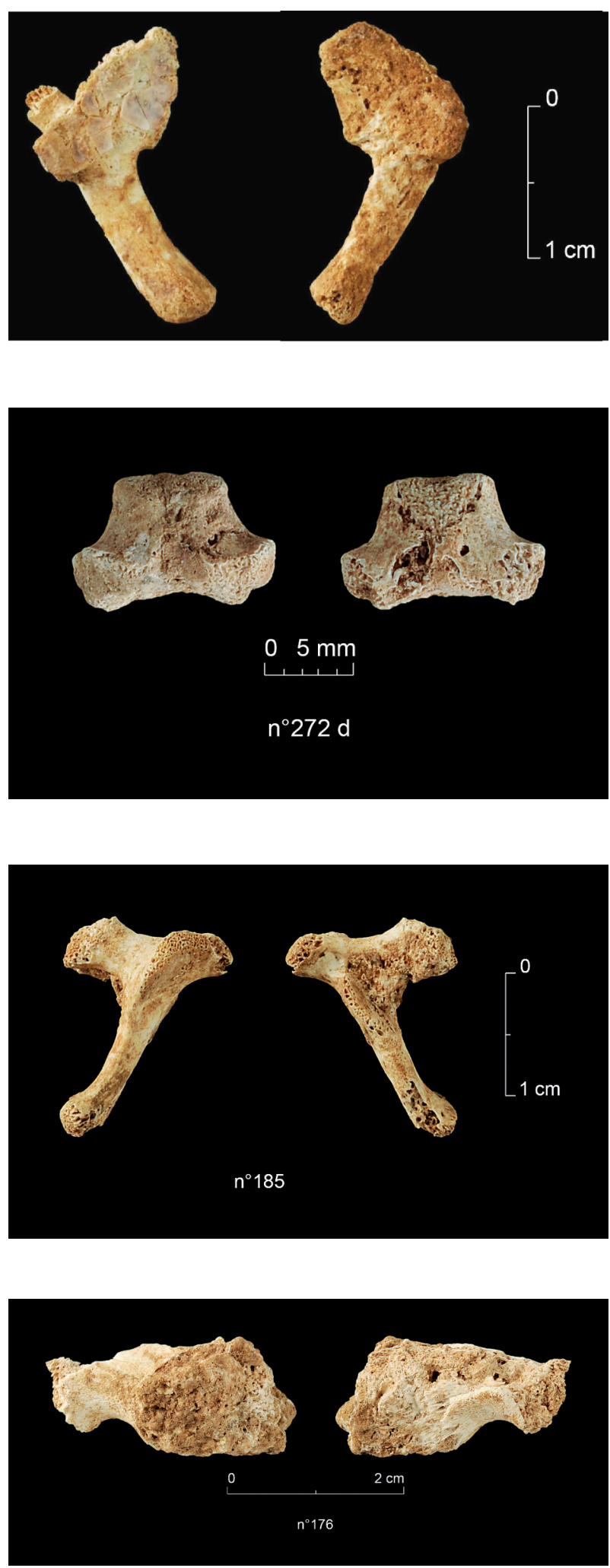

\subsection{4 | Sexe}

Différentes méthodes de diagnose du sexe des sujets immatures à partir de la morphométrie du squelette existent, mais leur fiabilité est très discutée (Leroy et Henry-Gambier 2017). Ici l'état de conservation du squelette rend d'autant plus vaine toute tentative de détermination.

\section{FIGURE 18}

Squelette humain : atlas n 188-186, vue supérieure (ㅇ Nathalie Gambier). Human skeleton: Atlas no. 188-186, upper face (๑ Nathalie Gambier).

\section{FIGURE 19}

Squelette humain : axis n² 272e, dent, faces postérieure et antérieure (๑ Nathalie Gambier).

Human skeleton: Axis no. 272e, dens, posterior and anterior side (@ Nathalie Gambier).

\section{FIGURE 20}

Squelette humain : hémi-arc neural droit de vertèbre thoracique nº 185, (g) face supérieure, (d) face inférieure (๑ Nathalie Gambier).

Human skeleton: Right arch of thoracic vertebrae no. 185, upper and lower face (○ Nathalie Gambier).

\section{FIGURE 21}

Squelette humain : ilium droit n 176, faces médiale et latérale (๑ Nathalie Gambier).

Human skeleton: Right Ilium $n^{\circ}$ 176, mediale and latéral view (๑ Nathalie Gambier).

\subsection{5 | Âge dentaire}

Aucune des dents n'a commencé son éruption. L'évaluation du stade de calcification des couronnes et des racines par comparaison avec celui de populations actuelles a été faite d'après différents travaux (Moorrees et al. 1963 ; AlQahtani et al. 2010) et à partir d'observation directe de l'état de formation des couronnes et des racines. 

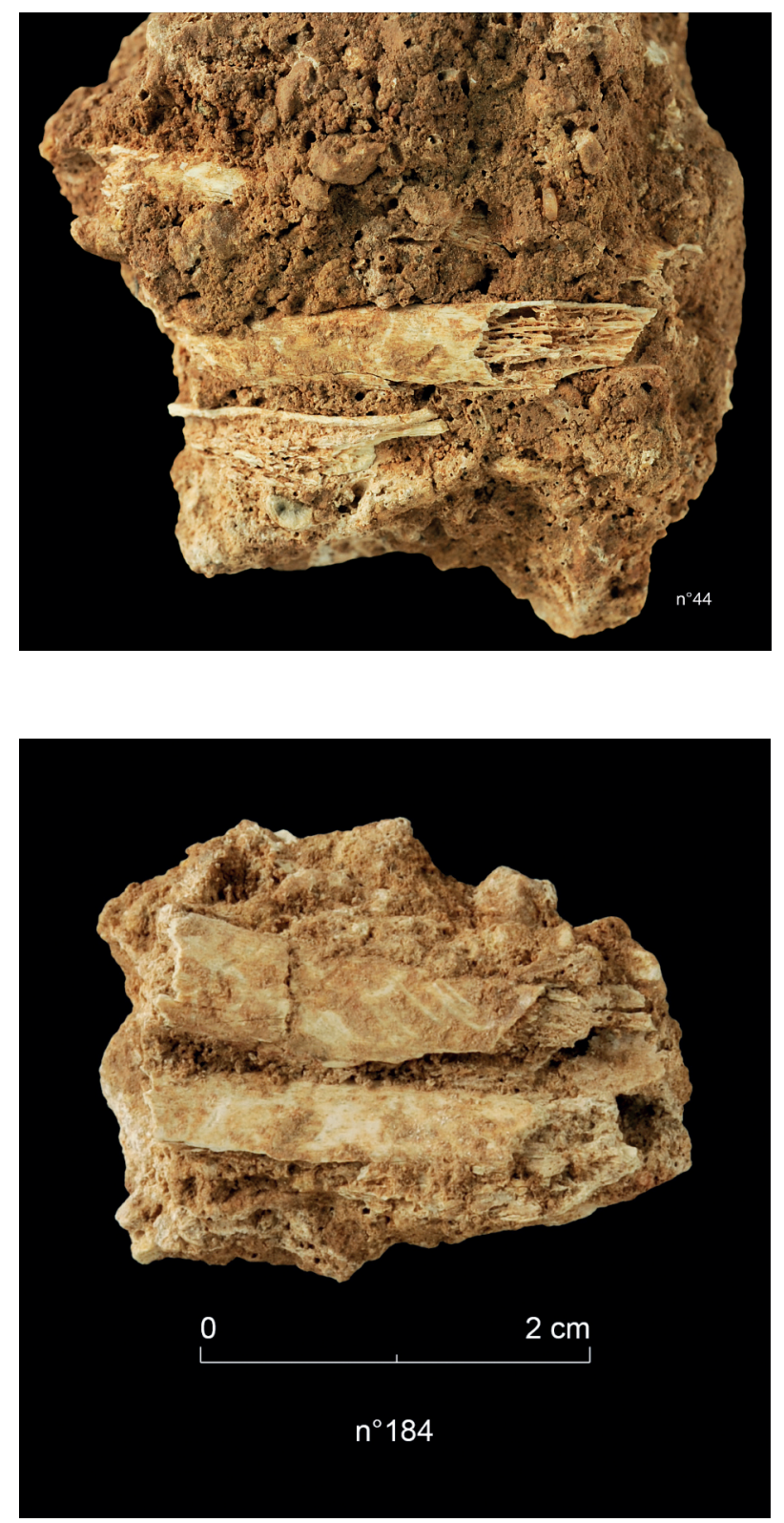

\subsubsection{1 | Dents inférieures}

- La couronne des deux incisives centrales est pratiquement formée : stade Crc.

- La couronne du germe de la canine déciduale inférieure correspond au stade $\mathrm{Cr} 1 / 2$ ou 3/4.

- La couronne de la seconde molaire déciduale inférieure est au stade $\mathrm{Cr} 1 / 2$.

\subsubsection{2 | Dents supérieures}

- La couronne des deux premières molaires déciduales supérieures est au stade $\mathrm{Cr} 1 / 2$.

- La couronne des secondes molaires déciduales supérieures gauche et droite est au stade Coc ou 1/2.

- La couronne de la première et de la seconde incisive supérieure gauche est formée, et la racine est au stade Ri.

En référence à des populations actuelles, ce développement de la denture concorde avec un âge de $7,5 \pm 3$ mois, selon les travaux de S.J. AlQahtani et collaborateurs (2010), et avec un âge compris entre 1 et 6 mois, selon ceux de C. Moorrees et collaborateurs (1963) à partir des dents inférieures.

\section{FIGURE 22}

Squelette humain : côtes, fragments, bloc n 44 (๔ Nathalie Gambier). Human skeleton: Ribs fragments, block no. 14 (๔ Nathalie Gambier).

\section{FIGURE 23}

Squelette humain : côtes n 184 (๔ Nathalie Gambier).

Human: skeleton: Ribs no. 184 (৫ Nathalie Gambier).

\subsection{6 | Maturation osseuse}

La symphyse mandibulaire est totalement ouverte (fig. 17). Dans les populations actuelles, à la naissance, les deux moitiés de la mandibule sont séparées. Elles fusionnent au cours de la première année (Scheuer et Black 2000). Les deux pièces de la dent de l'axis sont soudées (fig. 19). Dans les populations actuelles, la fusion se produit entre 7 et 8 mois in utero et la naissance (Scheuer et Black 2000). En outre, il apparaît que les hémi-arcs neuraux présents n'étaient pas soudés entre eux ni au corps vertébral. Les fusions entre les deux hémi-arcs et entre l'arc neural et le corps vertébral interviennent entre 2 et 6 ans (Scheuer et Black 2000).

Le développement osseux ainsi que les quelques estimations de dimensions des os infracrâniens indiquent un très jeune âge, au plus quelques mois après la naissance. 

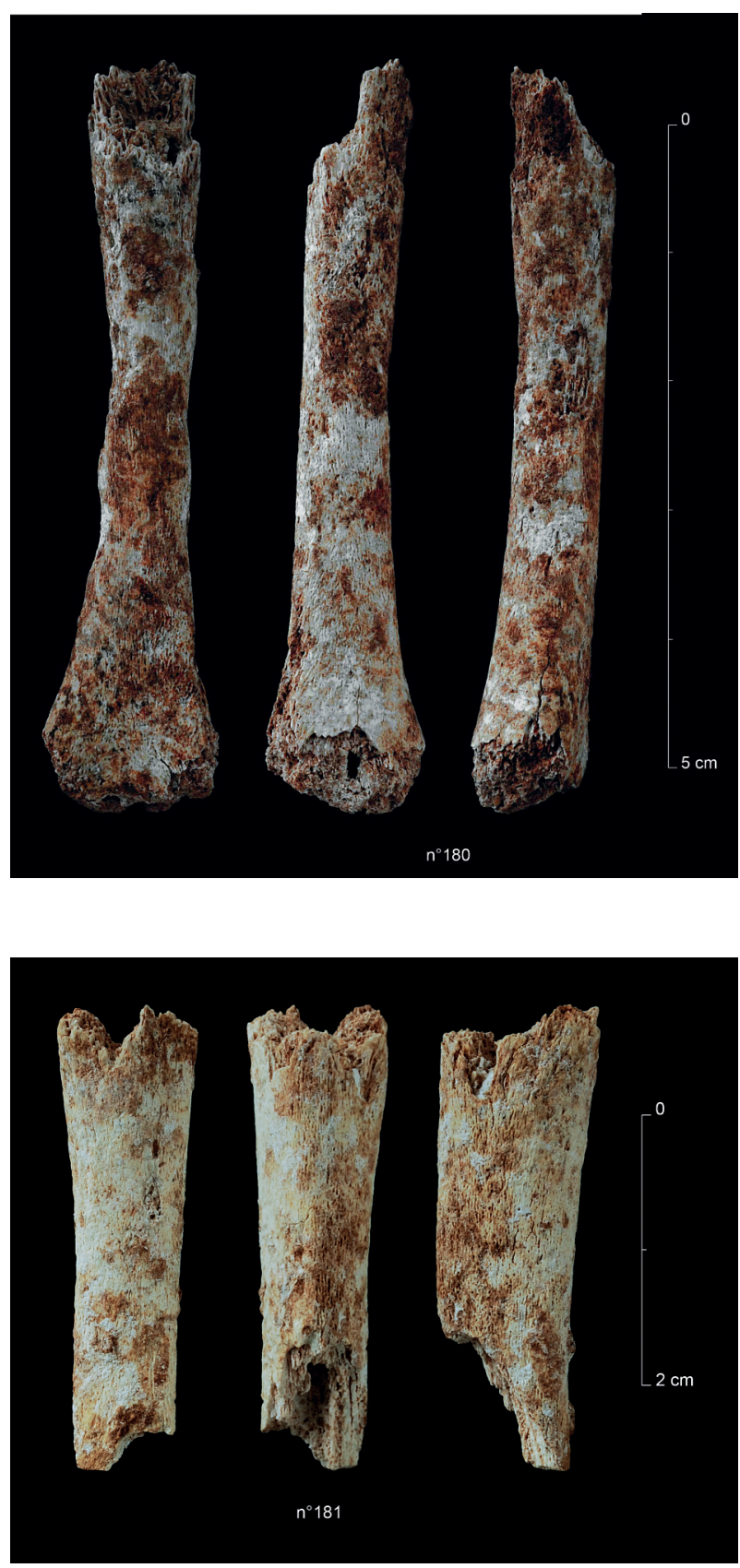

\subsection{7 | Pathologie et cause de la mort}

On peut penser que la naissance, les premiers mois et les premières années des enfants dans les populations du Paléolithique étaient à haut risque. Les causes possibles de décès pouvaient alors être multiples. Ici, aucune lésion osseuse ou dentaire d'ordre pathologique permettant de privilégier une hypothèse n'a été observée.

\subsection{8 | Bilan}

Ce squelette appartient à un nourrisson âgé d'au plus dix mois. Les causes du décès sont inconnues. Le taux de représentation du squelette est faible, avec une absence des os de la ceinture pectorale, des mains, de l'avant-bras et des pieds, ainsi que des corps vertébraux. Les os longs préservés sont incomplets. La fragmentation est importante, en particulier celle du crâne, dont les os sont, en outre, aplatis. La surface corticale est très altérée. Il est

\section{FIGURE 24}

Squelette humain : humérus droit nº 180, faces postérieure, antérieure et médiale (@ Nathalie Gambier).

Human skeleton: Right humerus no. 180, posterior, anterior and medial face (৫ Nathalie Gambier).

\section{FIGURE 25}

Tibia droit (?) n 181, faces postérieure, antérieure et médiale ( Nathalie Gambier).

Right (?) tibia no. 181, posterior, anterior and medial face (๑ Nathalie Gambier).

possible que certains des os absents soient dans le sédiment des blocs 15 et 16, en particulier ceux de la moitié supérieure du squelette, et notamment des mains. Quelques fragments de phalanges et/ou de métacarpiens sont en effet visibles dans le bloc $n^{\circ} 15$, sous la mandibule. Des causes naturelles d'ordre taphonomique, la fouille et les conditions de conservation ultérieures expliquent cet état. Fragilité, petitesse des os et méconnaissance du squelette d'enfant n'ont pas facilité son exhumation ni sa protection. Dernier point, les caractéristiques morphologiques observables sont analogues à celles décrites pour d'autres enfants fossiles et pour les enfants actuels d'anatomie moderne de la même catégorie d'âge. 


\section{6 | ÉTUDE DES COQUILLES}

Cinq espèces ont été identifiées (tabl.4). Trois sont des petits gastéropodes: Homalopoma sanguineum, Tritia neritea, Vitta picta. Deux sont des cyprées : Zonaria pyrum et Schilderia achatidea (fig. 26).

\section{1 | Les petits gastéropodes}

\subsubsection{Homalopoma sanguineum (Linné 1758)}

\subsubsection{1 | Données actualistes}

C'est un gastéropode de la famille des Colloniidae. Cette espèce à coquille rouge plutôt fine, de 6 à $7 \mathrm{~mm}$ de diamètre, est strictement méditerranéenne. Connue depuis le Pliocène, elle vit aujourd'hui dans la zone médio-infralittorale, où elle est plutôt rare et constitue des colonies isolées (Poppe et Goto 1991).

\subsubsection{2 | Les spécimens de Labattut}

Soixante-cinq exemplaires ont été décomptés (fig.27 et 28). Les coquilles sont altérées³. Elles sont décalcifiées, usées, encroûtées et souvent mutilées (fig. 27 et 28). Certaines des

\section{[3] État des coquilles}

- usées : coquille avec traces d'usage ;

- mutilées/dégradées : coquille avec cassures franches, anciennes ou récentes (fouille ou postfouille);

- décalcifiées : coquille calcaire dissoute ou en phase de dissolution ;

- encroûtées : coquille recouverte par des concrétions calcaires dont des vermiculations dues aux racines;

fraîches : coquille non altérée, animal ramassé vivant ou mort depuis peu ;

- roulées: coquille ramassée sur des laisses de mer et soumises à la houle, au vent et au sable. Stigmates parfois très difficiles à distinguer de ceux liés à l'usure. altérations sont manifestement en relation avec l'usage (cassures), mais aussi avec le contexte sédimentaire (altération chimique et physique), la fouille et l'histoire postfouille (cassures). On distingue cependant bien les cordons spiraux et on note une persistance de la couleur d'origine. La taille des coquilles concorde avec les moyennes actuelles, et l'écart-type faible suggère un tri (tabl.5).

\subsubsection{3 | Répartition culturelle}

Cette espèce est attestée dans les niveaux d'habitat de nombreux sites pendant tout le Paléolithique supérieur, avec peut-être un pic au Magdalénien, si l'on en juge par le nombre de sites où elle est signalée (Taborin 1993a; Stiner 1999 ; Álvarez Fernández 2002, 2006, 2009 ; Estrada et al. 2010 ; Avezuela Aritsu et Álvarez Fernández 2012, Peschaux 2017). On la retrouve de l'Espagne à l'Allemagne, dans le Magdalénien moyen (ex. Tito Bustillo, Asturies; Enlène, Ariège...) et dans le Magdalénien supérieur (Andernach-Martinsberg 2 et Gönnersdorf, Allemagne). Elle n'est jamais présente en grand nombre (entre un et une trentaine de spécimens), sauf au Reclau Viver (Espagne), où plus de 2000 spécimens ont été signalés en contexte solutréen (Álvarez Fernández 2006).

Le nombre d'Homalopoma sanguineum trouvé à Labattut est un des plus élevés pour le Magdalénien. Enfin, Homalopoma sanguineum n'est pas signalé, à notre connaissance, dans les sépultures du Paléolithique supérieur ou de l’Épipaléolithique européen.

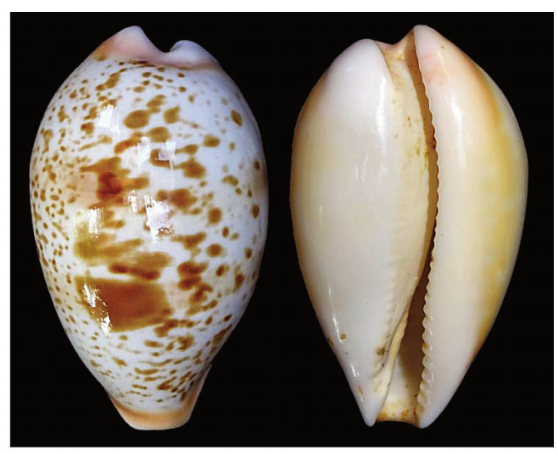

1

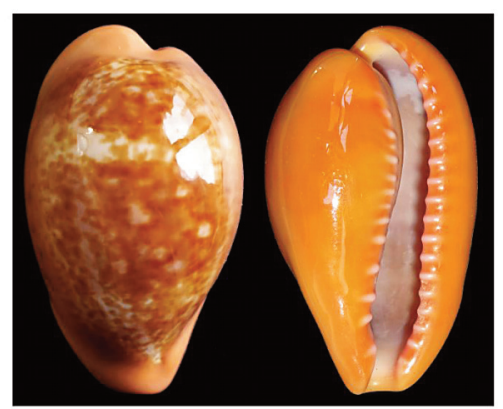

2

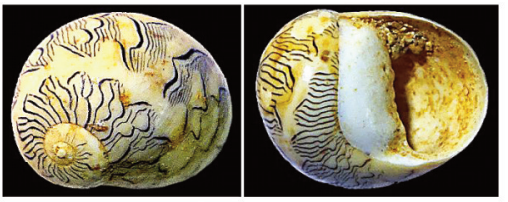

3

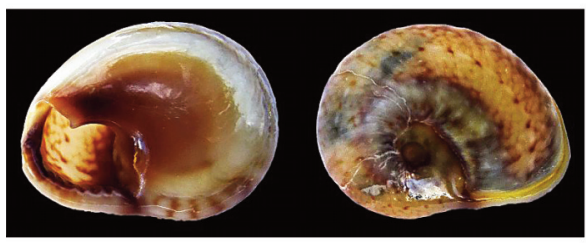

4

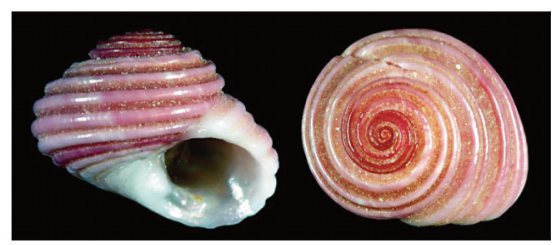

5

\section{FIGURE 26}

Gastéropodes: (1, 2,4, 5 spécimens actuels, 3 fossile Miocène)

1 - Schilderia achatidea, haut. 4,2 cm,

2 -Zonaria pyrum, haut. $3,3 \mathrm{~cm}$,

3 - Vitta picta, long. 0,6 cm,

4 - Tritia neritea, long. $1,2 \mathrm{~cm}$,

5 - Homalopoma sanguineum, long. $0,5 \mathrm{~cm}$,

(๑) Philippe Rocher, Laurent Charles).

Gasteropods: (1, 2, 4, 5, living, 3 Miocen fossil).

1 - Schilderia achatidea, height $4,2 \mathrm{~cm}$,

2 - Zonaria pyrum, height $3,3 \mathrm{~cm}$,

3 - Vitta picta, length $0,6 \mathrm{~cm}$,

4 - Tritia neritea, length $1,2 \mathrm{~cm}$,

5 - Homalopoma sanguineum, length $0,5 \mathrm{~cm}$, (๑ Philippe Rocher, Laurent Charles). 

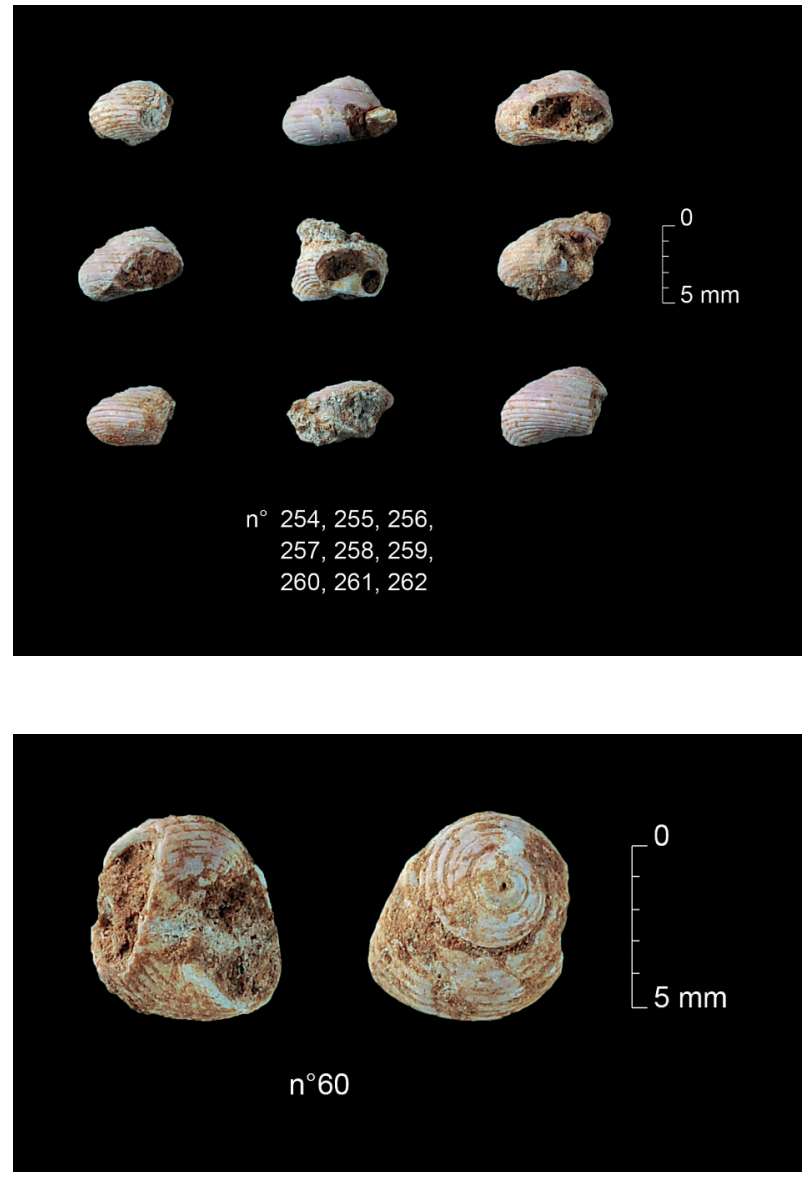

\begin{tabular}{|l|r|}
\hline Genre & Nombre \\
\hline Vita picta & 14 \\
\hline Homalopoma & 65 \\
\hline Tritia & 87 \\
\hline Zonaria & 8 \\
\hline Schilderia & 18 \\
\hline Cypraea sp. & 1 \\
\hline Indéterminables & 4 \\
\hline Total & 197 \\
\hline
\end{tabular}

\section{TABLEAU 4}

Nombre de coquilles de chaque genre.

Number of shells of each genus.

\section{FIGURE 27}

Homalopoma sanguineum n 254 à 262 (๔ Nathalie Gambier).

Homalopoma sanguineum no. 254 to 262 (ㄷ Nathalie Gambier).

\section{FIGURE 28}

Homalopoma sanguineum $n^{\circ} 60$ (ㄷ Nathalie Gambier).

Homalopoma sanguineum no. 60 (๔ Nathalie Gambier).

\subsection{2 | Tritia neritea (Linné 1767)}

\subsubsection{1 | Données actualistes}

Gastéropode de la famille des Nassariidae (anciennement Cyclope neritea), Tritia pellucida (Risso, 1826) est une espèce strictement méditerranéenne ; elle est plus petite et avec une coquille plus fine (Poppe et Goto 1991) que Tritia neritea. Certains critères morphologiques, dont la taille, nous font pencher pour cette dernière (tabl. 5). Identifiée depuis le Pliocène, Tritia neritea est une espèce dont la coquille, de couleur vert d'eau à marron, mesure $8 \mathrm{~mm}$ de diamètre maximal moyen. Elle vit dans la zone supra à médio-littorale de la Méditerranée, dans la mer Noire et le nord-est de l'Atlantique. À la suite d'une introduction récente, elle est présente sur la côte aquitaine (Bachelet et al. 1980), où par exemple une centaine d'individus peuvent être récoltés en une demiheure dans les substrats sablo-vaseux de la zone d'écoulement des nappes à Arcachon (milieux saumâtres).

\subsubsection{2 | Les spécimens de Labattut}

À Labattut, quatre-vingt-neuf coquilles de couleur blanche (fig. 29 et 30), avec des traces d'ocre et de diamètre maximum situé entre 8 et $10 \mathrm{~mm}$, ont été décomptées (tabl.4). Leur état de conservation est comparable à celui des coquilles d'Homalopoma sanguineum. Contexte sédimentaire, usage, fouille et histoire postfouille se sont conjugués pour expliquer leur état actuel.

Les tailles concordent avec les moyennes actuelles, et le faible écart-type suggère un tri (tabl.5).

\subsubsection{3 | Répartition culturelle}

Vivant, ce coquillage est recouvert d'un léger mucus qui le ternit; une fois lustrée, la coquille est brillante. Disponibilité et esthétique ont pu contribuer au succès de ce taxon connu de l'Aurignacien au Magdalénien (Fischer 1896 ; Barge 1983 ; Taborin 1993a ; Stiner 1999 ; Álvarez Fernández 2009 ; Martinez 2015 ; Peschaux 2017). En France, 


\begin{tabular}{|c|c|c|c|c|c|c|c|c|c|c|}
\hline & Homalopoma & Tritia & & Vitta & Z. pyrum & & & Sh. Achatidea & & \\
\hline & Dia max. $(\mathrm{mm})$ & Long. maxi. (mm) & Larg. max. (mm) & Dia max. $(\mathrm{mm})$ & $\begin{array}{l}\text { Long. maxi. } \\
(\mathrm{mm})\end{array}$ & $\begin{array}{l}\text { Larg. } \\
\text { maxi.(mm) }\end{array}$ & $\begin{array}{l}\text { Haut. } \\
\text { maxi. } \\
(\mathrm{mm})\end{array}$ & $\begin{array}{l}\text { Long. maxi. } \\
(\mathrm{mm})\end{array}$ & $\begin{array}{l}\text { Larg. } \\
\text { maxi. } \\
(\mathrm{mm})\end{array}$ & $\begin{array}{l}\text { Haut. } \\
\text { maxi.(mm) }\end{array}$ \\
\hline Moyenne & 6,6 & 8,6 & $\begin{array}{r}6,6 \\
\end{array}$ & 5,6 & 33,8 & 21,5 & 17,6 & 31,7 & 20,6 & 16,7 \\
\hline Ecart -type & 0,6 & 0,6 & 0,5 & 0,9 & 2,9 & 1,7 & 1,3 & 3 & 2 & 2 \\
\hline $\mathrm{N}$ & 53 & 73 & 74 & 11 & 8 & 8 & 8 & 17 & 17 & 15 \\
\hline
\end{tabular}

- TABLEAU 5 -

Dimensions des coquilles (moyenne, écart-type, nombre de coquilles mesurables).

Shell dimensions (mean, standard deviation, number of measurable shells).

une trentaine de coquilles est signalée dans l'Aurignacien de Rothschild (Hérault; Barge 1983). Entre un et une dizaine de spécimens sont décrits dans des niveaux d'habitat du Solutréen et du Magdalénien moyen et supérieur. Les sites magdaléniens de Gönnersdorf, d'Andernach-Martinsberg 2 et de Petersfels, en Allemagne, auraient livré quelques exemplaires de Cyclope sp. (Álvarez Fernández 2009).

Tritia neritea est aussi une coquille très fréquente (plusieurs dizaines) en Italie, dans les niveaux Gravettien/Épigravettien ancien, aussi bien dans les sépultures de cette période que dans les niveaux d'habitat; ces coquilles deviennent très fréquentes dans certaines sépultures épipaléolithiques de France et d'Italie (Coppola et Vaca 1995 ; Henry-Gambier 2001 ; Gazzoni et Fontana 2011)

\subsection{3 | Vitta picta (Férussac, 1823)}

Gastéropode de la famille des Neritidae, Vitta picta est une espèce fossile du Miocène inférieur. C'est une des rares coquilles fossiles qui peut conserver ses motifs et une certaine brillance (fig. 26). La coquille est beige à blanc cassé et sa taille moyenne est de $5 \mathrm{~mm}$.

\subsubsection{1 | Les spécimens de Labattut}

D'une couleur beige-blanc légèrement rosée (ocre) et d'une taille comprise entre 4 et $7 \mathrm{~mm}$, Vitta picta est le plus petit des gastéropodes de Labattut, quatorze exemplaires ont été identifiés (tabl. 4 et 5).

Les coquilles sont très mal conservées et présentent une forte altération chimique de surface et des cassures. Aucune n'a conservé ses motifs. Le contexte sédimentaire explique sans doute cet état de conservation (fig. 31 et 32).

\subsubsection{2 | Répartition culturelle}

En l'état des données archéologiques, Vitta picta a une répartition limitée à cinq départements français: la Dordogne, le Lot, le Lot-et-Garonne, l'Indre et la Vienne. Toutefois, sa présence dans les sites est peut-être à réévaluer en raison de la confusion possible avec Theodoxus fluviatilis, autre néritine de morphologie proche mais terne et plus fragile, courante en milieu fluviatile. Vitta picta est une espèce signalée dans le Solutréen de l'abri Lachaud (Dordogne); dans le Badegoulien des abris Fritsch (Indre), Lachaud (Dordogne), du Cuzoul de Vers (Lot) et Cassegros (Lot-et-Garonne); dans le Magdalénien inférieur d'Antigny (Vienne); et dans le Magdalénien moyen de la Garenne, où ses coquilles dominent l'assemblage (Taborin 1993a; Peschaux 2017)
La seule sépulture où l'espèce est décrite, celle de l'enfant de la Madeleine (Vanhaeren et d'Errico 2001), est postérieure au Magdalénien (Gambier et al. 2000).

\subsubsection{3 | Perforations, techniques et traces d'usage}

L'encroûtement et le mauvais état de conservation des coquilles de ces trois espèces de petits gastéropodes gênent la lecture des orifices et de leurs contours. Il est très difficile de trancher en faveur d'une technique de percement ou d'un type d'usage et de son intensité.

- Tritia neritea possède un orifice de forme irrégulière dont l'emplacement sur la face dorsale est opposé à l'ouverture (fig. 29 et 30). Ici, une perforation par percussion, technique la plus utilisée pour cette espèce (Taborin 1993a), est la plus probable.

- Homalopoma sanguineum montre un orifice de forme ovale à l'opposé de l'ouverture (fig. 27 et 28). Y. Taborin (1993a) indique, pour cette espèce, un percement par percussion dans la presque totalité des cas, avec, parfois, un départ par abrasion. Ici, l'abrasion est la technique qui semble avoir été utilisée.

- Vitta picta présente un orifice ovale à l'arrière de la coquille (fig. 31 et 32). Y. Taborin (1993a) décrit plusieurs techniques de percement, dont l'ouverture de l'orifice par abrasion, technique qui semble aussi avoir été employée à Labattut.

Sur Tritia neritea, comme sur Homalopoma sanguineum, l'usage se manifeste par un agrandissement de l'orifice vers l'arrière et par un émoussé des bords. Sur Vitta, des traces d'usure, plus difficiles à mettre en évidence en raison de l'état de conservation, existent au niveau des bords de l'orifice (fig. 28 et 30 ).

L'usure des bords des orifices est compatible avec le passage d'un lien. Et dans le cas de Tritia et d'Homalopoma, l'allongement vers l'arrière de l'orifice pourrait indiquer un usage mais plus dommageable pour la coquille (fig. 27 et 29).

\section{2 | Les cyprées}

\subsection{1 | Données actualistes}

Deux espèces ont été identifiées, Schilderia achatidea et Zonaria pyrum. Elles sont anciennement connues sous le vocable générique Cypraea. Elles sont considérées comme peu communes actuellement (Poppe et Goto 1991).

- Schilderia achatidea (Gray in G.B.Sowerby I, 1837) : d'une longueur moyenne d'environ $37 \mathrm{~mm}$, la coquille est assez fine, blanche à marron et brillante. Les denticulations de la lèvre externe sont discrètes (fig. 26). 

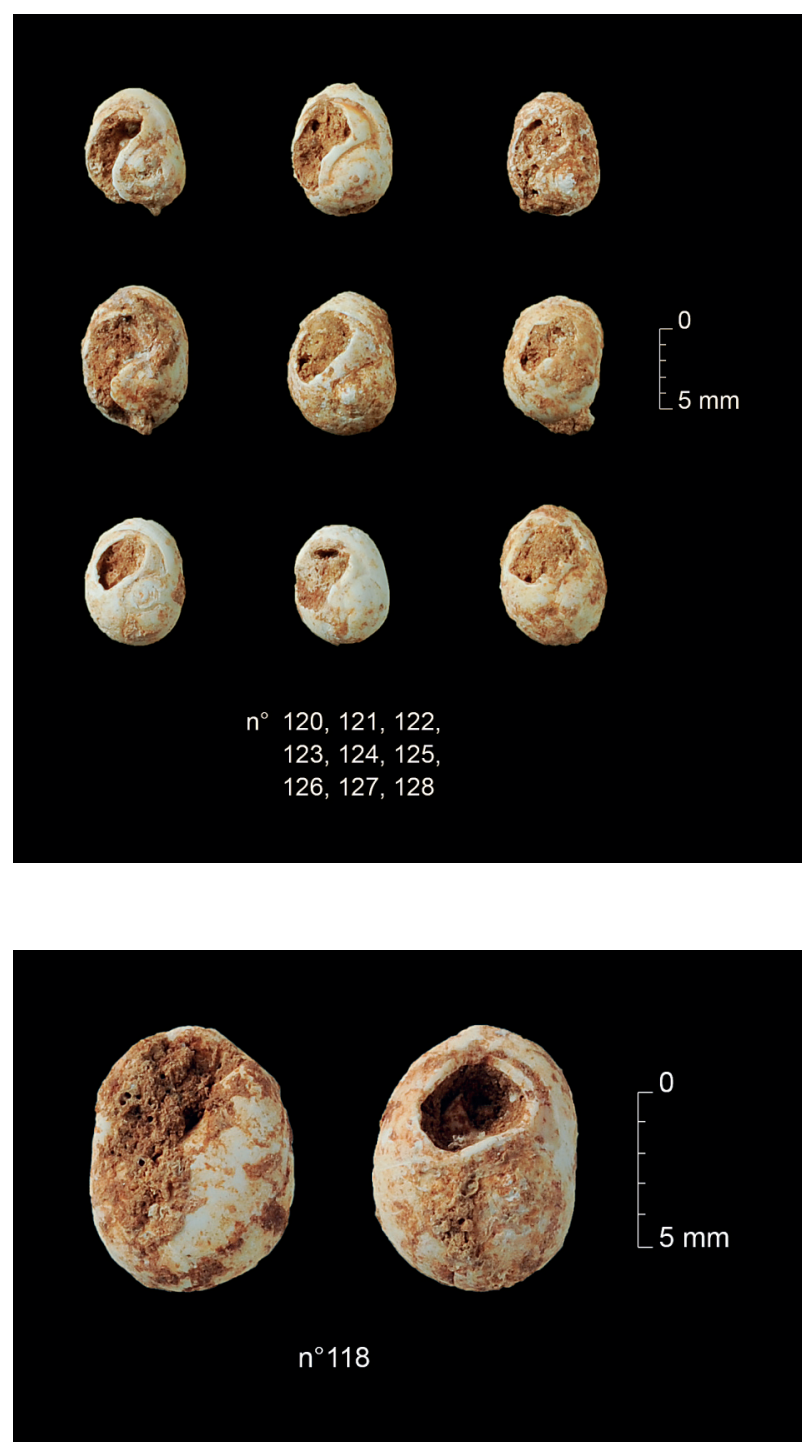

\section{FIGURE 30}

Tritia neritea $\mathrm{n}^{\circ} 118$ (๔ Nathalie Gambier).

Tritia neritea no. 118 (๔ Nathalie Gambier)

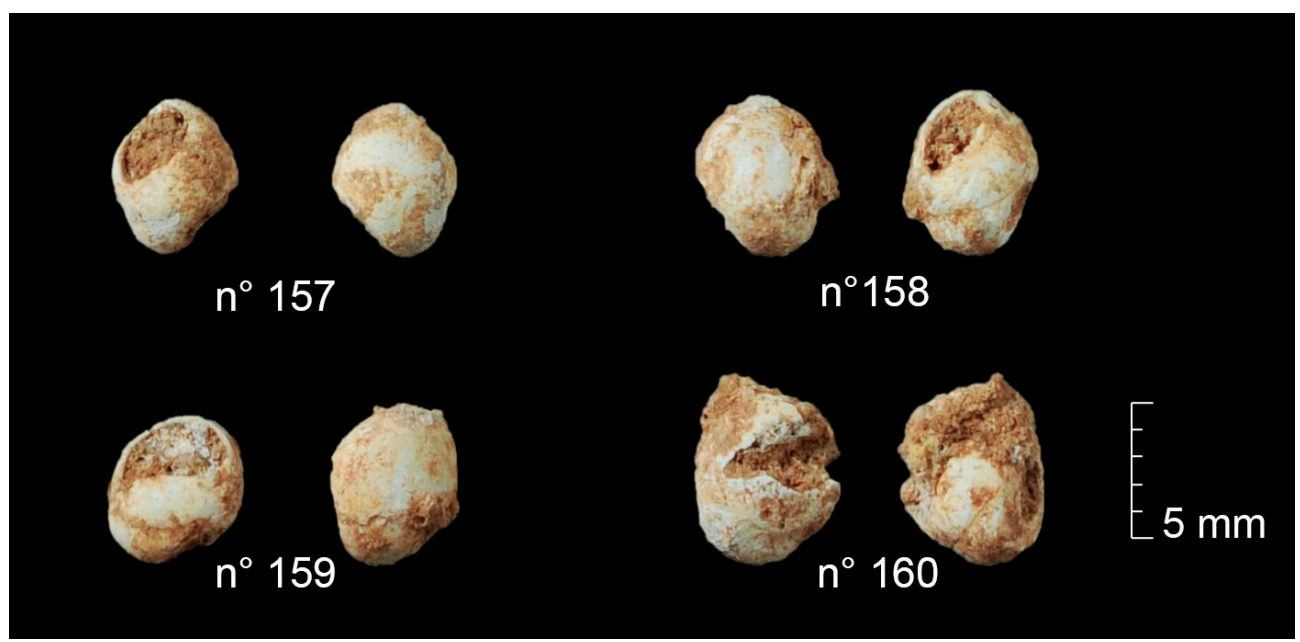

\section{FIGURE 31}

Vitta picta nos 157, 158, 159, 160 (৫) Nathalie Gambier).

Vitta picta nos. 157, 158, 159, 160 (৫) Nathalie Gambier).
Schilderia est connue depuis le Miocène. Actuellement, on la trouve entre 35 et $80 \mathrm{~m}$ de profondeur, sur les côtes de l'Afrique de l'Ouest et, plus rarement, en Méditerranée occidentale (mer d'Alboran : Poppe et Goto 1991).
- Zonaria pyrum (Gmelin, 1791) : d'une longueur moyenne de $36 \mathrm{~mm}$ et de couleur marron à orangée, la coquille est dense, épaisse et brillante (fig. 26). Sur la face ventrale, les denticulations de la lèvre externe sont grossières. 


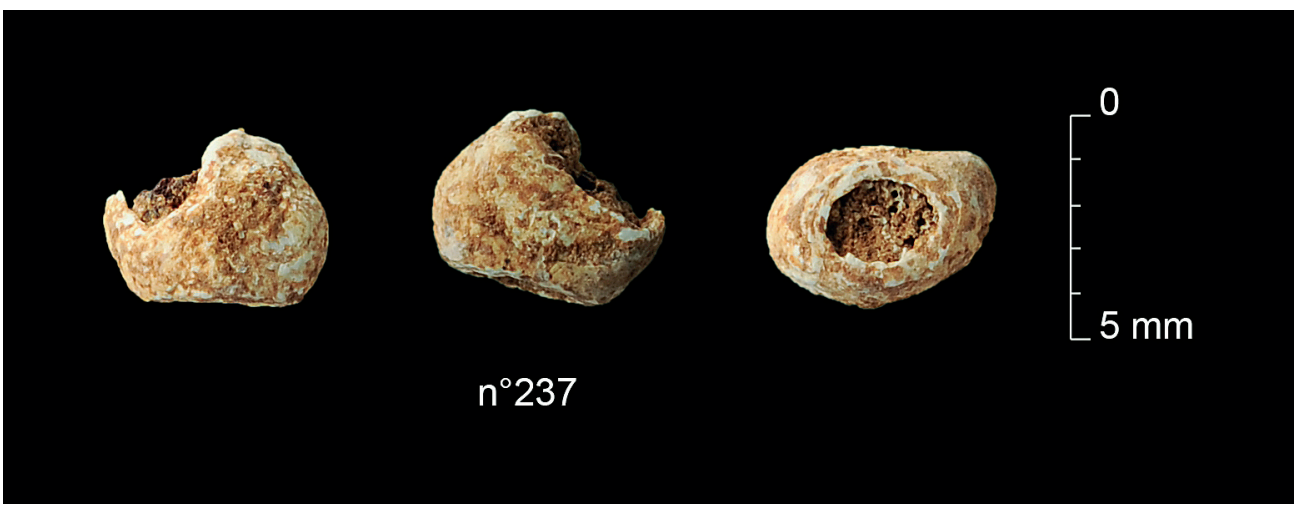

\section{FIGURE 32}

Vitta picta $n^{\circ} 156,158,160,161$ (c) Nathalie Gambier).

Vitta picta no. 156, 158, 160, 161 (c) Nathalie Gambier).
Cette espèce est connue depuis le Miocène. Elle vit actuellement en Méditerranée et dans l'Atlantique (Espagne, Portugal et Afrique de l'Ouest), entre 2 et $80 \mathrm{~m}$ de profondeur (Poppe et Goto 1991).

\subsubsection{Les spécimens de Labattut}

Schilderia achatidea est clairement identifiée pour quinze exemplaires. Trois spécimens (nos 19, 20, 35), dont la face ventrale est en partie masquée par du sédiment, ont une forme globuleuse plaidant aussi en faveur de cette espèce. Un exemplaire non retrouvé ( $n^{\circ}$ D3823-97-29) est cité par Y. Taborin (1993a - p. 181) comme issu de Labattut. Sa forme évoque aussi ce taxon. In fine, ce serait dix-neuf exemplaires de l'espèce qui auraient été présents (ex. : fig. 33, 34 à $37,42,43$ ).

Zonaria pyrum est représenté par huit exemplaires (ex. : fig. 38, 39, 40, 41).

L'échantillon est ainsi constitué de vingt-sept cyprées (tabl.4). La longueur moyenne des coquilles est de $32 \mathrm{~mm}$ (tabl.5). Contrairement aux petits gastéropodes, elles sont très bien conservées. De couleur blanc cassé, encore épaisses, avec la trace du manteau perceptible et les denticules labiaux presque intacts. On note sur la plupart un reliquat de brillance. Une seule ( $\left.n^{\circ} 34\right)$ est incomplète et cassée en deux morceaux. Il s'agit d'une cassure récente. Plusieurs (nos 19, 25, 35, 40) ont quelques lacunes (2 à $10 \mathrm{~mm}^{2}$ ) sur les deux faces ou sur les bords des lèvres. Des concrétions, masquent par endroits la surface (fig. 41, 42, 43) ; un écaillage, des cupules et des vermiculations d'extension variable (mais faible) creusent la surface externe de certaines. Une couleur rosée et des points d'ocre sont observables sur les coquilles nos 26, 27, 28, 29 et 55 .

Aucune trace de sable d'origine marine n'a été trouvée à l'intérieur des coquilles (ex. $n^{\circ}$ 27). Le remplissage actuel, lorsqu'il est encore présent, est celui du sédiment de la couche archéologique.

\subsection{3 / Répartition culturelle}

Les recherches en cours montrent qu'une révision des déterminations des cyprées et de leur fréquence dans les sites datés du Paléolithique supérieur est nécessaire. Ainsi, celles associées à l'homme de la sépulture de Laugerie-Basse, déterminées comme fossiles (Taborin $1993 a$ - p. 431), appartiennent en réalité aux espèces pyrum et achatidea (détermination Dolin 2015-2016, Chauvière étude en cours). Le recensement des cyprées réalisé par Y. Taborin (1993a) - cent vingt-huit exemplaires pour une quarantaine de sites essentiellement français - ainsi que la fabrication de fac-similés, comme à Pair-non-Pair, en Gironde (Taborin 2004b), attestent, en dépit des incertitudes et du biais probable de l'échantillon, de l'intérêt des groupes du Paléolithique supérieur pour ces coquillages.

Ainsi, plusieurs espèces fossiles (brochii, inflata, polysarca...) ou actuelles (lurida, spurca, achatidea, pyrum...) sont mentionnées en France et en Italie, dans des niveaux d'habitat contemporains du Gravettien, de l'Épigravettien ancien, du Badegoulien et du Magdalénien et, plus rarement semble-t-il, dans ceux de l'Aurignacien et du Solutréen (Fisher 1876 ; Rivière 1887 ; Fischer 1896 ; Lenoir et Terraza 1971 ; Taborin 1991, 1993a, 2004b ; HenryGambier 2001 ; Vanhaeren et d'Errico 2003 ; Granger et Airvaux 2010 ; Peschaux 2017).

Zonaria pyrum est une espèce signalée surtout dans des sites de la moitié sud de la France (Dordogne, Lot, Pyrénées-Orientales, Gard, Alpes-Maritimes) et en Italie (Ligurie), notamment dans les sépultures synchrones du Gravettien ou de l'Épigravettien ancien.

Schilderia achatidea (anciennement C. physis) serait beaucoup moins représentée, quelle que soit la région. On la connaît en Ligurie, dans les grottes des Balzi Rossi (collection Rivière-Goury, Peschaux étude en cours), et dans le Magdalénien du Mas d'Azil, en Ariège.

D'après les données publiées, avec vingt-sept exemplaires, Labattut est le site d'Europe le plus riche en cyprées, suivi par Laugerie-Basse (Magdalénien moyen ancien, zone de la sépulture), avec dix-huit spécimens, puis par l'abri Faustin. Dans ce dernier site, le Magdalénien supérieur a livré treize Prozonarina expansa (anciennement C. Brocchii, détermination Dolin 2017), espèce fossile des faluns miocènes d'Aquitaine, et trois Cypraea sp, toutes biperforées (Lenoir et Terraza 1971). Les niveaux du Magdalénien moyen d'Enlène auraient aussi livré au moins huit Cypraea sp d’origine méditerranéenne (Taborin 2004a).

\subsection{4 | Perforations, techniques et traces d'usure}

Toutes les coquilles ont un orifice ( $T 1$, nomenclature Y. Taborin 1993a) localisé sur la face dorsale de la coquille, dans la zone opposée à l'ouverture, au-dessus du canal siphonal. Sa forme et ses dimensions sont variables (dimension max. $5 \mathrm{~mm}$ ) : ovale à triangulaire, à sommet antérieur déporté du côté interne (fig. 44). Latéralement, on voit les traces répétées du passage de l'outil, sous la forme de stries. Les coquilles nos 25, 33, 50, 52 et 53 présentent, en outre, des stries de dérapage ou de préparation. 


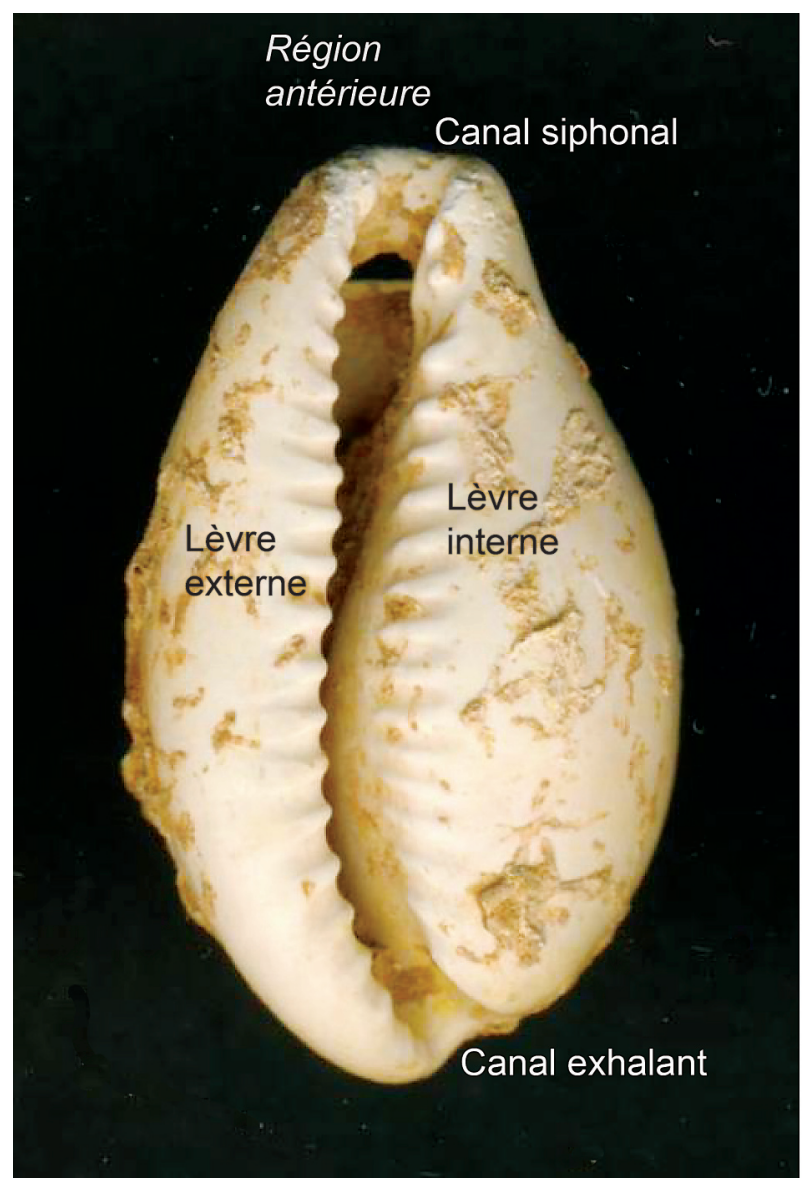

\section{FIGURE 33}

Cyprée sp. : morphologie de la coquille d'après Dolin et Lozouet (2004) Cyprée sp.: Morphology of the shell after Dolin and Lozouet (2004).

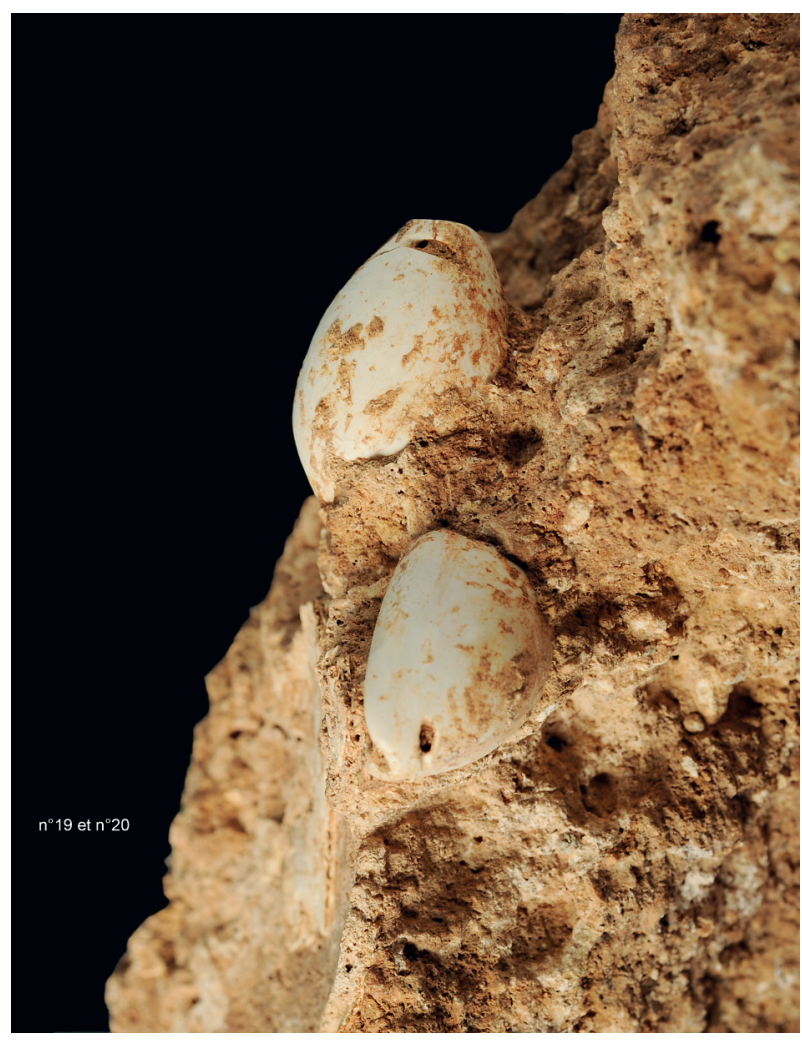

\section{FIGURE 34}

Schilderia achatidea nos 19 et 20, bloc n¹8 ( Nathalie Gambier). Schilderia achatidea nos. 19 and 20, block $n^{\circ} 18$ (๔ Nathalie Gambier). 


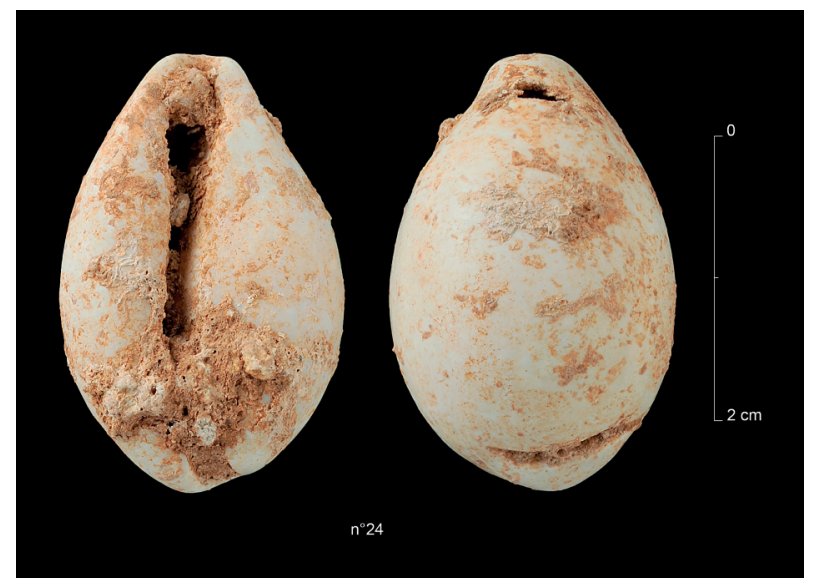

\section{FIGURE 35}

Schilderia achatidea $n^{\circ} 24$ (๔) Nathalie Gambier) Schilderia achatidea no. 24 (๔ Nathalie Gambier).

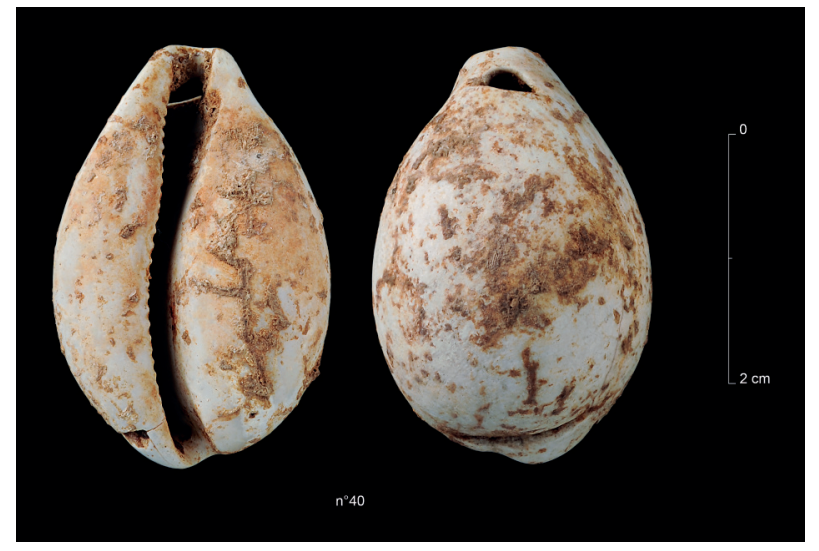

\section{FIGURE 36}

Schilderia achatidea $n^{\circ} 40$ (๔ Nathalie Gambier). Schilderia achatidea no. 40 ( Nathalie Gambier).

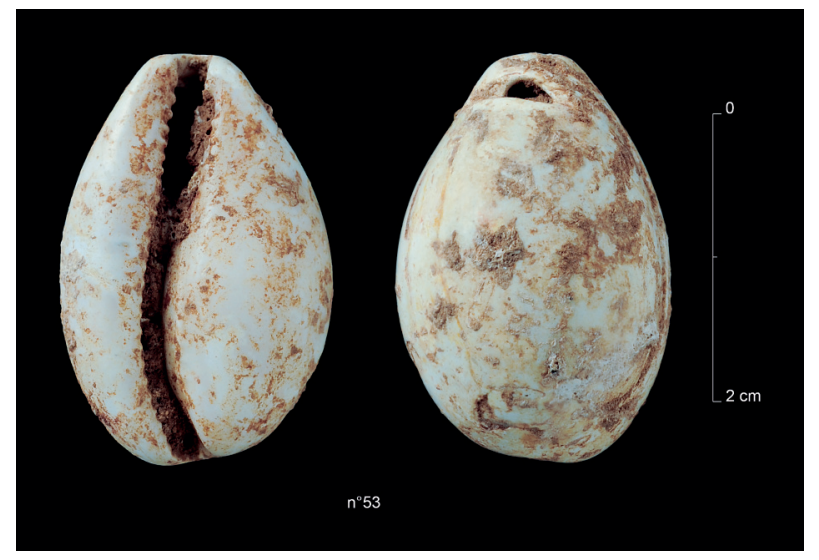

\section{FIGURE 37}

Schilderia achatidea $n^{\circ} 53$ (๔ Nathalie Gambier). Schilderia achatidea no. 53 (๔ Nathalie Gambier).

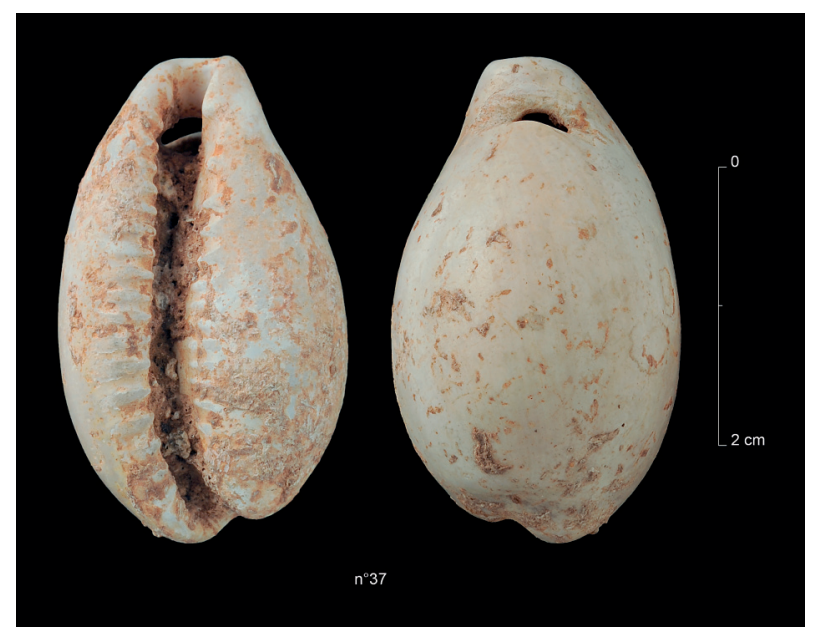

\section{FIGURE 38}

Zonaria pyrum n 37 (๔ Nathalie Gambier). Zonaria pyrum no. 37 (๔ Nathalie Gambier). 

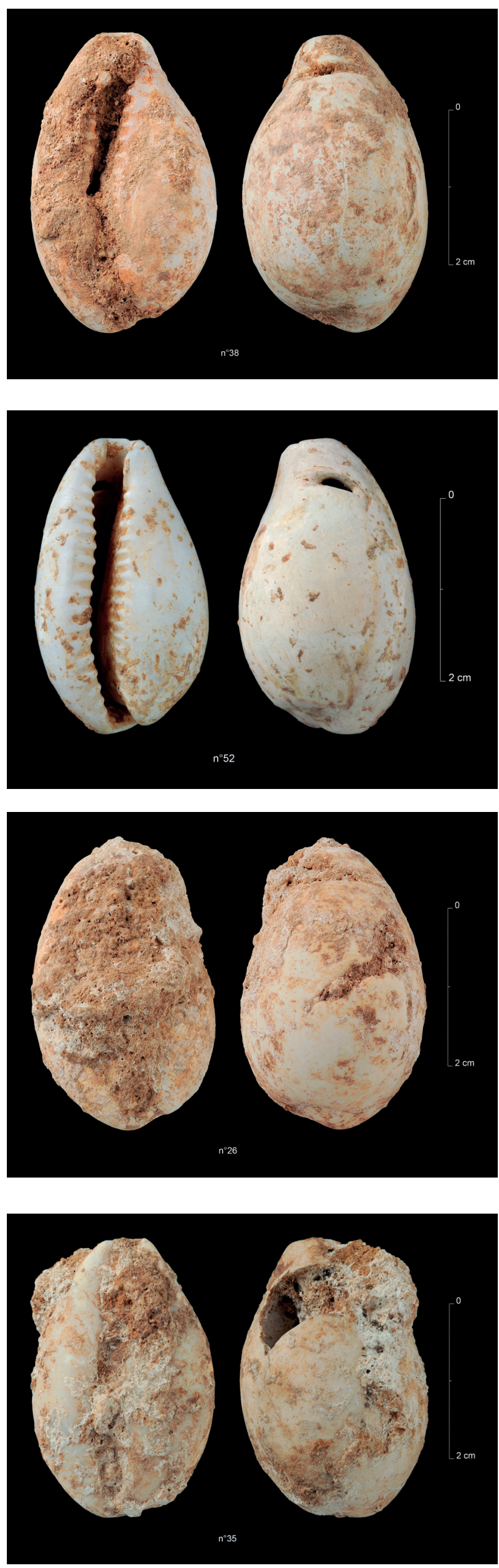

\section{FIGURE 39}

Zonaria pyrum n 38 (@ Nathalie Gambier).

Zonaria pyrum no. 38 (๑ Nathalie Gambier).

\section{FIGURE 40}

Zonaria pyrum nº 52 (๔ Nathalie Gambier).

Zonaria pyrum no. 52 (๔ Nathalie Gambier).

\section{FIGURE 41}

Zonaria pyrum $n^{\circ} 26$ avec dégradation naturelle de la face dorsale (๔ Nathalie Gambier).

Zonaria pyrum no.. 26 with natural degradation of the dorsal surface (๑ Nathalie Gambier).

\section{FIGURE 42}

Schilderia achatidea $n^{\circ} 35$ avec lacune sur la face dorsale (๔ Nathalie Gambier). Schilderia achatidea no. 35 with gap on dorsal face (ㄷ Nathalie Gambier). 


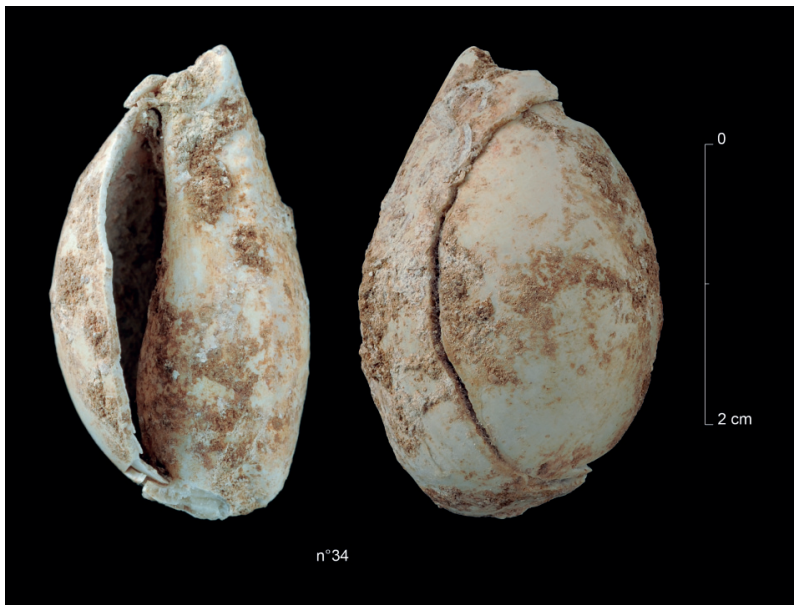

Trois coquilles de Schilderia (nos 24, 27, 40) sont biperforées (ex. fig.36). Le second orifice (T2) est ouvert sur la face dorsale, à l'opposé du premier, au-dessus du canal exhalant, près de l'apex. Circulaire, il a un diamètre très étroit (1 à $2 \mathrm{~mm}$; fig. 45).

La technique utilisée est le sciage. Le sillon réalisé est plus ou moins large et profond. Dans le cas de T1, il est horizontal ou légèrement oblique vers la partie interne ou externe (fig.44). Pour T2, le sillon, déporté du côté externe de la coquille, est très étroit (fig. 45). Des essais ont été tentés sur une coquille de cyprée actuelle et sur une coquille fossile du Miocène : il faut dix minutes pour percer le spécimen actuel et une minute pour le spécimen fossile dont le test est moins épais et plus fragile. Cette technique aboutit directement à l'ouverture de la coquille, comme le soulignait Y. Taborin (1993a). L'essai montre que le sciage laisse un orifice de petit diamètre à bord tranchant. Pour passer une attache, il faut araser le bord et donc agrandir l'orifice. Au cours du Paléolithique supérieur, le sciage n'est pas la seule technique de percement des cyprées. À Faustin, à Enlène ou à la Marche, la perforation a été réalisée par rotation (Taborin 1993a).

Sur les coquilles de Labattut, les bords des orifices T1 et du sillon sont émoussés (fig. 44). Les microstries latérales résultant du sciage sont plus ou moins atténuées. Sur certaines des coquilles, la déviation vers le bord interne de l'orifice est assimilable à un début d'encoche ou de déformation liée au frottement d'un cordon. Ce sont les seuls indices indiscutables d'usage, car nous n'observons pas de stigmate convaincant de polissage, ni sur les faces dorsale ou ventrale ni dans le secteur de la fossula, pourtant directement en contact avec un lien éventuel ou un support.

Dans le cas du second orifice, l'absence ou la discrétion des traces d'usure et le très petit diamètre de l'orifice interroge : orifice non fonctionnel, ou peu utilisé, ou encore utilisation peu dommageable, avec le passage d'un lien très fin (fig. 45) ?

Y. Taborin (1993b) propose cinq systèmes de fixation pour les cyprées. Aucun n'est compatible avec les traces observées à Labattut. La légère déformation vers le haut de l'orifice T1 suggère une fixation verticale, tandis que l'atténuation des stries latérales de sciage impliquerait une fixation latérale. Ce constat évoquerait un maintien fort des coquilles par trois points, ce qui expliquerait l'absence d'impacts de chocs anciens.

\section{FIGURE 43}

Schilderia achatidea $n^{\circ} 34$, cassure fouille ou postfouille ( Nathalie Gambier) Schilderia achatidea no. 34, with excavation or post excavation (ㅇ Nathalie Gambier).

\section{7 | ORIGINE GÉOGRAPHIQUE DES COQUILLES}

Vitta picta est une espèce fossile assez commune dans certains niveaux saumâtres aquitaniens, où une vingtaine d'individus peuvent être collectés sans tamis en une demiheure. Les quatorze spécimens conservés à Labattut proviennent sans doute des faluns du Miocène inférieur de Gironde (communes de Pessac, Mérignac, Saucats), soit de 130 à 200 km à vol d'oiseau du vallon de Castelmerle.

Tritia neritea, Homalopoma sanguineum, Zonaria et schilderia sont des taxons considérés comme ayant une origine méditerranéenne. Les températures marines annoncées pour le Dryas ancien, soit environ 10 à $15^{\circ} \mathrm{C}$ (ex. Essalami et al. 2007 ; Naughton et al. 2016), à l'est et à l'ouest de Gibraltar pourraient ne pas avoir été favorables au développement de ces espèces et donc au ramassage d'animaux vivants. C'est en particulier le cas des cyprées. Les températures actuelles où vivent la majorité des cyprées de Labattut (surtout Schilderia, espèce subtropicale) varient de 17 à $28^{\circ} \mathrm{C}$ (Sénégal) et de 15 à $25^{\circ} \mathrm{C}$ (mer d'Alboran), températures assez largement au-dessus de celles admises pour le Dryas ancien. Les cordons littoraux plio-pléistocènes méditerranéens ont donc pu constituer une source d'approvisionnement, comme le proposait Y. Taborin (1993a).

Dans le cas des Tritia, leur capacité d'adaptation aux variations de températures (Massé et al. 1978 dans Sauriau 1991) rend possible un ramassage de coquillage vivant. La même remarque peut s'appliquer à Homalopoma sanguineum

Dans le cas des cyprées, la conservation des coquilles suggère qu'une partie de la couleur et de la brillance, une certaine solidité et, peut-être, une certaine sonorité existaient encore au moment du ramassage. Ces caractéristiques ont pu constituer des critères de choix expliquant l'exclusion des cyprées fossiles du Miocène inférieur, dépourvues de ces qualités et donc moins attractives, et cela malgré leur disponibilité.

Pour des raisons peut-être analogues, les sites redonniens de la façade Atlantique, où Zonaria et Schilderia sont connus, n'ont manifestement pas été sélectionnés, les coquilles étant décolorées, plutôt petites et, le plus souvent, rares et fragiles.

Aujourd'hui, les cyprées sont rares en Méditerranée, mais leur fréquence a manifestement varié au cours du temps. Ainsi les espèces pyrum, spurca et lurida se comptaient 

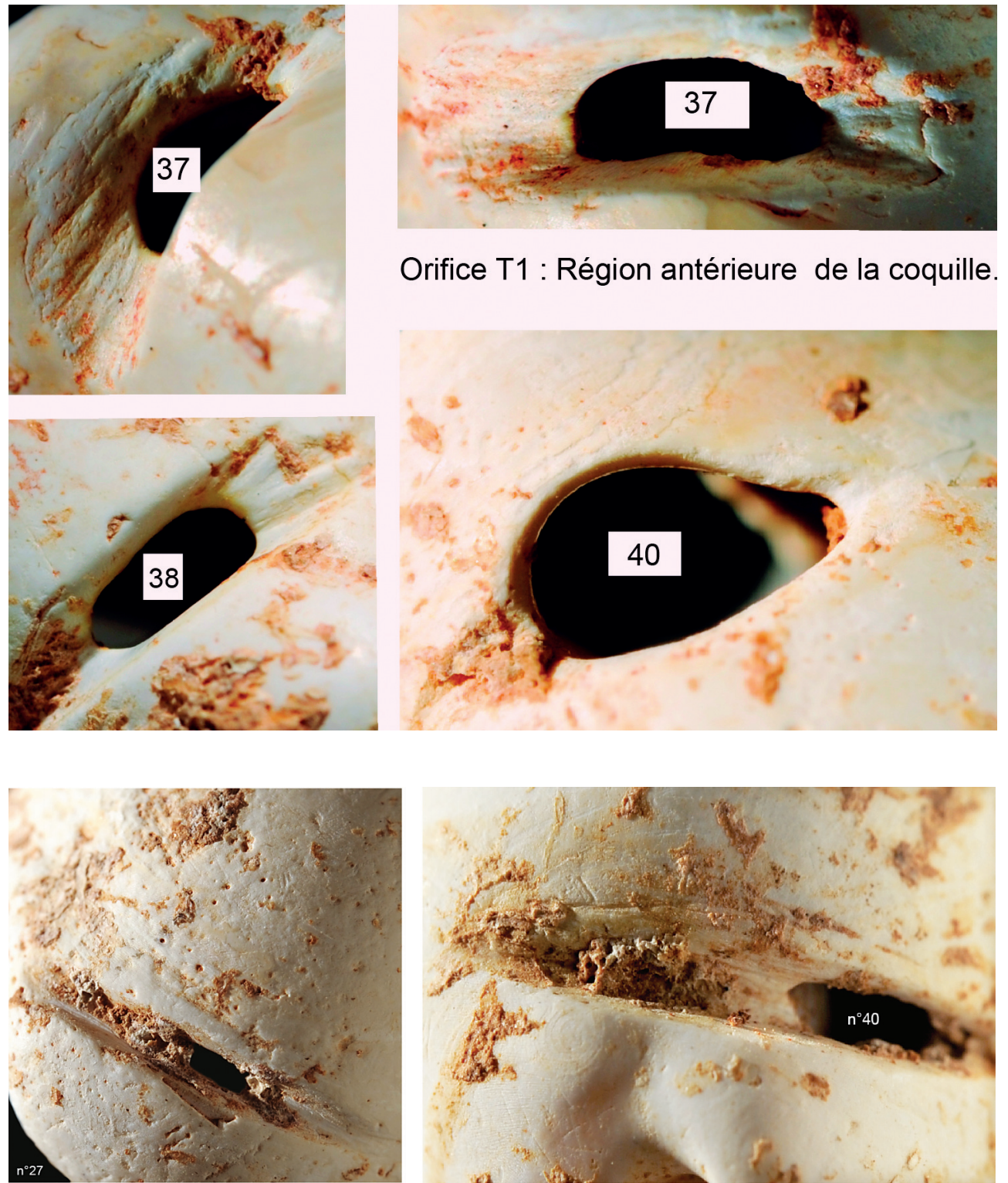

\section{FIGURE 44}

Coquilles nos 37, 38, 40 : zone de l'orifice T1 (๑ Nathalie Gambier).

Shells nos. 37, 38, 40: Area of the hole $\mathrm{T1}$ (๑ Nathalie Gambier).

\section{FIGURE 45}

Coquilles nos 27,40 : zone de l'orifice T2 (๔ Nathalie Gambier).

Shells nos. 27, 40: Area of the hole T2 (๔ Nathalie Gambier).

Orifice T2 : Région postérieure de la coquille

par milliers au marché de Naples en 1850 (Crosse et Fischer 1896). Ces mêmes auteurs déplorent cependant au même moment la grande rareté de l'espèce achatidea. Dans tous les cas, réunir vingt-sept cyprées, quelles que soient les modalités d'acquisition (accumulation par échange ou récolte directe), n'était probablement pas aisé.

\section{1 | Bilan}

Hormis Vitta picta, espèce fossile, toutes les coquilles conservées vivent encore actuellement et ont comme probable origine d'anciens cordons de plage de la Méditerranée, ce qui implique des distances d'au moins $500 \mathrm{~km}$.

\section{Plusieurs remarques peuvent être faites:}

- Les exemplaires dégagés sont tous adultes et perforés. On note un tri selon leur taille des petits gastéropodes et, à un moindre degré, des cyprées, mais tous se situent parmi les coquilles adultes de dimension moyenne. Faute d'éléments de comparaison contemporains (sépulture d'adulte ou d'enfant, parure dans les niveaux d'habitat), il est impossible de démontrer que la taille des petits gastéropodes traduirait, comme cela a été avancé pour d'autres sites (White 1999 ; Vanhaeren et d'Errico 2001), une miniaturisation des éléments de parure spécifique aux individus immatures.

- Les restes de couleur sur Homalopoma et un reliquat de brillance sur les cyprées nous portent à penser que ces coquilles ont été récoltées encore colorées : rouge sangorange pour Homalopoma sanguineum, orangé-marron pour Zonaria pyrum, marron-beige pour Schilderia achatidea, marron-orangé pour Tritia neritea et beigeblanc pour Vitta picta, le tout formant un assemblage dominé par des couleurs chaudes (fig. 26).

- Les techniques de percement de chaque espèce ne sont pas distinctives, elles sont connues dans d'autres sites et à divers moments du Paléolithique supérieur.

- Les coquilles sélectionnées appartiennent à des espèces traditionnelles, recherchées pour la parure pendant toute la durée du Paléolithique supérieur d'Europe occidentale et trouvées pour la plupart dans les niveaux d'habitat. Elles ne traduisent pas une appartenance culturelle 
spécifique, si ce n'est la confirmation de l'attachement des groupes contemporains du Magdalénien pour les coquilles méditerranéennes, prédilection qui trouve son apogée au Magdalénien moyen (Taborin 1993a). Pour cet aspect, le site de Labattut est exemplaire. On reste donc, pendant des millénaires, ancré dans l'immuable et le respect des traditions pour le choix des coquillages, comme l'a souligné Y. Taborin.

- La réunion de Tritia neritea, Homalopoma sanguineum, Vitta picta et des deux genres de cyprées n'est, pour l'instant, décrite dans aucun autre site. La révision de la parure d'Enlène (Magdalénien moyen, Ariège) pourrait cependant apporter de nouveaux éléments.

- Bien que l'on ne puisse pas totalement écarter l'hypothèse d'un ramassage par un groupe (ou un individu) se déplaçant sur plusieurs centaines de kilomètres, l'hypothèse d'une collecte auprès d'autres groupes plus proches de la Méditerranée, au fil des rencontres, s'accorde peut-être plus avec ce que l'on sait de la mobilité des populations de chasseurs-cueilleurs. Quelle que soit l'hypothèse, l'origine méditerranéenne des coquillages implique un déplacement d'objets et des contacts avec d'autres groupes. Elle confirme l'existence de réseaux de circulation et d'échange.

\section{8 | INTERPRÉTATION DU DÉPÔT}

La description du dépôt n'a fait l'objet que de brèves remarques dispersées dans les lettres de $M$. Castanet et d'une mention de D. Peyrony dans son journal. Aucun schéma ni aucune photographie du squelette en place n'a été publié.

\section{1 | Le squelette}

Le squelette est aujourd'hui très incomplet. L'hypothèse de destructions anciennes liées à la fragilité des os et aux processus postdépositionnels ne peut être écartée, mais il est probable qu'il était plus complet lors de la découverte. L'état du crâne, presque complet en dépit d'une fragmentation intense, et de la mandibule, la présence d'arcs neuraux et de la dent de l'axis sont des indices d'une conservation supérieure à celle constatée cent ans plus tard. L'aspect des altérations et des cassures indique que les déficits sont en majorité dus à la fouille et aux aléas de l'histoire postfouille.

Selon M. Castanet (20 avril 1913 dans Delluc 1985 - p. 848), « les jambes étaient tournées du côté de la tranchée ». Le 6 mai 1913, D. Peyrony écrit dans son journal : « Il occupait un faible espace, semblait replié sur lui-même. » Ces deux notes évoquent un squelette en flexion orienté sensiblement nord-sud, tête osseuse au nord, et dont les connexions auraient été préservées. Les dents en ordre anatomique sur l'os maxillaire gauche et sur la mandibule, les deux corps mandibulaires non soudés en connexion lâche, ainsi que les blocs avec des fragments de côtes en position anatomique plaident en faveur du maintien d'au moins une partie des connexions.

Il reste que les données disponibles ne permettent pas de déterminer avec certitude la position du squelette.

\section{2 | Matériel associé}

Aucune industrie lithique ou osseuse ni aucun objet d'art mobilier n'a été décrit autour du squelette.

H. Breuil et R. Lantier (1951) mentionnent des canines de cervidés constituant avec les cyprées un collier. Aucune de ces dents n'a été retrouvée, et aucun des protagonistes de la découverte n'en a signalé. Cette mention n'a donc aucune valeur, d'autant que ni $\mathrm{H}$. Breuil ni R. Lantier ne sont venus sur le site au moment de la découverte ou du prélèvement.

Seules des coquilles ont été mentionnées et retrouvées. Leur relation avec les os est problématique, faute d'un enregistrement de leur position lors des fouilles. Néanmoins, leur association étroite avec le squelette est confirmée par les spécimens encore en place dans les blocs. Ainsi, les exemplaires de Tritia neritea, de Vitta picta et d'Homalopoma sanguineum des blocs $n^{\circ} 15$ (os maxillaire) et $n^{\circ} 16$ (mandibule) indiquent une proximité avec la tête osseuse. Une coquille d'Homalopoma sanguineum sur le bloc $n^{\circ} 44$ (avec côtes) constitue un maigre indice d'une association entre petits gastéropodes et squelette infracrânien. Deux spécimens de Schilderia achatidea uniperforés et l'empreinte d'un troisième sur le bloc $n^{\circ} 18$, près d'un placage de voûte, témoignent aussi d'une proximité des cyprées avec la tête osseuse. Ce sont ces dernières qui sont apparues les premières lors de la fouille, ce qui suggère qu'elles étaient au-dessus du squelette (M. Castanet, 11 avril 1913 dans Delluc 1985 p. 846).

Bien que l'alignement de deux coquilles de Tritia neritea séparées par une Homalopoma sanguineum sur le bloc $n^{\circ} 36$ (fig.46) ou la double perforation de trois des cyprées puissent représenter les vestiges possibles d'un motif, l'arrangement des coquilles nous échappe. Sur les trois espèces de petits gastéropodes, l'emplacement de l'orifice permet le passage d'un cordon par l'ouverture, mais la destination de chaque élément (coquilles enfilées pour former un bijou, cousues pour orner un vêtement, un contenant, une protection ou tout autre objet) est inconnue.

Quant aux cyprées, le terme de « collier », parure portée autour du cou, employé par la quasi-totalité des auteurs à leur propos ne repose pas sur une observation de terrain mais sur une idée préconçue de leur usage. Comme nous l'avons décrit, les traces d'usure mises en évidence suggèrent plutôt une fixation solide sur un support constituant un objet de nature inconnue.

\subsection{1 | Ocre}

De l'ocre est signalé dans la terre entourant le squelette et sur une pierre sous le squelette (M. Castanet, 11 avril et 4 novembre 1913 dans Delluc 1985 - p. 846 et 856). Cette information est corroborée par la couleur rose diffuse du sédiment, des os et des coquilles de Tritia neritea et de Vitta picta, ainsi que par des points d'une couleur plus intense sur plusieurs cyprées. 


\subsection{2 | Architecture}

M. Castanet annonce un ensemble de $60 \mathrm{~cm}$ de diamètre, épais de 45 à $50 \mathrm{~cm}$, inséré dans l'éboulis sous la terre végétale (11 et 20 avril 1913 dans Delluc 1985 - p. 846 et 848). Cette description confirme la remarque de D. Peyrony et évoque le creusement d'une petite fosse dont les dimensions sont compatibles avec la stature d'un enfant actuel de quelques mois (49-70 $\mathrm{cm}$ pour un enfant de 1 à 10 mois, selon Remontet et al. [1999]). Il ne semble pas qu'il y ait eu d'autres aménagements pérennes, excepté la pierre ocrée sous le squelette. L'hypothèse d'une présence fortuite de cette pierre ne peut malgré tout pas être écartée.

\subsubsection{Une sépulture?}

L'ocre et la probable fosse plaident en faveur d'un dépôt intentionnel. En revanche, les informations sont insuffisantes pour en restituer l'agencement originel, en particulier la position du corps et son rapport précis aux coquilles. Faute d'une connaissance de l'état de toutes les connexions anatomiques, il est, en toute rigueur, difficile d'affirmer le caractère primaire du dépôt ${ }^{4}$. Cependant, au vu des os et des petits coquillages associés, du maintien constaté de certaines connexions, l'hypothèse d'un dépôt primaire perturbé, anciennement et lors des fouilles, est envisageable. En revanche, apprécier le milieu (espace vide ou colmaté) dans lequel se serait alors opérée la décomposition du corps est problématique. Néanmoins, le maintien en place de la série dentaire, des deux corps mandibulaires, des côtes et la séquence de TritiaHomalopoma pourraient être des indices d'espace colmaté.

Que penser du contexte de ce dépôt ? S'agissant d'un très jeune enfant isolé localement, aucun autre indice de Magdalénien moyen récent n'étant en effet connu dans le vallon, la nature funéraire du dépôt n'est pas évidente, d'autant que nous manquons d'éléments de comparaison. En effet, l'enfant de l'abri Labattut n'a pas d'équivalent, car aucune sépulture d'enfant indiscutable et contemporaine n'est connue en Europe. La sépulture double de l'abri Lafaye, un enfant et une femme adulte,

[4] Un dépôt primaire est le dépôt d'un cadavre ou d'une portion de cadavre réalisé alors que les éléments du squelette conservent encore la totalité de leurs relations anatomiques (Boulestin et al. 2005 - p. 26-27).

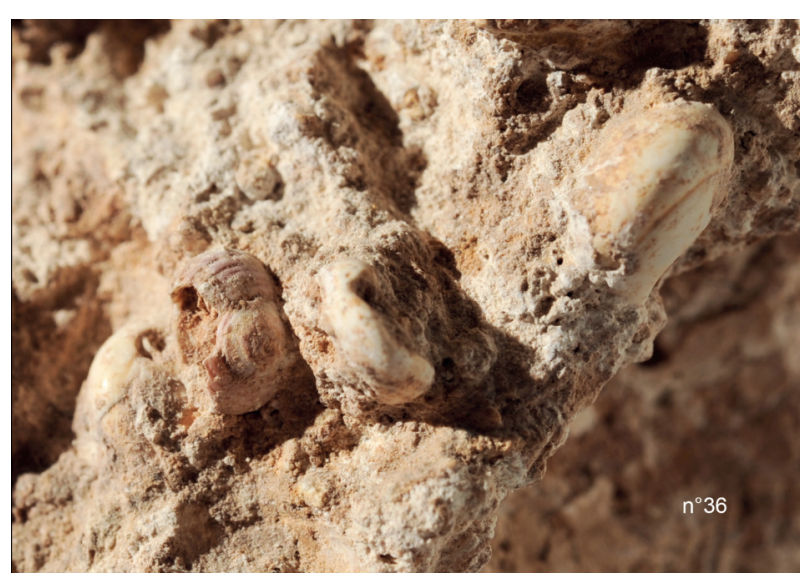

est synchrone de la phase ancienne du Magdalénien moyen, et l'enfant est âgé de 2-3 ans (Leroy et HenryGambier 2017). Le squelette de périnatal du site de plein air de Wilczyce (Pologne), vestige d'une possible sépulture remaniée et/ou non identifiée lors des fouilles, est contemporain d'une phase plus tardive du Magdalénien (Irish et al. 2008 ; Boron 2010).

Les autres sépultures de la classe d'âge 0-5 ans connues en Europe pour le Paléolithique supérieur sont contemporaines du Gravettien ou de l'Épipaléolithique. L'inventaire des sépultures d'adultes confirme l'isolement chronologique. Les plus proches de l'enfant de Labattut sont contemporaines du Magdalénien moyen ancien et de l'Épipalaéolithique, les plus éloignées sont contemporaines du Gravettien et de l'Épigravettien ancien (Gambier et al. 2000 ; Henry-Gambier 2001 ; Duarte 2002 ; Einwögerer et al. 2006 ; Henry-Gambier 2008 ; Gazzoni et Fontana 2011 ; Henry-Gambier et al. 2013 ; Barshay-Szmidt et al. 2016).

Toutefois, au-delà de la diversité réelle des sépultures constatée au cours du Paléolithique supérieur, le creusement d'une fosse, l'installation d'une pierre sous le corps (?), l'ocre, la présence de mobilier (objets d'ornementation) sont des points de convergence avec ce que l'on connaît par ailleurs pour certaines des sépultures d'adultes et d'enfants que nous venons d'évoquer. L'hypothèse d'un dépôt funéraire est donc, sinon incontestable, en tout cas probable ou possible.

L'isolement spatial de cette sépulture pourrait, en outre, correspondre à une mise à l'écart en raison du jeune âge du défunt, comme cela semble parfois avoir été le cas dans certains groupes du Paléolithique supérieur et de périodes plus récentes (ex. : Henry-Gambier 2013). Il pourrait aussi résulter du hasard: par exemple un décès au cours d'un déplacement du groupe.

\section{9 | DISCUSSION ET CONCLUSION}

Le squelette de l'abri Labattut appartient à un enfant de sexe inconnu, âgé de quelques mois et décédé au cours d'un intervalle de temps contemporain de la deuxième phase du Magdalénien moyen, et non du Solutréen comme cela avait été admis.

En dehors de quelques remarques sur les dents et la mandibule, l'état du squelette ne permet pas une étude biologique approfondie. On ne note pas de traits morphologiques particuliers. Aucune pathologie n'a été observée. Les causes du décès sont inconnues.

\section{FIGURE 46}

Bloc $n^{\circ} 36$ avec alignement de coquilles d'Homalopoma et de Tritia (๑ Nathalie Gambier).

Block no. 36 with Homalopoma and Tritia shells alignment (@ Nathalie Gambier). 
Les données de terrain sont trop partielles pour aller très loin dans l'interprétation du dépôt ou dans la mise en évidence des gestes autour du défunt (position originelle du corps ou des coquillages...), mais plusieurs éléments sont en faveur d'une sépulture individuelle en fosse, analogue à celles que d'autres sites du Paléolithique supérieur européen ont livrées pour des adultes ou des enfants.

Cette sépulture est un document important qui comble (certes, partiellement) une lacune dans la connaissance des pratiques funéraires contemporaines du Magdalénien, pratiques qui restent peu documentées, contrairement à ce qui est souvent admis. Elle est la seule sépulture individuelle d'enfant synchrone du Magdalénien. Sa singularité et son intérêt tiennent, outre sa datation, au très jeune âge du défunt ainsi qu'à la quantité et au type des coquillages associés. Pour le Paléolithique supérieur d'Europe, elle est une des sépultures où le nombre de coquilles est le plus élevé. L'origine méditerranéenne de quatre des cinq espèces présentes indique la circulation d'individus, de groupes et/ou d'objets à travers les territoires et sur des distances importantes. Cela suggère peut-être que ce type de coquilles avait une valeur symbolique, dépassant le seul attrait d'ordre esthétique et pratique. Les cyprées sont particulièrement spectaculaires. Signalées par quelques spécimens dans plusieurs sépultures gravettiennes d'adultes en Italie ainsi que, en France, dans celles de Laugerie-Basse $(\mathrm{N}=18)$ et de Saint-Germain-la-Rivière $(N=1)$, attribuées au Magdalénien moyen ancien, les cyprées forment ici, avec vingt-sept individus, un cas unique en Europe. Leur « association » à plusieurs dizaines d'Homalopoma sanguineum, de Tritia neritea et de quelques Vitta picta fossiles confirme cette singularité et fait de la sépulture de Labattut un document majeur, en dépit des incertitudes que nous avons soulignées.

En Europe, les découvertes de vestiges humains datés du Paléolithique supérieur sont nombreuses, mais toutes ne peuvent être interprétées en termes funéraires 5 . L'inhumation représente la pratique funéraire la mieux documentée, quel que soit l'âge au décès, mais les exemples sont rares. Parmi les défunts inhumés, un nombre non négligeable d'adultes et d'enfants étaient habillés, parés et/ou entourés d'objets divers, parfois de grande qualité (Henry-Gambier 2001 ; Vanharen et d'Errico 2003 ; Henry-Gambier 2008 ; Henry-Gambier et al. 2013). D'autres étaient dépourvus de tout mobilier et de parure, sans que l'on puisse démontrer que cela était délibéré. Non conservation, mobilier périssable, remaniements anciens et récents, fouilles destructives peuvent dans plusieurs cas être la cause de cette pénurie. Parmi ces tombes datées entre 30000 et 10000 ans (BP), la proportion d'enfants de la classe d'âge 0-5 ans est faible, et la fiabilité des informations n'est pas à la hauteur des questions. Là aussi, lacunes de la recherche, fouille peu soigneuse, fragilité des os d'enfants, pratiques funéraires spécifiques aux très jeunes enfants peu favorables à la conservation et à la découverte se combinent pour expliquer cette

[5] Le chiffre de 200 sépultures, parfois avancé pour le Paléolithique supérieur (ex. Testart 2012), provient essentiellement de deux synthèses bibliographiques anciennes (May 1986; Binant 1991). Il est surévalué, les interprétations des dépôts de vestiges osseux étant discutables. situation. Plusieurs de ces sépultures de jeunes enfants Krems-Wachtberg (Autriche), le Figuier, Pataud, La Madeleine (France), Wilczyce (Pologne), grotte des Enfants (Italie) - affichent un mobilier (et/ou de la parure) différent de celui de l'enfant de l'abri Labattut, mais d'ampleur comparable ou tout aussi spectaculaire : perles d'ivoire et scapulae de mammouth gravées à KremsWachtberg, dents de renard perforées à Wilczyce (Einwögerer et al. 2006 ; Irish et al. 2008), coquilles, silex et objets mobiliers à la grotte des Enfants, à La Madeleine et au Figuier (Henry-Gambier 2001 ; Vanhaeren et d'Errico 2001 ; Slimak et Plisson 2008). Sans vouloir proposer d'explications communes et définitives sur la signification et la variabilité de ce matériel, en raison notamment de la dispersion chronologique et géographique des sépultures, il y a matière à s'interroger et à discuter.

Dans le cas de l'enfant de Labattut, les petits gastéropodes ont pu constituer une ornementation de vêtement. Les cyprées, dont la taille ne paraît pas adaptée au décor d'un vêtement vu le jeune âge du sujet et sa stature supposée, ont pu orner un objet (couverture, système de portage, de protection ou autre). Les stigmates d'utilisation indiquent que le ou les supports décorés n'ont pas été conçus pour cet enfant et/ou pour la circonstance. Cela dit, que l'enfant de Labattut en ait été ou non le premier destinataire, cet ensemble témoigne de l'intérêt (voire de l'affection) et des soins apportés à de jeunes enfants.

Il reste que l'ensemble de cyprées paraît d'autant plus exceptionnel qu'il est associé à un très jeune enfant. Estil interprétable comme la preuve d'une différenciation sociale en fonction de la richesse?

Des auteurs (ex. Buzhilova 2000 ; Trubitt 2003 ; Vanhaeren et d'Errico 2003 ; Hayden 2008 ; Gazzoni et Fontana 2011; Anghelinu 2012 ; Guy 2017) considèrent que la rareté des sépultures, le dispositif de la tombe et l'abondance et/ou la qualité du mobilier et de la parure permettent d'évaluer le degré de richesse d'un défunt, de caractériser l'organisation sociale d'un groupe et de mettre en évidence l'existence d'une société économiquement différenciée et inégalitaire dès le Paléolithique supérieur. Cette approche est critiquée par des auteurs dont A. Testart (2000, 2007), pour qui les motivations du dépôt de mobilier dans les tombes sont multiples et difficiles à cerner dans le registre archéologique, et Y. Taborin (2004b - p. 197), pour qui la richesse et la diversité des parures découvertes dans les niveaux d'habitat témoignent « d'un usage habituel et très pratique » de celles-ci.

La rareté des sépultures ne peut pas être interprétée comme l'indice d'une sélection des défunts fondée sur le statut particulier de ceux-ci, seuls les individus au sommet de la hiérarchie sociale (et leurs proches) étant inhumés (ex. : Vanhaeren et d'Errico 2003). En effet, rien n'indique que l'inhumation a une valeur particulière (Henry-Gambier 2013) ; d'une certaine façon, ses « mérites » sont de favoriser la conservation du dispositif (architecture, mobilier) et du squelette, et d'être plus facilement identifiable dans le registre archéologique. L'ethnographie comme l'histoire montrent que le champ des possibles en matière de traitement des défunts est vaste. Dans le cas des enfants, en particulier les plus jeunes, nous avons vu que la très grande rareté des sépultures paléolithiques est explicable de bien des manières. 
Quant au mobilier, un des problèmes est d'en apprécier la « richesse » et de déterminer le sens des variations observées. Aussi « déterminer dans l'absolu si un objet d'un certain type peut avoir une valeur économique dans la société étudiée » constituerait une piste prometteuse (Boulestin 2016 - p. 282) mais difficile à mettre en œuvre. Peut-on dire que les cyprées de Labattut sont un exemple de ce type d'objet ? L'origine lointaine, une disponibilité supposée faible, la standardisation de chaque élément, l'absence (apparente) d'utilité pratique dans le quotidien et la possible intégration dans l'univers symbolique du groupe font partie des critères définissant les « biens de prestige ou de valeur » dans les sociétés à richesse (ex. : Vanhaeren et d'Errico 2003 ; Hayden 2008 ; Gallay 2010). En revanche, autant que l'on puisse en juger ici, la chaîne opératoire de fabrication de chaque élément n'est ni complexe ni chronophage, comme cela est attendu pour certains de ces biens précieux. Et, dernier point, il est, en l'état actuel des études et de la fiabilité des informations, difficile d'estimer la fréquence des cyprées dans les habitats, et parfois même dans les sépultures.

Si l'on retient l'hypothèse selon laquelle elles font partie d'un ensemble de "prestige », marque de richesse, la sépulture de Labattut apporterait alors un indice en faveur de l'existence dès le Paléolithique supérieur et dans certains groupes de chasseurs-cueilleurs d'inégalités fondées sur la richesse. Cette hypothèse reste à notre avis non démontrable et à discuter en intégrant les différents domaines d'activité de ces groupes. D'autant que, en admettant que les cyprées de Labattut constituaient un ensemble valorisé, une valeur symbolique et non économique ne peut pas être écartée.

In fine, la sépulture de Labattut, en tout cas pour ce qui nous en est parvenu, représente un exemple original et fort d'attentions entourant un très jeune défunt.

\section{REMERCIEMENTS}

Nous remercions C. Schwab, conservatrice au musée d'Archéologie nationale (Saint-Germain-en-Laye), qui nous a confié l'étude de ce document, J.-J. Cleyet-Merle, directeur du Musée national de préhistoire (Les Eyzies), ainsi que le personnel du musée, qui nous a toujours accueillis avec bienveillance, et en particulier Mmes J. Angot et M.-D. Dehé pour leur aide dans les recherches documentaires. Nous remercions aussi l'ANR, projet Guérope (dir. L. Baray) et projet Magdatis (dir. J.M. Pétillon) qui ont financé une partie de l'étude.

Nos remerciements vont aussi à L. Dolin pour la détermination des coquilles.

Un grand merci à L. Charles pour ses compétences en malacologie, à C. Letourneux et à J.-M. Pétillon pour la relecture du manuscrit et leurs conseils ainsi qu'à A.M. Gadioux et C. Villatte pour leur amical et constant soutien.

\section{RÉFÉRENCES BIBLIOGRAPHIQUES}

ALQAHTANI S.J., HECTOR M.P., LIVERSIDGE H.M. 2010 - Brief Communication: The London Atlas of Human Tooth Development and Eruption, American Journal of Physical Anthropology, 142, p. 481-490.
ÁLVAREZ FERNÁNDEZ E. 2002 - Ejemplares perforados del gasteropodo Homalopoma sanguineum en Europa occidental durante el Paleolitico superior, Cypsela, 14, p. 43-54.

ÁLVAREZ FERNÁNDEZ E. 2006 - Los objetos de adorno-colgantes del Paleolítico superior y del Mesolítico en la Cornisa Cantábrica y en el Valle del Ebro : una visión europea, Salamanca, Universidad de Salamanca (Colección Vítor, 195).

ÁLVAREZ FERNÁNDEZ E., 2009 - Magdalenian Personal Ornaments on the Move: a Review of the Current Evidence in Central Europe, Zephyrus, 63, p. 45-59.

ANGHELINU M. 2012 - On Paleolithic Social Inequality. The Funerary Evidence, In : Kogălniceanu R., Curcă R-G., Gligor M., Stratton S. (eds), Homines, Funera, Astra, Proceedings of the International Symposium on Funerary Anthropology, Alba Iulia (Romania), 5-8 June 2011, Oxford, Archaeopress (BAR International, 2410), p. 30-43.

ANONYME 1913 - Découverte d'un squelette d'enfant solutréen, L'Homme préhistorique, 1, 6, p. 205.

AVEZUELA ARISTU B., ÁlVAREZ-FERNÁNDEZ E. 2012 Solutrean Personal Ornaments in the Iberian Peninsula, Espacio, Tiempo y Forma, serie I Prehistoria y Arqueología, 5, p. 323-332.

BACHELET G., CAZAUX C., GANTES H., LABOURG P.-J. 1980 Contribution à l'étude de la faune marine de la région d'Arcachon. IX, Bulletin du Centre d'étude et de recherche scientifique de Biarritz, 13, 1, p. 45-64.

BARGE H. 1983 - Essai sur les parures du Paléolithique supérieur dans le sud de la France. La faune malacologique aurignacienne de l'abri Rothschild (Cabrières, Hérault), Bulletin du musée d’Anthropologie préhistorique de Monaco, 27, p. 69-83.

BARSHAY-SZMIDT C., COSTAMAGNO S., HENRY-GAMBIER D, LAROULANDIE V. PÉTILLON J.-M., BOUDADI-MALIGNE M., KUNTZ D., LANGLAIS M., MALLYE J.-B. 2016 - Upper Magdalenian of the Western Aquitaine/Pyrenean Region of France (ca. 19-14 ka cal BP): Proposing a New Model for Its Chronological Phases and for the Timing of Occupation, Quaternary International, 414, p. 62-91.

BINANT P. 1991 - Les sépultures du Paléolithique, Paris, Errance (collection Archéologie aujourd'hui).

BORON T. 2010 - Le mobilier magdalénien en matières dures d'origine animale du site de Wilczyce 10 (district de Sandomierz, Pologne), Bulletin de la Société préhistorique française, 107, 3, p. 507-520.

BOULESTIN B. 2016 - Les sépultures mésolithiques de Téviec et Hoedic : révisions bioarchéologiques, Oxford, Archeopress.

BOULESTIN B., DUDAY H. 2005 - Ethnologie et archéologie de la mort: de l'illusion des références à l'emploi d'un vocabulaire, In : Mordant C., Depierre G. (dir.), Les pratiques funéraires à l'âge du Bronze en France, Paris, CTHS-Société archéologique de Sens (Documents préhistoriques, 19), p. 17-35. 
BOURDIER C. 2008 - La frise sculptée de l'abri Reverdit (Sergeac, Dordogne) : première approche analytique des œuvres, Paleo, 20, p. 23-46.

BOURDIER C., PÉTILLON J.-M. CHEHMANA L., VALLADAS H. 2014 - Contexte archéologique des dispositifs pariétaux de Reverdit et de Cap-Blanc: nouvelles données, In : Paillet P. (dir.), Les arts de la Préhistoire : micro-analyses, mises en contextes et conservation, actes du colloque ANR-MADAPCA, paris, 2011, Paleo numéro spécial, 2014, p. 285-294.

BREUIL H. 1929 - Gravures aurignaciennes supérieures de l'abri Labattut à Sergeac. Dordogne, Revue anthropologique, 39, p. 147-151.

BREUIL H., LANTIER R. 1951 - Les hommes de la pierre ancienne, Paris, Payot.

BUZHILOVA A.P. 2000 - Pair and Old Burials in Upper Palaeolithic. Selective Criteria of the Buried, in Alexeeva T.I., Bader O. (eds), Homo sungirensis. Upper Palaeolithic Man: Ecological and Evolutionary Aspects of the Investigation, Moscow, Scientific World, p. 441-448.

COPPOLA D., VACCA E. 1995 - Les sépultures Paléolithiques de la caverne de Sainte-Marie d'Agnano à Ostuni (Italie), In : Otte M. (dir.), Nature et Culture, actes du colloque international de Liège, 13-17 1993, Liège, université de Liège (ERAUL 68), p. 797-810.

CROSSE H., FISHER P. 1896 - Note sur la distribution géographique de Cypraea achatidea Gray dans la Méditerranée, Journal de conchyliologie, Paris, 44, p. 218.

DELAGE F. 1935 - Les roches de Sergeac (Dordogne), L'Anthropologie, 45, p. 281-317.

DELAGE F. 1938 - Abri de la Souquette, Bulletin de la Société historique et archéologique du Périgord, 65, p. 104-126.

DELAGE F. 1947 - Les rochers de l'Acier à Sergeac, Bulletin de la Société historique et archéologique du Périgord, 75, p. 92-99.

DELLUC G. 1985 - L'art pariétal préhistorique de l'époque archaïque en Aquitaine, thèse de 3e cycle, université Paris VI - Pierre-et-Marie-Curie, Paris, 2 vol.

DELLUC S. 1987 - Les galets gravés de l'abri Labattut, In : Sarlat et le Périgord, actes du 39e congrès d'études régionales, Sarlat, 26-27 avril 1987, Périgueux, Société historique et archéologique du Périgord (supplément au Bulletin de la Société historique et archéologique du Périgord), p. 203-223.

DELLUC B., DELLUC G. 1981 - La dispersion des objets de l'abri Blanchard (Sergeac, Dordogne), Bulletin de la Société d'études et de recherches préhistoriques des Eyzies, 30, p. 77-95.

DELLUC B, DELLUC G. 1991 - L'art pariétal archaïque en Aquitaine, Paris, éditions du CNRS (supplément à Gallia Préhistoire, 28).

DELLUC B., DELLUC G., 2006 - Louis Didon (1866-1927) : préhistorien, archéologue et maître d'hôtel, Bulletin de la Société historique et archéologique du Périgord, 133, p. 97-122.
DELLUC B., DELLUC G. 2010 - Marcel Castanet, paysan et fouilleur des sites préhistoriques de Sergeac, Bulletin de la Société historique et archéologique du Périgord, 137, p. 501-530.

DIDON L. 1911 - L'abri Blanchard des Roches (commune de Sergeac). Gisement aurignacien moyen, Bulletin de la Société historique et archéologique du Périgord, 38, p. 246261 et p. 321-345.

DIDON L. 1921 - Note sur l'abri Labattut à Sergeac, Bulletin de la Société historique et archéologique du Périgord, 48, p. 296.

DOLIN L., LOZOUET P. 2004 - Nouvelles espèces de gastéropodes (Mollusca: Gastropoda) de l'Oligocène et du Miocène inférieur de l'Aquitaine (sud-ouest de la France). Partie 3. Cypraeidae et Ovulidae, Paris, Cossmanniana, hors-série 4.

DUARTE C. 2002 - The Burial Taphonomy and Ritual, In : Zilhao J., Trinkaus E. (eds), Portrait of an Artist as a Child. The Gravettian Human Skeleton from the Abrigo do Lagar Velho and Its Archeological Context, Lisboa, Instituto Portugueses de Archeologia (Trabalhos de Arqueologia, 22), p. 187-201.

EINWÖGERER T., FRIESINGER H., HÄNDEL M., NEUGEBAUERMARESCH C., SIMON U., TESCHLER-NICOLA M. 2006 - Upper Infant Burials, Nature, 444, p. 285.

ESSALLAMI L., SICRE M. A. KALLEL N., LABEYRIE L., SIANI G. 2007 - Hydrological Changes in the Mediterranean Sea Over the Last 30,000 Years, Geochem. Geophys. Geosyst., 8, Q07002, doi:10.1029/2007GC001587

ESTRADA A., TEJERO J.M, MANGADO X., PETIT M. FULLOLA J.M., ESTEVE X., BARTROLÍ R. 2010 - From the Mediterranean Sea to the Segre River. Manipulated Shells From Magdalenian Levels of Parco'Cave (Alos de Balaguer Lleida, Spain), Munibe, Suplemento-Gehigarria 31, p. 70-77.

FISCHER H. 1896 - Note sur les coquilles récoltées par M. É. Piette dans la grotte du Mas d'Azil, L'Anthropologie, 6, p. 633-652.

FISCHER M.P. 1876 - Sur les coquilles récentes et fossiles trouvées dans les cavernes du midi de la France et de la Ligurie, Bulletin de la Société géologique de France (3e série), 4, p. 329-340.

GALLAY A. 2010 - Une approche anthropologique de la notion de bien de prestige, In : actes du 12e colloque sur les Alpes dans l'Antiquité, Yenne, 2-4 octobre 2009, Bulletin d'Études préhistoriques et d'archéologiques alpines, 21, p. 29-43.

GAMBIER D., VALLADAS H., TISNÉRAT-LABORDE N., ARNOLD M., BRESSON F. 2000 - Datation de vestiges humains présumés du Paléolithique supérieur par la méthode du carbone 14 en spectrométrie de masse par accélérateur, Paleo, 12, p. 201-212.

GAZZONI V., FONTANA F. 2011 - Quelle mort? Quelle vie? Pratiques funéraires et organisation sociale des chasseurs-cueilleurs de la péninsule italienne, Bulletins et mémoires de la Société d'anthropologie de Paris, 23, 1-2, p. 52-69. 
GRANGER J.-M., AIRVAUX J. 2010 - Nouveaux éléments de parure du Magdalénien moyen de la grotte de la Marche (Lussac-les-Châteaux, Vienne) : les coquillages, Préhistoire du Sud-Ouest, 18, p. 123-139.

GUY E. 2017 - Ce que l'art préhistorique dit de nos origines, Paris, Flammarion (Au fil de l'histoire).

HARDY M. 1880 - La station préhistorique des Roches, commune de Sergeac, Bulletin de la Société historique et archéologique du Périgord, 7, p. 110-113.

HAYDEN B. 2008 - L'origine des inégalités, Paris, CNRS Éditions.

HENRY-GAMBIER D. 2001 - La sépulture des enfants de Grimaldi, Baoussé-Roussé, Italie : anthropologie et palethnologie funéraire des populations de la fin $d u$ Paléolithique supérieur, Paris, éditions CTHS-RMN (Documents préhistoriques, 14).

HENRY-GAMBIER D. 2008 - Pratiques funéraires et comportements des populations gravettiennes en Europe : bilan des données et interprétations, In : Rigaud J.-P. (dir.), Le Gravettien : entités régionales d'une paléoculture européenne, actes de la table ronde Le Gravettien : entirés régionales d'une paléoculture européenne, Les Eyzies-deTayac, Paleo, 20, p. 399-438.

HENRY-GAMBIER D. 2013 - Les Gravettiens, In : Otte M. (dir.), Les Gravettiens, Errance (Civilisations et culture), p. 307-330.

HENRY-GAMBIER D. 2018 - Les populations du Paléolithique supérieur de la France. Biologie et pratiques funéraires, In : Djinjian F. (dir.), La Préhistoire de la France, vol. 2, Paris, Hermann (Histoire et Archéologie), p. 184-20.

HENRY-GAMBIER D., VILLOTTE S., BEAUVAL C., BRUZEK J., GRIMAUD-HERVÉ D. 2013 - Les vestiges humains : un assemblage original, In : Nespoulet R., Chiotti L., HenryGambier D. (dir.), Le Gravettien final de l'abri Pataud (Dordogne, France) : fouilles et études 2005-2009, Oxford, Archaeopress (BAR International 2458), p. 135-177.

IRISH J.D., BRATLUND B., SCHILD R., KOLSTRUP E., KROLIK H., MANKA D., BORON T. 2008 - A Late Magdalenian Perinatal Human Skeleton From Wilczyce, Poland, Journal of Human Evolution, 55, p. 736-740.

LE ROY M., HENRY-GAMBIER D. 2017 - À propos des vestiges humains du Magdalénien du sud-ouest de la France : l'enfant inédit de l'abri Lafaye (Tarn-et-Garonne), Paleo, 28, p. 157-178.

LENOIR M., TERRAZA S. 1971 - Le Magdalénien supérieur de l'abri Faustin, commune de Cessac (Gironde), Bulletin de la Société préhistorique française. Études et travaux, 68, 1, p. 311-327.

MARTINEZ S.V. 2015 - Os adornos em concha do Paleolítico Superior da Região de Murcia (Espanha), mémoire de maîtrise d'archéologie, Universidade do Algarve, Algarve.

MAY F. 1986 - Les sépultures préhistoriques, Paris, Éditions CNRS.

MOORREES C., FANNING E., HUNT E. 1963 - Formation and Resorption of Three Deciduous Teeth in Children, American Journal of Physical Anthropology, 21, p. 205-213.
MORMONE J.-M. 1983 - L'abri Labattut à Sergeac. Quelques notes sur un sondage effectué en 1981, Bulletin de la Société historique et archéologique du Périgord, 110, p. 210-220.

NAUGHTON F., SANCHEZ GONI M.F., RODRIGUES T., SALGUEIRO E. COSTAS S. DESPRAT S., DUPRAT J., MICHEL E., ROSSIGNOL L., ZARAGOSI S., VOELKER A.H.L., ABRANTES F. 2016 - Climate Variability Across the Last Deglaciation in NW Iberia and Its Margin, Quaternary International, 414, 1, p. 9- 22.

OAKLEY K.P., CAMPBELL B.G., MOLLESON T.I. 1971 - Catalog of Fossil Hominids. Part II: Europe, London, British Museum (Natural History).

O'HARA J. F., WHITE R., GARRETT Z. S., HIGHAM T., ROUSSOT A. 2015 - Le site aurignacien de l'abri de la Souquette (commune de Sergeac, Dordogne) : son histoire archéologique, In : White R. et Bourrillon R. (dir.), Aurignacian Genius : art, technologie et société des premiers hommes modernes en Europe, actes du symposium international, 8-10 avril 2013, New York University, P@lethnologie, 7, p. 99-118.

PESCHAUX C. 2017 - La parure des sociétés du Dernier Maximum glaciaire. Évolution des pratiques et traditions ornementales entre la fin du Solutréen, le Badegoulien et le début du Magdalénien dans les Bassins parisien, ligérien et aquitain, thèse de doctorat d'histoire de l'art et d'archéologie, université Paris 1 Panthéon-Sorbonne, Paris.

PEYRONY D. 1935 - Le gisement de Castanet, vallon de Castelmerle, commune de Sergeac (Dordogne). Aurignacien I et II, Bulletin de la Société préhistorique de France, 32, 9, p. 418-443.

PEYRONY D. 1949 - Le Périgord préhistorique. Paris, imprimerie Ribou, Société historique et archéologique du Périgord.

POPPE G.T., GOTO Y. 1991 - European Seashells. Volume I (Polyplacophora, Caudofoveata, Solenogastra, Gastropoda, Wiesbaden, Hemmen.

REIMER P.J., BARD E., BAYLISS A., BECK J.W., BLACKWELL P.G., BRONK RAMSEY C., BUCK C.E., CHENG H., EDWARDS R.L., FRIEDRICH M., GROOTES P.M., GUILDERSON T.P., HAFLIDASON H., HAJDAS I., HATTE C., HEATON T.J., HOFFMANN D.L., HOGG A.G., HUGHEN K.A., KAISER K.F., KROMER B., MANNING S.W., NIU M., REIMER R.W., RICHARDS D.A., SCOTT E.M., SOUTHON J.R., STAFF R.A., TURNEY C.S.M., VAN DER PLICHT J. 2013 IntCal13 and Marine13 Radiocarbon Age Calibration Curves 0-50,000 Years Cal BP, Radiocarbon, 55, 4, p. 1869-1887.

REMONTET L., MAMELLE N., LOCARD E., LEHINGUE Y. 1999 Archives pédiatriques, 6, p. 520-529.

REVERDIT A. 1878 - Stations et traces des temps préhistoriques dans le canton de Montignac-sur-Vézère, Bulletin de la Société historique et archéologique du Périgord, 5, p. 384-419.

RIGAUD J.-P. 1982 - Informations préhistoriques, Gallia Préhistoire, 25, 2, p. 407-436.

RIVIÈRE É. 1887 - De l'antiquité de l'homme dans les AlpesMaritimes, Paris, librairie J.-B. Baillière et fils.

ROBIN D. 1986 - Sergeac, Castelmerle, abri Reverdit, Gallia Préhistoire, 29, p. 240-241. 
ROUSSOT A. 1982 - Abri de la Souquette, Gallia Préhistoire, 25, p. $112-114$.

ROUSSOT A. 1984 - Abri Reverdit, in L'Art des Cavernes. Atlas des grottes ornées paléolithiques françaises, Paris, Imprimerie nationale (Atlas archéologique de la France), p. $222-224$.

ROUSSOT A. 1985 - Instruments perforés de la collection Reverdit conservés au Bristish Museum, Bulletin de la Société historique et archéologique du Périgord, 112, p. 339-344.

SAURIAU P.G. 1991 - Spread of Cyclope neritea (Mollusca: Gastropoda) Along the North-Eastern Atlantic Coasts in Relation to Oyster Culture and to Climatic Fluctuations, Marine Biology, 109, p. 299-309.

SCHEUER J. L., BLACK S. 2000 - Development Juvenile Osteology, New York, Academic Press.

SLIMAK L., PLISSON H. 2008 - La sépulture paléolithique de l'enfant du Figuier (Ardèche, France) : emboîtement d'une symbolique funéraire, in Bailly M., Plisson $\mathrm{H}$. (dir.), La valeur fonctionnelle des objets sépulcraux, actes de la table ronde d'Aix-en-Provence, 25-27 octobre 2006, Préhistoire Anthropologie méditerranéennes, 14, p. 29-38.

SMITH P.E.L. 1966 - Le Solutréen en France, Delmas, Bordeaux.

SONNEVILLE-BORDES (de) D. 1960 - Le Paléolithique supérieur en Périgord, Delmas, Bordeaux.

STINER M.C. 1999 - Palaeolithic Mollusc Exploitation at Riparo Mochi (Balzi Rossi, Italy): Food and Ornaments From the Aurignacian Through Epigravettian, Antiquity, 73, 282, p. 735-754.

STRAUS L.G., GONZÁLEZ-MORALES M.R., CARRETERO J.M. 2015 - The Red Lady of El Mirón Cave: Lower Magdalenian Human Burial in Cantabrian Spain, Journal of Archaeological Science, 60, p. 1-138.

STREET M., JORIS O. 2015 - The Age of the Oberkassel Burial in the Context of Climate, Environment and the Late Glacial Settlement History of the Rhineland, In : Giemsch L., Schmitz R.W. (eds), The Late Glacial Burial From Oberkassel Revisited, Darmstadt, Verlag Philipp von Zabern (Rheinische Ausgrabugen, 72).

TABORIN Y. 1991 - La parure des Solutréens et des Magdaléniens anciens des Jamblancs, Paleo, 3, p. 101-108.

TABORIN Y. 1993a - La parure en coquillage au Paléolithique, Paris, CNRS éd. (Supplément à Gallia Préhistoire, 29).

TABORIN Y. 1993b - Traces de façonnage et d'usage sur les coquillages perforés, in Anderson P.C, Beyries S., Otte M., Plisson H. (dir.), Traces et fonction : les gestes retrouvés, actes du colloque international de Liège, 8-10 décembre 1990, Liège, Université de Liège (Eraul, 50), p. 254-267.

TABORIN Y. 2004a - Les coquillages, In : Clottes J., Delporte H. (dir.), La grotte de la Vache (Ariège), fouilles Romain Robert, vol. 1, Paris, RMN-CTHS (Documents préhistoriques, 16), p. 391-403.
TABORIN Y. 2004b - Langage sans parole. La parure aux temps préhistoriques, Paris, La Maison des roches.

TESTART A. 2000 - Que peut dire aujourd'hui l'anthropologie sociale des chasseurs-cueilleurs d'hier? In : Les derniers chasseurs-cueilleurs d'Europe occidentale, actes du colloque international de Besançon, octobre 1998, Besançon, Presses universitaires franc-comtoises (Annales littéraires, 699 ; série « Environnement, société et archéologie », 1), p. 343-349.

TESTART A. 2007 - Enjeux et difficultés d'une archéologie sociale funéraire. In : Barray L, Brun P. Testart A. (dir.), Pratiques funéraires et sociétés. Nouvelle approche en archéologie et en anthropologie sociale, Dijon. Éditions Universitaires de Dijon.

TESTART A. 2012 - Avant l'histoire : l'évolution des sociétés, de Lascaux à Carnac, Paris, Gallimard.

TRUBITT M.B. 2003 - The Production and Exchange of Marine Shell Prestige Goods, Journal of Archaeological Research, 11, 3, p. 243-277.

VAN KLINKEN G.J. 1999 - Bone Collagen Quality Indicators for Palaeodietary and Radiocarbon Measurements, Journal of Archaeological Science, 26, 6, p. 687-695.

VANHAEREN M., d`ERRICO F. 2001 - La parure de l’enfant de La Madeleine (fouilles Peyrony). Un nouveau regard sur l’enfance au Paléolithique supérieur, Paleo, 13, p. 201-240.

VANHAEREN M., d`ERRICO F. 2003 - Le mobilier funéraire de " la dame » de Saint-Germain-la Rivière (Gironde) et l'origine paléolithique des inégalités, Paleo, 15, p. 195-238.

WHITE R. 1999 - Intégrer la complexité sociale et opérationnelle : la construction matérielle de l'identité sociale à Sungir, In : Préhistoire d'os recueil d'études osseuse préhistorique offert à Henriette Camps-Faber, Aix-enProvence, Publication de l'université de Provence, p. 319-331.

WHITE R., MENSAN R., BOURRILLON R., CRETIN C., HIGHAM T., CLARK A., SISK M., TARTAR E., GARDERE P., PELEGRIN J., VALLADAS H., TISNERAT-LABORDE N., SANOIT (de) J., CHAMBELLAN D., CHIOTTI L. 2012 - Context and Dating of a Newly Discovered Aurignacian «Vulvar» Representation From Abri Castanet, France, Proceedings of the National Academy of Science, 109, 22, p. 8450-8455.

\section{Sources manuscrites}

BREUIL H. 1913 - Lettre du 6 septembre 1913 à H. Hubert, archives musée d'Archéologie nationale.

DIDON L. 1913 - Lettre du 7 mai 1913 à H. Hubert, 7 mai 1913, archives musée d'Archéologie nationale.

PERIN P. 2004 - Lettre du 7 janvier à F. Semah, copie pour information de P. Perin à D. Henry-Gambier, archives D. Henry-Gambier.

PEYRONY D. 1913 - 5 et 15 mai, 1913, journal de D. Peyrony, p. 24-25, archives Musée national de préhistoire. 